\title{
WestVirginiaUniversity
}

THE RESEARCH REPOSITORY @ WVU

Graduate Theses, Dissertations, and Problem Reports

1999

\section{Development of a decision support system for assessment of mobile bridges}

Vikram Ramamoorthy

West Virginia University

Follow this and additional works at: https://researchrepository.wvu.edu/etd

\section{Recommended Citation}

Ramamoorthy, Vikram, "Development of a decision support system for assessment of mobile bridges" (1999). Graduate Theses, Dissertations, and Problem Reports. 954.

https://researchrepository.wvu.edu/etd/954

This Thesis is protected by copyright and/or related rights. It has been brought to you by the The Research Repository @ WVU with permission from the rights-holder(s). You are free to use this Thesis in any way that is permitted by the copyright and related rights legislation that applies to your use. For other uses you must obtain permission from the rights-holder(s) directly, unless additional rights are indicated by a Creative Commons license in the record and/ or on the work itself. This Thesis has been accepted for inclusion in WVU Graduate Theses, Dissertations, and Problem Reports collection by an authorized administrator of The Research Repository @ WVU. For more information, please contact researchrepository@mail.wvu.edu. 


\title{
DEVELOPMENT OF A DECISION SUPPORT SYSTEM FOR ASSESSMENT OF MOBILE BRIDGES
}

\author{
Vikram Ramamoorthy
}

\author{
Thesis \\ Submitted to \\ The College of Engineering and Mineral Resources at \\ West Virginia University \\ in Partial fulfillment of the requirements \\ for the Degree of \\ Master of Science \\ in \\ Industrial Engineering
}

Dr. R.S. Ahluwalia, Ph.D. (Chair)

Dr. Shen En Chen, Ph.D.

Dr. B. Gopalakrishnan, Ph.D.

Dr. Hota V.S. GangaRao, Ph.D.

1999

Morgantown, West Virginia

Keywords: Decision Support Systems, Internet-based, Expert systems, Bridge evaluation, AVLB, Vibration Testing 


\begin{abstract}
The development of a prototype Decision Support System (DSS) for the condition assessment of the Armored Vehicle Launched Bridge (AVLB) has been demonstrated in the current work. AVLB is a mobile bridge that has been used by the US Army for tank and assault vehicle crossing. It is employed for spanning short gaps of 50 feet or less in the terrain. The condition assessment of such bridges, to ensure safety of personnel and tank, is of strategic importance. The methodology of the prototype DSS is based on a refined visual inspection procedure and a previously established vibration measurement technique.

Conforming to the design requirements, the DSS has been developed as an Internet based, interactive application, and is integrated with an automated vibration measurement system. The web-based DSS, which incorporates an expert system and a database system, can be run from a web-browser. The development of the system, as described in this thesis, involved: identification of important visual and vibration inspection parameters; development of an expert system for bridge condition assessment, based on these parameters; and design of a database for storing important inspection data and other vital bridge records. The prototype system has been validated through limited test runs. Discussion on further verification and validation issues has also been put forth in this work.

The unique feature of this DSS is its accessibility through the Internet, which is practical considering that the AVLB is deployed worldwide. With a central database, this system provides a useful research tool for further study of the AVLB behavior and damage mechanisms, and can be used to establish failure prediction model and remaining life assessment.
\end{abstract}


This work is dedicated to my loving parents, sister, grandmother and my late grandfather C.K. Narasimhan who embodied virtues that are difficult to practice in this day and age 


\section{ACKNOWLEDGEMENTS}

I express my gratitude to Dr. Shen-En Chen without whose valuable guidance and advise this research effort wouldn't have materialized. I would sincerely like to thank my committee chair Dr. Ahluwalia for his valuable directions and encouragement.

This provides me a platform to thank Dr. Hota V.S. GangaRao for his timely support in providing me an opportunity to work on a project of such dynamic nature. I gratefully acknowledge the enlightening suggestions and help of Dr. B. Gopalakrishnan and for serving on my thesis committee.

I am also appreciative of the technical and facilitative efforts of Mr. Samer H. Petro in administering the project. Special thanks are also due to Suhas Venkatappa, colleague and friend, who weathered the storm with me, quite admirably.

Financial assistance provided by the US Army (contract \# DAAE07-95-C-9004) is acknowledged.

I am greatly appreciative of my numerous roommates and friends who made my stay at Morgantown quite an enriching and learning experience. Naming all such individuals is quite beyond the scope of this page. 


\section{TABLE OF CONTENTS}

TITLE PAGE

.. $\mathrm{i}$

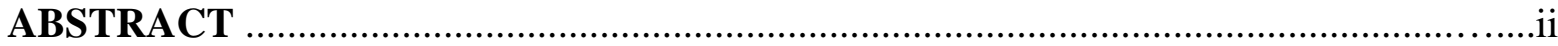

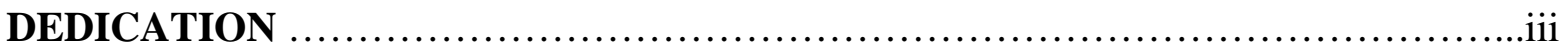

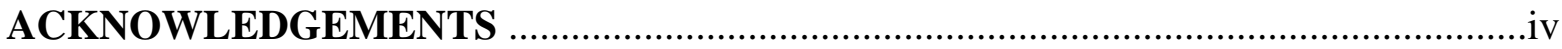

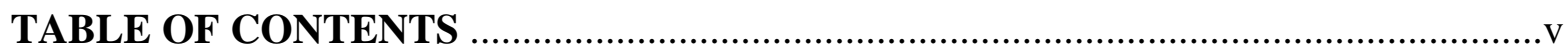

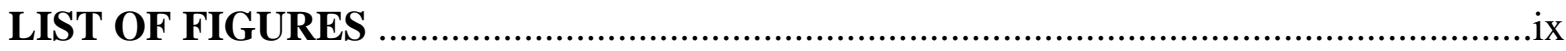

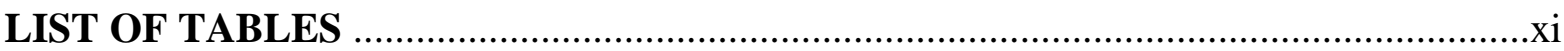

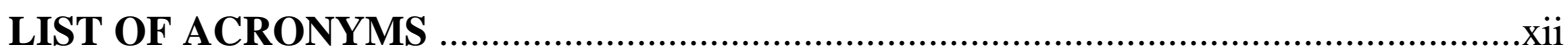

\section{CHAPTER 1. INTRODUCTION}

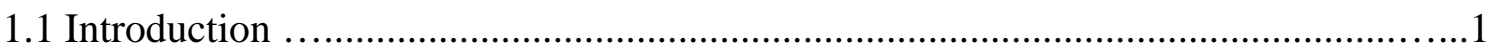

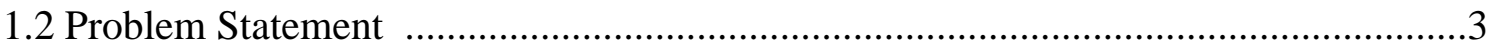

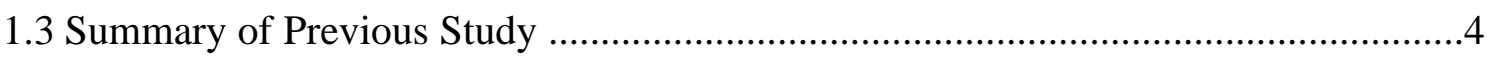

1.4 System Development Approach..............................................................................

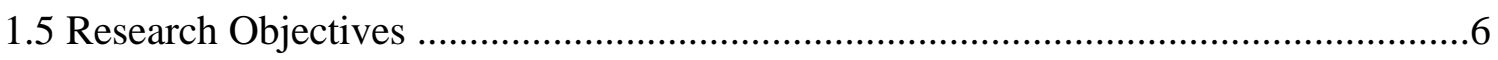

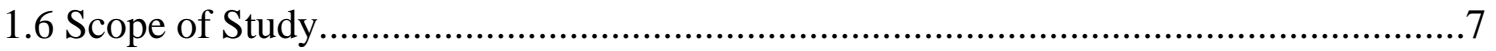

\section{CHAPTER 2. LITERATURE REVIEW}

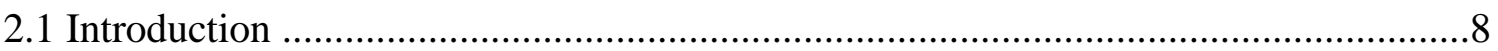

2.2 Artificial Intelligence and Expert Systems ............................................................ 
2.3 Bridge Condition Assessment.............................................................................13

2.3.1 Bridge and Other Structural Assessment Systems.............................................14

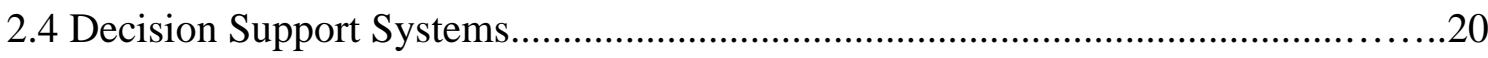

2.4.1 Decision Support Systems in Bridge Management..........................................21

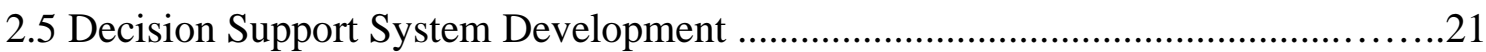

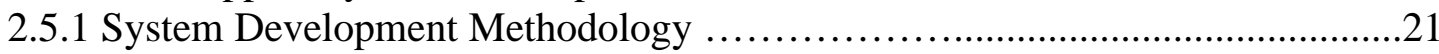

2.5.2 Development of the Initial Prototype Decision Support System ........................23

2.6 Study of Web-Browser as an Application Environment ……….............................27

2.6.1 Web-Based Applications for Structural Monitoring ………...........................28

2.6.2 Web-Based Decision Support Systems ........................................................29

2.6.3 Need for Selection of Web Browser as the DSS Environment ...........................30

2.6.4 Suitability of Development of DSS as a Web-Based Application ....................32

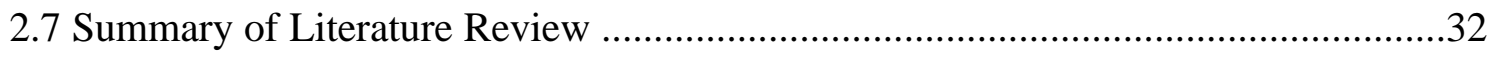

\section{CHAPTER 3. KNOWLEDGE ACQUISITION AND SYNTHESIS}

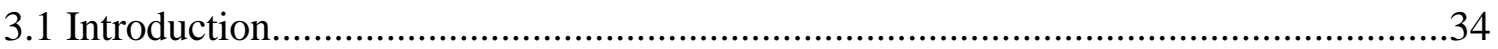

3.2 Knowledge Acquisition .......................................................................................

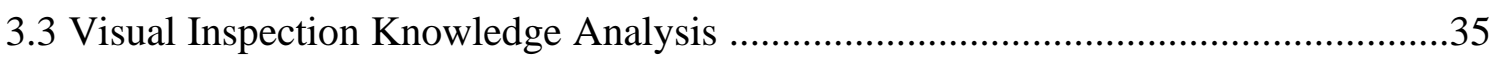

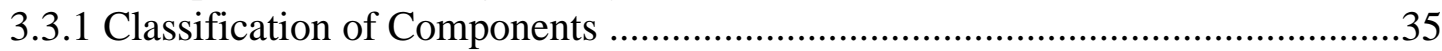

3.3.1.1 Functional Components ....................................................................38

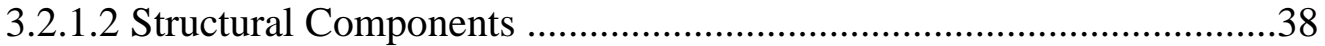

3.3.2 Damage Scenarios ....................................................................................4

3.3.3 Hierarchy Criteria for Determining Criticality of Components ...........................46

3.3.4 Visual Inspection Procedure Development .......................................................48

3.4 Knowledge Acquisition for Vibration Inspection .............................................53

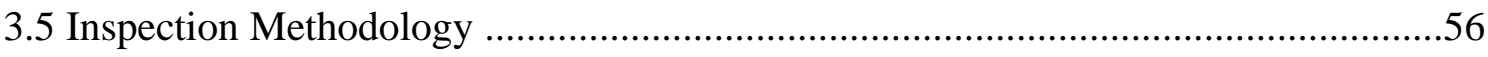

\section{CHAPTER 4. DECISION SUPPORT SYSTEM DEVELOPMENT}

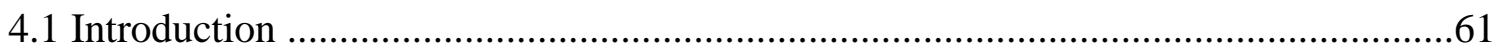

4.2 The AVLB Decision Support System Model ...........................................................61

4.3 Expert System Module .............................................................................64

4.3.1 Visual Inspection Program Development ………….......................................64 
4.3.2 Vibration Inspection Program Development .......................................... 74

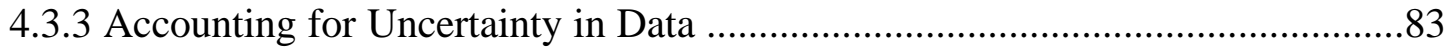

4.4 Checks and Maintenance Module Development ........................................84

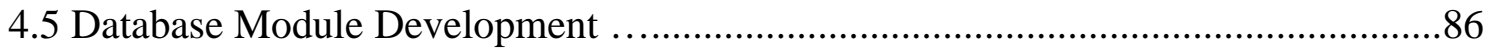

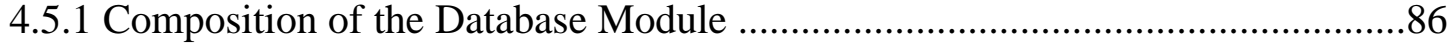

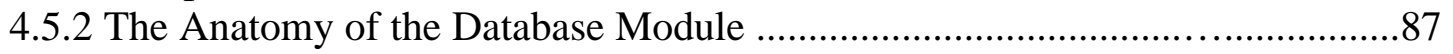

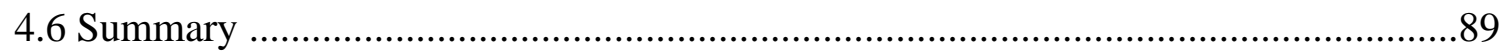

\section{CHAPTER 5. SYSTEM IMPLEMENTATION}

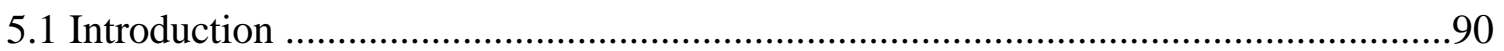

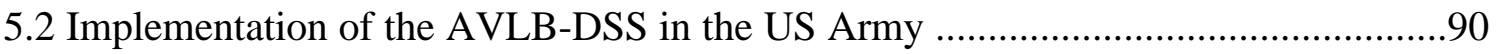

5.3 Consulting the AVLB Decision Support System (AVLB-DSS) ..........................91

5.3.1 Consulting the AVLB Introduction Module ................................................. 91

5.3.2 Consulting the Expert System Inspection Module ....................................... 92

5.3.2.1Consulting the Visual Inspection Section ........................................92

5.3.2.2 Consulting the Vibration Inspection Section ...................................96

5.3.3 Execution of the Checks and Maintenance Module ....................................... 98

5.3.4 Execution of the Database Module ............................................................99

\section{CHAPTER 6. DISCUSSION}

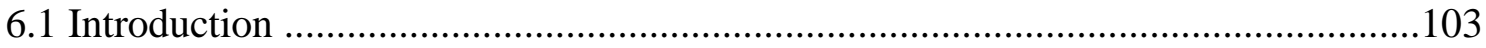

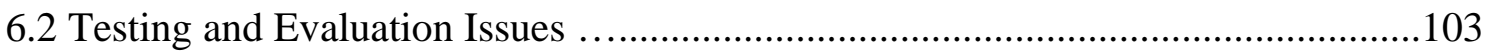

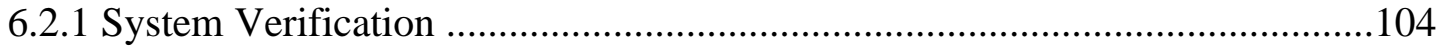

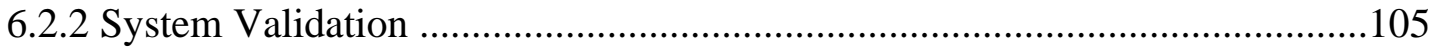

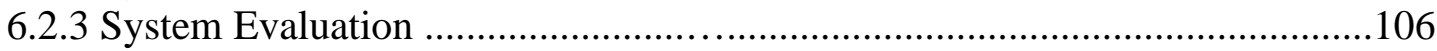

6.3 Discussion on Existing DSS and Structural Evaluation .....................................108

6.4 Discussion on AVLB System Reliability Concept ............................................109

6.5 Discussion on the Study of Benefit-Cost Analysis of the Project .........................111

6.6 Web-Based Application Trade-off ..............................................................113

6.6.1 Advantages of Web-Based Applications ................................................114

6.6.2 Limitations of Web-Based Applications ..................................................115 


\section{CHAPTER 7. CONCLUSIONS AND RECOMMENDATIONS}

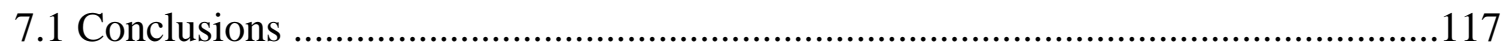

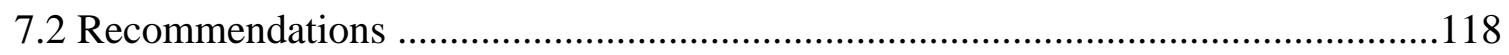

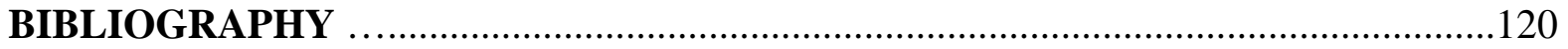

\section{APPENDIX A}

VP-Expert Program Code for the Initial Prototype System

\section{APPENDIX B}

Knowledge Acquisition through Interview of AVLB Personnel

\section{APPENDIX C}

DSS Application Requirements

C.1 System Requirements.................................................................................149

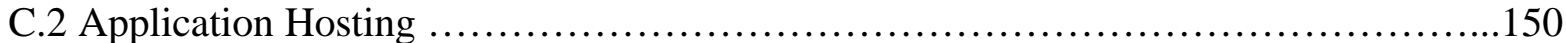

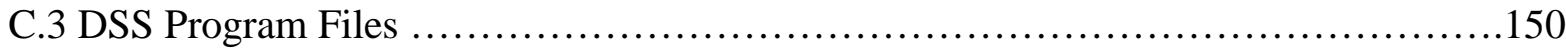

\section{APPENDIX D}

Application Verification Tests

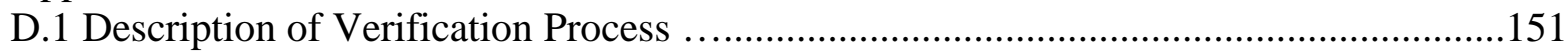

D.2 Verification Test Sheets .................................................... 152

D.3 Summary of Verification Tests .................................................

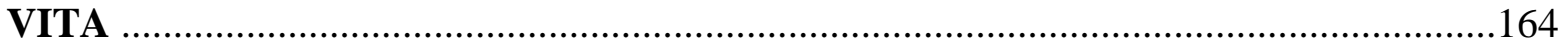

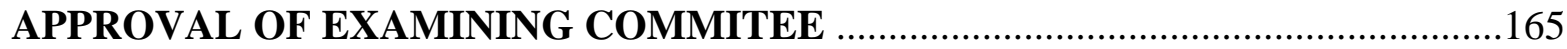




\section{LIST OF FIGURES}

Figure 1.1 US Army AVLB Carried on a Launcher Tank .......................................... 1

Figure 2.1 Expert System Framework ..............................................................11

Figure 2.2 Graphical Tree Display of the Trace of the Inference Mechanism in

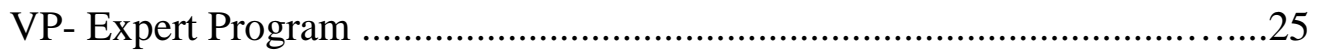

Figure 3.1 Damaged Bracing on AVLB from Static Tests (Henry et al., 1996) ..............39

Figure 3.2 Damaged Rivet on AVLB from Static Tests (Henry et al., 1996) ..................39

Figure 3.3 The Automated Damage Detection Algorithm (Venkatappa, 1997) .............54

Figure 3.4 Schematic Drawing of the Inspection System Concept ...............................59

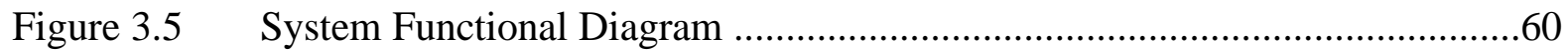

Figure 4.1 AVLB Decision Support System Structure .......................................63

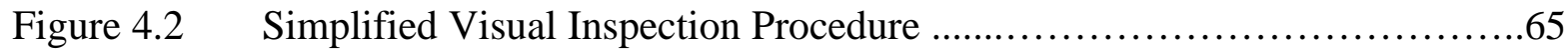

Figure 4.3 Flowchart of the Detailed Visual Inspection Procedure ....................67-70

Figure 4.4 Flowchart of the Vibration Inspection Procedure ..................................75-79

Figure 4.5 ASCII Text File Format from which Vibration Data is read into the DSS .....81

Figure 4.6 Internet Database Connectivity Chain .............................................8

Figure 5.1 Quick Visual Inspection Consultation .........................................93

Figure 5.2 First Interface of the Detailed Visual Inspection Section ...........................94

Figure 5.3 First Stage of Visual Inspection Section Consultation ................................95

Figure $5.4 \quad$ Visual Inspection Results ................................................... 96

Figure 5.5 Vibration Inspection Section Consultation ..........................................97

Figure 5.6 Image Map of AVLB 60 with Inspection Plan for Cross Bracing ...............98

Figure 5.7 AVLB Database Information Update Screen ....................................... 99 


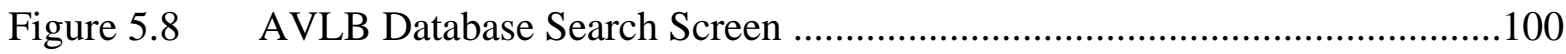

Figure 5.9 Database Querying by AVLB Identification Number ...................................101

Figure 5.10 Information Retrieved for a User Input Query of M600 in Figure 5.9 …...102

Figure 6.1 Exponential Decay of AVLB Reliability with Increase in Tank Crossings .111 


\section{LIST OF TABLES}

Table 3.1 Categorization of Components on Functional and Structural Bases .37

Table 3.2 Classification of Components into Primary and Secondary Elements ........40

Table 3.3 Likely Damage Modes of Primary Components (Complete to Partial) .......43

Table 3.4 Likely Damage Mode of Secondary Components (Complete to Partial) ......45

Table $3.5 \quad$ Prioritization of Structural Elements ...................................................47

Table $3.6 \quad$ Final Visual Inspection Procedure ....................................................... 52

Table 3.7 Comparison of Modal Frequencies (Hz) of the AVLB ..............................55

Table 4.1 Visual Inspection Decision-making Rules ........................................

Table 4.2 Vibration Inspection Decision-making Rules ......................................80

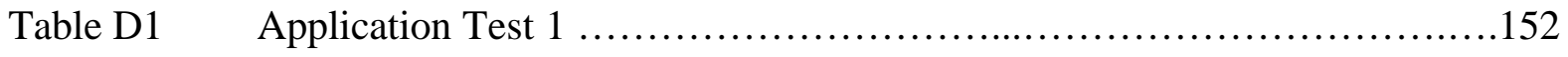

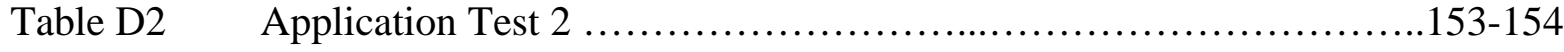

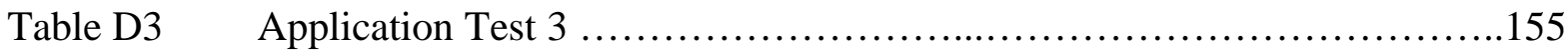

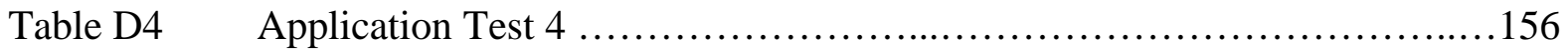

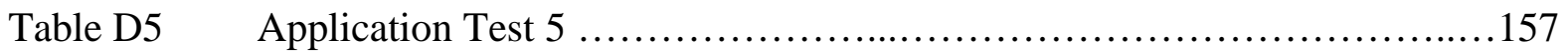

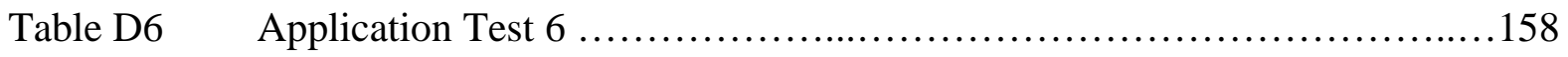

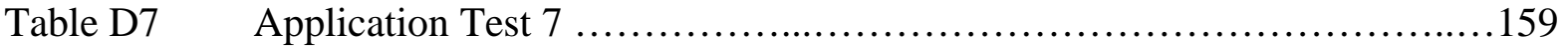

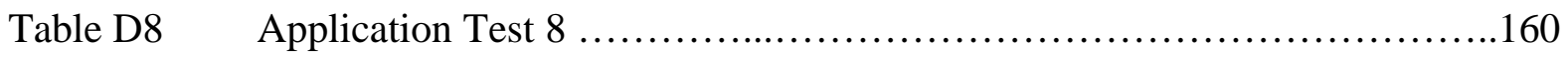

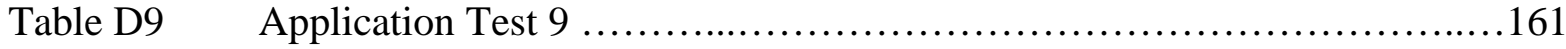

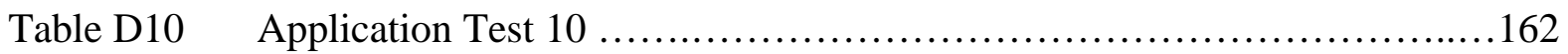

Table D11 Summary of Application Verification Tests .........................163 


\section{LIST OF ACRONYMS}

\begin{tabular}{|c|c|}
\hline AASHTO & American Association of State Highway and Transportation Officials \\
\hline AI & Artificial Intelligence \\
\hline API & Application Programming Interface \\
\hline ASCII & American Standard Code for Information Interchange \\
\hline AVLB & Armored Vehicle Launched Bridge \\
\hline BMS & Bridge Management System \\
\hline DSS & Decision Support Systems \\
\hline $\mathrm{ES}$ & Expert Systems \\
\hline $\mathrm{FE}$ & Finite Element \\
\hline FHWA & Federal HighWay Administration \\
\hline FTP & File Transfer Protocol \\
\hline HTML & HyperText Markup Language \\
\hline HTTP & HyperText Transfer Protocol \\
\hline MAC & Modal Assurance Criteria \\
\hline NDE & Non-Destructive Evaluation \\
\hline PMCS & Preventive Maintenance Checks and Services \\
\hline PWS & Personal Web Server \\
\hline RDBMS & Relational DataBase Management System \\
\hline SEDI & Strain Energy Damage Index \\
\hline SEMAC & Strain Energy Modal Assurance Criteria \\
\hline SLV & Scanning Laser Vibrometer \\
\hline SQL & Structured Query Language \\
\hline
\end{tabular}




\section{CHAPTER 1}

\section{INTRODUCTION}

\subsection{Introduction}

In the current thesis, the issue of developing a Decision Support System (DSS) for condition assessment of an Armored Vehicle Launched Bridge (AVLB) has been addressed.

The AVLB was developed by the US Army in the early 1950s, as a mobile assault bridge that can be launched by an armored vehicle (US Army, 1995.) In the subsequent years, the design of the launcher mechanism and the bridge underwent numerous changes. The AVLB model 60, supporting Military Load Class (MLC) of 60 tons, was developed in the 1960s. In 1991, due to increased weights of military transports, the capacity of AVLB was increased from MLC60 to MLC70. The models currently being deployed by the army units are both AVLB model 60 and model 70. Over a 25-year period, approximately 900 AVLBs were built. Figure 1.1 shows an AVLB in a folded position carried on top of an armored vehicle launcher.

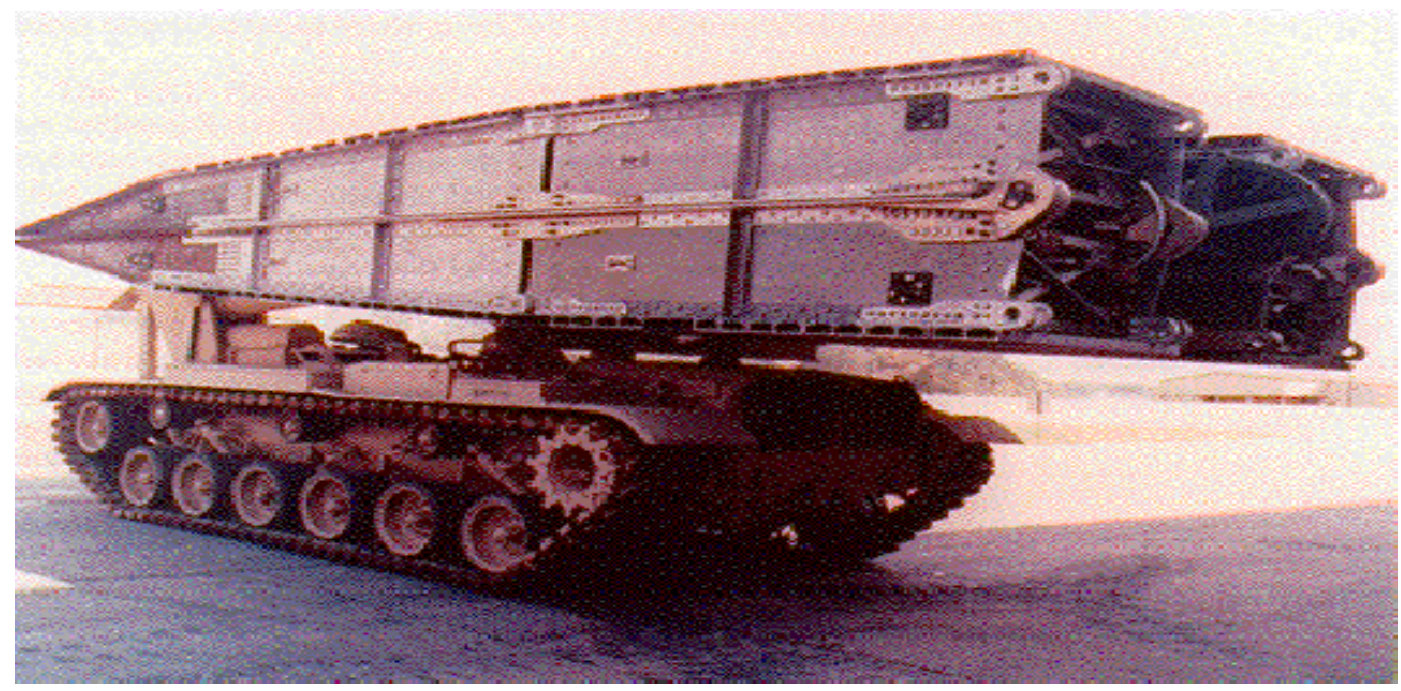

Figure 1.1 US Army AVLB Carried on a Launcher Tank 
Condition assessment of the AVLBs is an important process to ensure safety of the personnel crossing the bridges. Current inspection practice relies on non-technical personnel visually identifying damage. Judgements regarding mission capability are often arbitrary. The average life of existing AVLBs is 23 years, without a priori knowledge of past stress history. It is obvious that an absence of a scientific tool for bridge assessment would lead to bridge failures without warning, which may have catastrophic consequences.

DSS in the form of Bridge Management Systems (BMS) has emerged in the last decade to address some of the vital issues concerning bridge safety, planning and fund allocation for bridge maintenance, repair, rehabilitation, replacement and improvement (AASHTO, 1993). A BMS is an analytical system that includes a computerized database; a decision support tool that supplies, analyzes and evaluates collected data, adopts models and algorithms to make predictions and recommendations; and facilities for ongoing collection, processing and updating of necessary data. These data are used for the purpose of predicting 1. future bridge conditions, 2. maintenance and improvement needs, and 3. state of bridge deterioration.

AVLBs, being mobile, could be stationed at an army base or battle zone, anywhere in the world. Hence the testing facilities for inspection of these bridges may also be present at worldwide army bases. This scenario makes it ideal to develop an Internet-based BMS. The Internet, permitting exchange of information between any two computers in the world with network connection, is a rapidly growing technology. An Internet or Web-based system would ensure that the application hosted on a web server, could be consulted and run by any authorized personnel having connection to the Internet. Data can also be collected through the Internet and updated to one central database, rather than at different locations on stand- 
alone systems. To maintain privacy of the information, security features can be incorporated in the system to make it accessible to authorized personnel.

As an analytical tool, the Decision Support System (DSS) (refer Section 2.5) developed in this thesis incorporates an expert system, to make evaluations of the structural integrity of the AVLB. The goal of the expert system is to enable identification of premature deterioration and imminent failure of the AVLB, and to help take corrective measures through proper maintenance and repair.

\subsection{Problem Statement}

The current criteria developed for inspecting these bridges is presented in the Preventive Maintenance Checks and Services (PMCS) manual, published by the Army. The method of inspection relies on visual inspection of the bridge's structural details (e.g., bottom chords, hinges, main angles, connectors, etc.). The inspection procedure entails checking the bridge for badly damaged components, loose or missing critical parts, cracks of significant magnitude, and finally deciding on the Mission Capability (MC) of the bridge. The bridge components have been classified as primary and secondary structural elements, based on their criticality. The PMCS manual has also outlined the frequencies for inspection of the various components. However, the subjective nature of the visual inspection procedure cannot reliably achieve the required degree of refinement in early crack detection, and predict with accuracy the remaining number of safe tank crossings. 


\subsection{Summary of Previous Study}

Fall of 1995, West Virginia University was contracted by the U.S. Department of Defense (DOD) to develop an automated inspection system based on laser vibration measurements, for AVLB condition assessment. The goal of this project is to address in specific the shortcoming of the existing AVLB inspection procedures. This automated system is to enhance inspection with state-of-the-art vibration measurements and logic-based computer algorithm for decision making.

During Phase I of this project, research efforts were focused on the development of a damage detection algorithm based on changes in vibration parameters. To develop this algorithm, experimental tests were conducted on simple structural components including steel and aluminum plates, to establish their vibrational responses due to artificially made damages. Dynamic vibration signatures, in terms of frequency and mode shape shifts of different vibration modes were examined. Derivatives of the primary signatures were also studied. One of the derivatives, the strain energy distribution function was found highly sensitive to damage, as compared to mode shape variations and frequency shifts. As a result, a strain energy-based damage detection algorithm is developed. For automation, this algorithm has been programmed using virtual instrumentation software, Labview (National Instruments Co.)

To determine the applicability of this vibration-based technique on large structures, dynamic characteristics of an upgraded AVLB model 70 bridge were determined experimentally. The experimental results were compared to results from Finite Element Method (FEM) Analysis. The first three bending frequencies and mode shapes were established which are comparable with the FE model.

Phase II efforts are focused on the development of overall system concept and system 
integration, which entails automated vibration measurements and bridge evaluation algorithm.

\subsection{System Development Approach}

In this thesis, an approach to develop an integrated AVLB condition evaluation system is adopted. This system consists of an automated laser-based vibration measurement instrumentation, a Web-based expert system, and a database. In this approach, the constraints and requirements of the system is first identified; extensive investigation of existing methodologies is then conducted; then selection of the best alternative is made; and finally the actual system is developed.

In carrying out the detection of damage using vibration test results, a reference value of the measured parameters from an undamaged state is required. This is to compute the differential in the parameter values for damage identification. In developing the expert system, it is difficult to establish a realistic system, because:

1. Reference values to predict the structural integrity of the AVLB based on the vibration test results do not exist; and

2. Criteria for deeming the bridge as safe or unsafe for crossing do not exist.

3. No data maintained by the Army, with regard to failure of the bridge at any time with the corresponding number of tank crossings. 
In order to overcome the above constraints, it was decided to extend the expert system with database capabilities for on-line storage and retrieval of data, so that future analysis and development may be possible.

\subsection{Research Objectives}

To satisfy the system requirements, a DSS is developed incorporating an expert system as a tool for evaluation and assessment of damage of the AVLB. This system is precisely meant for handling problem scenarios using heuristic knowledge of the experts in the absence of an expert. Specific objectives of this research that were realized are enumerated below.

1. To identify important visual inspection and vibration testing parameters, necessary for a more scientific and objective condition assessment of the armored vehicle launched bridge.

2. To develop a decision support system integrated with an expert system for condition assessment, based on visual inspection procedures and vibration inspection parameters.

3. Provide database management capabilities to the system for storing and retrieving bridge test data and provide a quick access maintenance procedure for the various bridge structural elements.

4. Address verification and validation issues of the system. 


\subsection{Scope of Study}

To accomplish the objectives of the proposed effort, a thorough literature review was conducted in the problem area, which is presented in Chapter 2. Literature in the areas of decision support systems, expert systems and bridge condition evaluation systems are discussed in this chapter.

In Chapter 3, the knowledge acquisition and analysis for developing the visual inspection and vibration inspection sections of the expert system module are explained. For knowledge acquisition, information from technical manuals on AVLB and inputs from army personnel and structural engineers, have been integrated into the rule base of the expert system. This chapter also describes in detail the development of visual inspection module of the expert system.

Chapter 4 provides description of the actual development of the system with emphasis on the following:

a) Identification of specific bridge data necessary for effective AVLB management, and design of database system module.

b) Development of preventive maintenance checks module of the various AVLB components for quick access during consultation.

The implementation and execution of the system have been dealt with in Chapter 5 . The method of implementation has been demonstrated by explaining the various modules and sub-modules of the DSS. Chapter 6 presents a brief discussion on some important issues about system validation that are pertinent to the successful implementation of the current work. Finally, Chapter 7 states the conclusions and scope for future expansions of this research effort. 


\section{CHAPTER 2}

\section{LITERATURE REVIEW}

\subsection{Introduction}

This chapter presents the literature review covering the areas of Decision Support Systems (DSS) and Expert Systems (ES) developed for engineering and structural condition assessments. The specific issues involved in the development of a decision support system vis-a-vis the current problem have been addressed. A preliminary DSS design was done to better evaluate the suitability of the expert system approach, which is presented in Section 2.5.2.

The software requirements necessary for the development of an expert system integrated decision support system tool have been studied. The survey also emphasized on such areas as Web-based decision support systems and Internet based structural assessment systems. The literature review included resources available from Mountainlynx (WVU academic library consortium), Applied Science and Technology database of the Wilson Indexes, Compendex, and the World Wide Web.

\subsection{Artificial Intelligence and Expert Systems}

In order to understand the concepts of expert systems, one must examine the area from which they are derived - that of Artificial Intelligence (AI). AI is the discipline of creating machines that mimic human behavior or intelligence (Carrico et al, 1989). Since World War II, computer scientists have tried to develop techniques that would allow computers to behave more like humans. The entire research efforts constituting machine vision, neural networks, natural language processing, machine learning, pattern recognition, 
speech recognition approaches, decision support systems, robotic devices and expert systems, is termed Artificial Intelligence. Expert System, the focus of the current effort, has been defined by Feigenbaum as:

"An intelligent computer program that uses knowledge and inference procedures to solve problems that are difficult enough to require significant human expertise for their solution” (Barr et al, 1981).

Since the systems developed, attempt to capture the knowledge of a human expertise and contain heuristics and factual knowledge, they are also referred to as "Knowledge-Based Systems".

ES, when utilized in assisting decision making process, it becomes a subset of DSS. According to Barnett et al. (1988), the utility of an expert system depends on:

1. How faithfully it mimics an expert, and

2. The level of expertise in the problem domain

By this token, it is understood that models can never be $100 \%$ accurate, since no expert is omniscient. It is important that users of expert systems exercise caution while interpreting the results produced by expert systems.

An expert system, much like any computer program, consists of, a set of inputs; a set of outputs; and a set of modules, which are designed to map the inputs into the desired outputs. The modules consist of the inference machine in the form of rule base. The inputs provided by the user, through user interface, are processed by the inference engine. The output is derived by the application through inductive reasoning that is based on expert knowledge embodied in the knowledge base. 
Two approaches may be adopted by the inference engine to arrive at the desired goal: backward chaining and forward chaining (Carrico et al., 1989). Backward chaining is the pursuit of results by relying on experiences coded as rule base. In this approach, the inference engine determines the highest priority goals, based on the specifications of the developer. It then backward chains through asking questions about the pre-established rules, in order to find a rule or rules that lead to the goal. In the forward chaining mechanism, the system collects facts and checks if any goal applies along the way. A list of rules that are potentially satisfied is made, and the inference engine determines which of the rules should be invoked, based on priority. The conclusions, from the rules that are activated, are added to the knowledge in working storage and the inference engine cycles again to see if any rules are satisfied, because of the additional information.

A schematic representation of the modules in an expert system is shown in Figure 2.1. The components enclosed within the dashed lines viz. knowledge base, inference engine and user interface, constitute the physical body of the expert system. The expert knowledge and facts from historical records are stored in the knowledge base in the form of rules. The user inputs (problem scenarios) and answers to questions that are posed by the system through the user interface. The inference engine examines the inputs with existing facts and rules and decides the order in which inferences are made. The final inferences and answers provided by the system are presented to the user, through the user interface. 


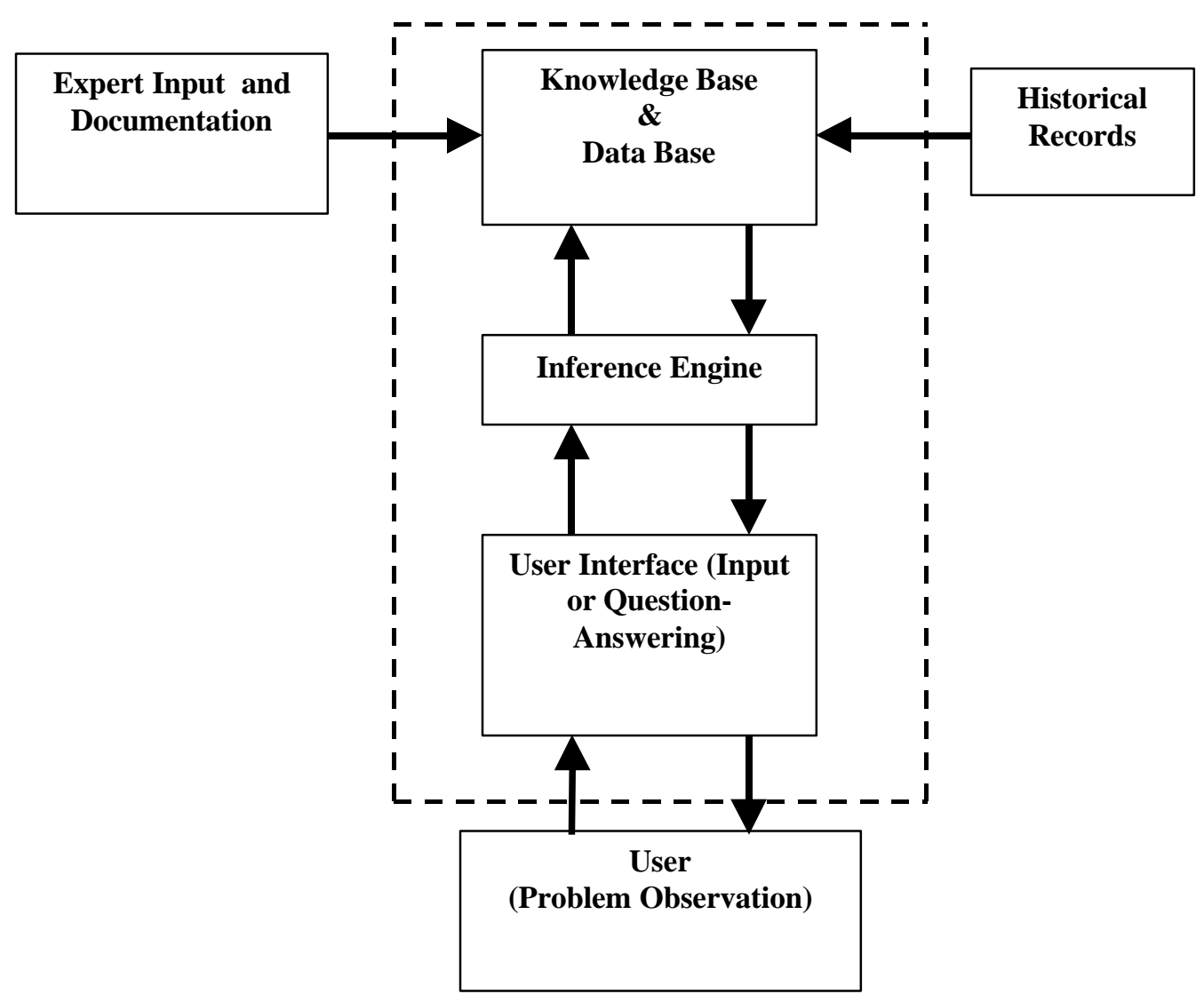

Figure 2.1 Expert System Framework 
The early ES developed were mainly in the medical domain. MYCIN (Buchanan, 1984) was the first large expert system with explanation facility for its reasoning, and was developed at Stanford University in the mid-1970s. It was designed to aid physicians in the diagnosis and treatment of meningitis and bacteremia infections. PUFF (Kunz, 1984) and CADUCEUS (Pople, 1975) were other expert systems developed in the medical domain. Expert systems gradually expanded into other domains in the form of PROSPECTOR (Duda, 1984) for geological mineral site evaluation; MACSYMA (Harmon, 1985) for mathematical problem solving by scientists and engineers; HEARSAY (Barr, 1981) for understanding and interpreting speech through conversation. XCON (Kraft, 1984), which was developed over the R1 system (McDermott, 1981), was employed to assist configuration of Digital Equipment Corporation (DEC) computers.

Expert System, in the strictest sense of the term, is a system embodying a number of characteristics that distinguishes it from conventional computer programs, which are enumerated as follows (Hayes Roth et al, 1983):

- The system must apply expert rules in a relatively efficient manner in order to reach acceptable conclusions.

- The system bases its reasoning on symbolic representation of world knowledge or facts.

- The system must have some knowledge of the basic principles in its domain of interest, to provide additional help when expert rules fail and to produce intelligent explanations of its own reasoning process.

- The system must be able to handle formidable problems in the real world domain.

According to Hayes-Roth et al (1983), very few ESs contain all the characteristics listed above. 


\subsection{Bridge Condition Assessment}

Bridge condition assessment aims at evaluating the effect of a damage, of any degree in a particular bridge component, on the overall performance of the bridge. Lack of a welldefined and reliable technique for assessing the condition of the bridge structure can result in unforeseen bridge failures of catastrophic proportions.

General bridge inspection procedure and guidelines have been illustrated in the Bridge Inspectors Training Manual (1990) of the Federal Highway Administration (FHWA), and the inspection manual published by American Association of State Highway and Transportation Officials (AASHTO).

The above manuals rely largely on visual inspection. Visual inspection of the structural elements of the bridge has long been used for determining bridge conditions. Besides visual inspection, bridge inspectors have also used various Non-Destructive Evaluation (NDE) techniques for determining bridge conditions. Vibration testing is one such technique that has come to be widely accepted among the structural engineering profession for structural integrity evaluation. Vibration testing is used to extract dynamic characteristics of a structure, and has been recommended as a viable approach for damage detection (Salane et al (1990), Aktan et al (1994), Alampalli et al (1992)) on bridge structures.

\subsubsection{Bridge and Other Structural Assessment Systems}

Expert knowledge on structural inspections has been integrated into expert systems structural engineering and condition assessments. Zuk et al. (1992) developed DOBES 
(Disposition of Older Bridges Expert System) for decision-making in bridge management, including determining the courses of action to be taken with regard to old highway bridges. DOBES is based on an extensive set of rules, criteria and procedures used by bridge engineers and authorities, with a view to making a consistent basis for evaluating various bridges.

Melham et al. (1990) built a twin module prototype expert system called FASTBRID, as an integrated engineering training aid for bridge inspection and remedial action. It was developed to accomplish two basic tasks: 1) to help the user in planning fatigue inspection by identifying and classifying fracture critical members; and 2) to determine how to do the inspection. FASTBRID was also meant to aid the user in evaluating the inspection results and in determining actions to be taken in case of a deficiency or suspicious observation. In the absence of any obvious defects, the system would conduct fatigue evaluation using different procedures, to calculate the approximate remaining life of the structure. The remaining life calculation is based on current AASHTO requirements on locally measured and predicted load patterns.

A hybrid system, BRIDGE-FIX (BRIDGE Fatigue Inspection eXpert), combining a rule based information system and multimedia technology was developed and implemented by Wilson et al. (1994). It was designed to aid inspectors and engineers in the fatigue evaluation of steel girder bridges. The knowledge base in this system was compiled from several sources, including technical literature, published papers, reports and interviews with

experts on bridge fatigue. Operating in two stages, the first employs information supplied by the user on bridge characteristics to target potential fatigue critical locations. In the second 
(post-operation) stage, BRIDGE-FIX interprets the observations about fatigue critical details from field testing and evaluates the criticality of any cracking that is discovered.

Kuprenas et al. (1996) created ASSESS, to provide uniform evaluation and damage assessment of earthquake damaged structures and to tag the condition of the structure in terms of safety level. Developed using VP Expert (Wordtech, 1995), an expert system shell, it used a top down design approach to identify and to classify the potential hazard associated with a seismically damaged structure. The possible elements that may be damaged for each possible hazard were then identified. Based on a set of rules, each damage assessment of hazard/element combination was tagged. A forward chaining inference method was used. To account for the uncertainty involved in assessments; confidence factors based on the users' relative confidence in a particular fact were used.

Avramadis et al. (1995) developed a prototype system called PADEX, for the antiseismic design of multi-story buildings. A double module system was built, which consists of a module for selection of elements governing earthquake resistant design, and an expert system component incorporating the knowledge of a structural engineer. The expert system components use heuristic and approximate methods, and perform computations to infer from the provided facts and rule bases.

An expert system for selecting the methods for retrofitting fatigue cracking in steel bridges was developed by Mikami et al. (1994). The system used a knowledge-based network model, which has the learning ability to modify relations, and with built-in certainty factors such as necessity, high possibility, possibility and low possibility. The system employed an inference engine coded in $\mathrm{C}$ language, which was able to provide inference results even in case of incomplete presence of facts. 
Goodier et al. (1996) developed a structural monitoring knowledge-based system using G2 shell from Gensym Corporation. This is a powerful real time hybrid knowledge based system that offers object paradigm to model knowledge, and allows connectivity of objects and production rules with several differing inferring techniques. The input data, in the form of voltages and frequency changes from the sensors, were converted into the dynamic characteristic engineering units. Based on the limit states established in the rulebase, the knowledge-based system would interpret the current structural behavior.

Males (1992) developed a prototype expert system dealing with customer inquiries for a water utility to allow non-technical administrative personnel to handle routine inquires about water quality. VP-Expert (Wordtech, 1995), was used and had integrated database connectivity features to store customer information and looking it up during consultation.

Salvaneschi et al. (1995) developed two decision support systems for monitoring structures: MISTRAL for monitoring dam and KALEIDOS for monitoring historical monuments. MISTRAL does real time interpretation and explanation of a dam, based on data coming from a monitoring system installed on a dam. Prolog and $\mathrm{C}$ were used for the programming. The interface is programmed in Visual Basic and the database is managed through MS Access. The KALEIDOS system employs a communication module, which receives data from the acquisition system. This is evaluated using a symbolic and numerical processor for qualitative and quantitative interpretation of data using heuristic knowledge. It is coded by empirical formulas accounting for the reliability and significance of the various structural elemental relationships. It provides a static as well as dynamic database of test.

The Engineering Analysis Center at Berkeley Nuclear Laboratories, UK, developed decision support systems for structural integrity assessments based on two different methods: 
the R6 and the R2 procedures (Durrans et al., 1992). R6 is a fracture mechanics-based evaluation procedure using 2-parameter approach, whereas R2 evaluates the dynamic loading effects.

AMADEUS was a Lisp-based expert system developed by Tazir et al. (1992), for onsite monitoring of buildings after earthquakes and determining their usability. The knowledge base was developed through literature reviews and interviews with domain experts. A backward chaining mechanism was used, which enabled justification of how a conclusion was reached and focused the reasoning on the goal. Thus, the expert system helped the inspector in arriving at a usability decision.

Miyamoto et al. (1995) constructed a risk management system for the evaluation of accident risk during the construction stage of steel bridge. It incorporated a risk evaluation model, and rules that deal with subjective information of bridge engineers relevant to the diagnostic system.

To account for the uncertainty and the subjective nature of knowledge, researchers have worked towards integration of other facets of AI, such as the theory of Fuzzy Sets, and Neural Networks (NN), with knowledge-based expert systems.

The Damage Assessment of Protective Structure (DAPS) expert system, developed by Ross et al. (1990), used the theory of Fuzzy Sets in order to quantify, combine and interpret linguistic damage descriptors. Rules for determining total damage, combined with numeric information and non-numeric information, gathered from structural engineering experts, are quantified using fuzzy weighed average algorithm. The output from structural integrity evaluation was combined with functionality and reparability evaluation modules to develop a complete assessment of the damaged structure. 
An expert system approach combined with inference procedure with fuzzy and uncertainty restriction were used by Yao (1985) to assess damage and safety of seismic impacted structures. The relevant knowledge is expressed as a collection of segmented knowledge, in the form of If-Then rules. The damage state of the existing structures is defined in terms of a numerical quantity between 0 and 10 , where ' 0 ' and ' 10 ' refer to 'no damage' and 'total collapse', respectively. The damage state is defined verbally. Observations about the damage state were derived from: (i) visual inspection at various portions of the structure, (ii) reading of accelerometer records during earthquake, (iii) nondestructive testing results, and (iv) loading tests before and after the earthquake. The knowledge and experience of human inspectors, design parameters, years of usage and other structural data were stored and used for the inference as reference data apart from inspection data. For the inference procedure, two statistical methods: Bayesian probability and Dempster and Shafer's probability, were applied to construct uncertainty and fuzzy restrictions. According to Yao (1985), probabilistic and statistic theories can be applied to interpret the degree of safety, if and only if:

(1) sufficient statistical data concerning loads and resistance of the structures are available, and

(2) adequate knowledge of structural behavior under various loading conditions and failure paths are available.

The system made a final decision based on the statistical inference techniques in terms of no damage, slight damage, moderate damage, severe damage, destructive damage or 
no appropriate answer.

Ogawa et al. (1985) developed SPERIL-II based on the prototype, SPERIL-I (Yao, 1985). The assessment process in SPERIL-II includes: 1) evaluation of local damageability from input data, 2) evaluation of global damageability, and 3) estimation of safety or damage state of the structure. Inexact reasoning based on Dempster and Shafer's theory of evidence was used to combine fuzzy information and certainty factors, to represent facts. Structural elements were assigned different weighting factors of importance according to their functions. Important structural elements were assigned weighting factor of 1 . Other elements were given a weighting factor of $x$, where $0<x<1$. Fuzzy sets for various descriptions of cracks were then defined; and If-Then type rules were used to obtain the damageability of the elements. Using this information, SPERIL-II gave an assessment of the damage state of the structure.

In summary, DSS in the form of expert system has been used with a degree of success in the last two decades to aid in the diagnosis and assessment of damage in structures. The rule base for most of them have been developed by acquiring knowledge from the experiences of structural experts or bridge engineers as the case may be, and from relevant literature. Although few have been developed within an expert system shell with built-in inference engine, most of the expert systems have been developed in third generation programming languages such as $\mathrm{C}$ or Fortran, or fourth generation language such as Visual Basic. A few systems employ confidence factors or fuzzy sets to account for uncertainty involved in answering certain questions posed by the expert system conclusively.

\subsection{Decision Support Systems}

Decision support systems can be defined in many ways. The simplest one is, "Decision Support Systems (DSS) are interactive computer-based systems intended to help 
managers/decision makers identify, structure, and/or solve semi-structured and unstructured problems and make choices among alternatives" (Power, 1997). More comprehensively, Thierauf (1988) has defined DSS as:

"Systems that allow the decision maker to combine personal judgement with computer output in a user-machine interface to produce meaningful information for support in the decision-making process. Such systems are capable of structured, semi-structured and unstructured problems and use queries to obtain information by request. As deemed appropriate they use quantitative models as well as database elements for problem solving."

DSS help decision-makers use and manipulate data; apply checklists and heuristics; and build and use mathematical models. Depending on the decision-making steps, DSS can be broadly classified into three categories: DSS for data storage and retrieval, DSS for data analysis, and DSS for decision analysis (Liebowitz, 1990). The present problem scenario requires data storage and retrieval as well as data analysis, which is ideally suited for developing a DSS.

Requirement of DSS to handle data storage and retrieval, calls for the use of a Data Base Management System (DBMS). Data analysis, depending on the complexity of the problem and data, can be handled by spread sheets, statistical models, Operations Research/Management Science (OR/MS) models, or expert systems (Liebowitz, 1990).

\subsubsection{Decision Support Systems in Bridge Management}

DSS in the form of Bridge Management Systems (BMS), to aid various activities related to effective and efficient management of bridges, has emerged and is gaining importance in the last decade (AASHTO, 1993 and Shirole et al., 1991). BMS include 
computerized database; decision support tool that supplies, analyzes and summarizes data, and uses models and algorithms to make predictions and recommendations; and facilities for ongoing collection, processing and updating of necessary data (AASHTO, 1993). Key functions of BMS includes: predicting long term bridge conditions, determining maintenance and improvement needs, preventing bridge deterioration and estimating bridge costs. According to Shirole et al. (1994), data that affect structural integrity of the bridge including critical fracture parameters and scour data should be used as input into the DSS model.

Shirole et al. (1991) has addressed some of the issues involved in developing successful DSS for bridge inspection. One of them is the necessity of a data base system that includes up-to-date information on construction, inventory, inspection, maintenance and safety, which should be stored in mainframe computers and should be accessible via network

to concerned agencies. Another necessity is modularity, wherein each module packed with built-in techniques, is independently accessible and is subjected to input data availability.

\subsection{Decision Support System (DSS) Development}

\subsubsection{System Development Methodology}

The development of an expert DSS requires a carefully planned, yet flexible, design and development environment. The stages involved in system construction from initial design to a working system are: (Barnett, et al., 1988)

1. Problem Analysis - After the suitability of the domain for ES development has been ascertained, information required for implementation have to be gathered. This step involves acquiring knowledge through interviewing experts, studying relevant manuals and literature. Knowledge analysis is then conducted to develop 
reasoning procedure. Elements to be included in the system need to be identified.

2. Initial Prototype - This step involves developing the system from the initially available knowledge base. User Interfaces and explanation facilities are also incorporated to demonstrate the suitability of the expert system model.

3. Expanded Prototype - Expanded prototype development involves testing and modifications of initial prototype. This involves: improvising over any shortcomings in the initial prototype such as, ease of use and user interface requirements; upgrading to state-of-theart software if necessary; refining initial knowledge base and identifying any other feature requirements.

4. Delivery System - After final refinement and testing, the delivery system is produced. The delivery system should be optimized with regard to performance, user interface, effectiveness, etc. This may entail implementation of some or all of the modules in a language or development environment different from one in which it was initially developed.

The first stage in any system development, consisting of domain knowledge acquisition, which can be an elaborate process. It may take anywhere between a few months to years before the entire expert knowledge and understanding of the behavior of a system could be formulated into well-devised rules. 


\subsubsection{Development of the Initial Prototype DSS}

To conduct a proof-of-concept study, an initial prototype DSS for the AVLB evaluation was developed. To develop the prototype expert system, it was decided to select an expert system shell for programming, based on the following criteria:

1. Fit of the tool to the problem

2. On-line help, documentation

3. Uncertainty handling

4. Integration capability with databases

5. Explanation of Reasoning

6. Very low cost

7. Simple English language-like rules

Existing ES shells including EXSYS, FLEX, CLIPS, M4 and VP-Expert, have been evaluated based on the above criteria. EXSYS, an expert system tool developed by Multilogic, Inc, with the ability to interface with the Internet was found to be expensive for our purpose (Multilogic, 1997). M4, a powerful tool for building knowledge-based systems, had most of the desired features but was also found to be expensive (Teknowledge Corp., 1997). CLIPS (NASA, 1993) was also examined, and was found not having a good user interface, and an elaborate coding procedure. Flex (Logic Programming Associates, 1997) a hybrid expert system tool was found to be expensive and had a complex coding procedure.

Finally, VP-Expert (Sawyer, 1995) - an ES shell developed by WordTech Systems was chosen as the development tool. VP-Expert was found to have features that were demonstrated in some of the bridge assessment systems reviewed in the literature, which are: 
1. Inference engine that uses both forward and backward chaining inference procedure,

2. Ability to exchange data with database, spreadsheets and ASCII text files,

3. Simple English-like rule construction,

4. Ability to explain its actions during consultation,

5. Ability to execute external DOS programs,

6. Confidence factors that permit accounting for uncertain information in knowledge base,

7. Ability to record and graphically display the rule-by-rule search pattern used behind the scenes during consultation, (Shown in figure 2.2)

8. Graphics support to a limited extent. 


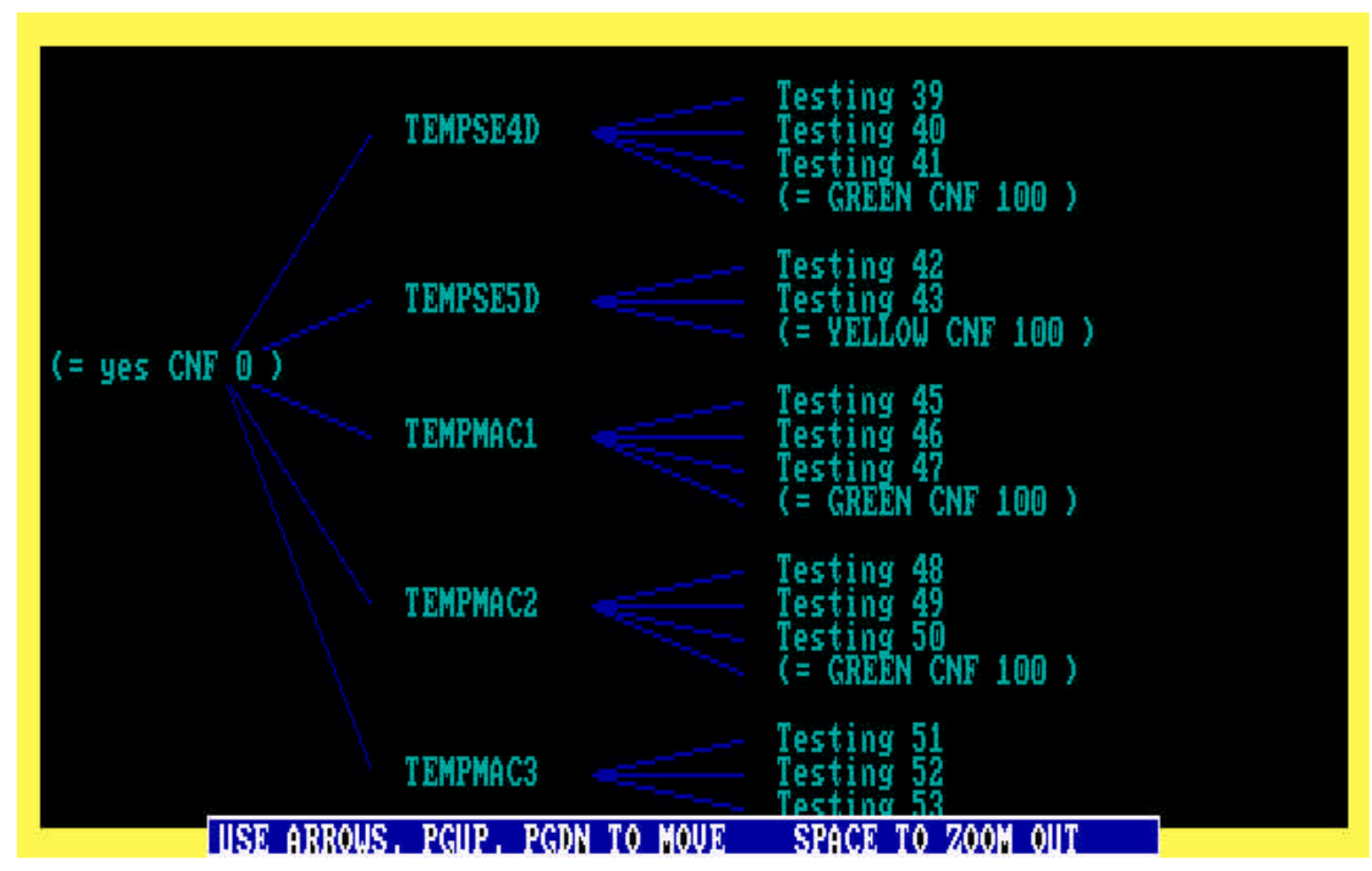

Figure 2.2 Graphical Tree Display of the Trace of the Inference Mechanism in VP-Expert Program.

Figure 2.2 shows a rule tree displaying a particular inference process, where rules 39 to 53 have been tested. Details of the rules can be observed in Appendix A, where the complete code is listed. As an example, rule 39 to 41 shows a green light for mode 4 strain energy values (TEMPSE4D) not exceeding pre-set limit states. Similarly, consultation results are shown for TEMPSE5D, TEMPMAC1, TEMPMAC2 and TEMPMAC3. VP Expert allows such tree presentation to show the path taken by the inference engine in progressing towards a solution. This system demonstrates the reasoning approach behind how the concept of expert system could be used to solve the task on hand. To test the model, inspection parameters consisting of dynamic characteristics of the bridge and visual inspection were used as inputs. The dynamic characteristics consist of the following:

1. SEDI (Strain Energy Damage Index) 


\section{Vibration frequency}

3. Vibration Damping

\section{MAC (Modal Assurance Criteria)}

Sample "limit state values" to define the criteria of safety of the model were used for the various inspection parameters listed above. A rule base consisting of about 75 rules were coded into the system. The rule-base was developed using the judgements of structural engineers and from the knowledge acquired through interviews, literature and from structural experts regarding possible modes of bridge failure and critical structural components. The inference engine chains backward by determining the highest priority goal from the specifications. The engine then asks questions for collecting facts about the rules, in order to fire the appropriate rules leading to the goal. Based on the values input into the system, the rule base decides the current state of the bridge. The condition assessment was done in terms of RED LIGHT for "bridge unsafe for crossing", YELLOW LIGHT for "cross with caution" and GREEN LIGHT for “cross safely”.

Evaluation and testing of the prototype system lead to the realization of inherent limitations of the VP-Expert system shell. These are:

1. The expert system shell runs only under MS DOS.

2. The expert system shell is incapable of handling large databases.

Also relational database handling capability is not available.

3. The user interface is not capable of multi-user application.

4. Program crashing may occur during certain processes. 


\subsection{Study of Web-Browser as an Application Environment}

In developing the decision support system incorporating an expert system and a Relational Database Management System (RDBMS), certain considerations are required for selecting the right software for system implementation.

Since computer applications and software became available over thirty years ago, engineers have been using desktop computers, running applications locally and sharing files stored on local file servers. However, based on current trend of development in computer technology, which encompasses the domain of Civil and Structural engineering, Bentley (1998,) has foreseen a replacement of desktop-oriented network architecture by Web-based networking. Software applications and data, stored in relational databases, will be shared by engineering and business entities over the Internet. He predicts that most Civil engineering software in very near future would be deployed over the Internet and run from a Web server. This provides a basis for total connectivity amalgamating information from different sources into a unified presentation that can be accessed with point-and-click simplicity.

Based on past few years of growth in microcomputer capabilities, Shirole (1994) expects that by the year 2000, for effective bridge management, all bridge-related information should be accessible at any time from any location, without requiring computer expertise. According to him, repair cases, checks for bridge inspections and application programs that automatically work together, would be included in an integrated bridge management system. This would require the application be deployed over a network of computers such as the Internet. 


\subsubsection{Web-Based Applications for Structural Monitoring}

One of the pioneering efforts in monitoring of instrumented civil structures over the Internet was by Fuhr et al. (1995). They developed a sensor interrogation system, which utilizes Internet global computer network as the information conduit from sensors to the user. Structural monitoring could be performed at a remote location as long as Internet was accessible. They carried out monitoring of variable dynamic states of the structure by information acquired from the sensors embedded into the Winooski hydroelectric dam. Almost real-time video images and additional information from sensors were continuously acquired, updated and stored on a computer. This information and current status report on the structure are later made available for access by any authorized personnel through FTP site or the World Wide Web.

Chen et al. (1996) developed an interactive knowledge-based data processing system accessible on the Internet. This system uses Internet-based utilities to connect to a remote instrumented structure to monitor and assess its conditions, in almost real-time. The system consisting of three components was employed to carry out an investigation on a $50 \mathrm{~m}$ high luminaire tower structure. The first component was an HTTP server, for making the system accessible over the Internet. The second component was PERL language scripts for manipulating text in files, extracting data from files and writing text files. It could also create and control other system processes and binary data like FORTRAN executables, Matlab, etc.,

which constituted the final system component. The combination of a HTTP server with PERL, provides the user the ability to access the system via Internet. The user will be able to manipulate the workstation environment and run the binary executables, from within the hypertext shell - all through the Internet. 


\subsubsection{Web-Based Decision Support Systems}

An extensive research on DSS applications on the Internet was carried out in order to ascertain the pragmatism and the viability for current application. Some of the executable decision support systems in different domains of knowledge, which have been successfully implemented and deployed on the Internet, are discussed below.

Kaplan et al. (1998) developed a Web-based DSS for Accounting Information System (AIS) reliability assessment. AIS-Reliability is a method used by auditors to assess the reliability of the accounting system of an organization, which can infer the reliability of the organization's financial statements. This prototype system to aid auditors was an essential step in assessing the reliability of an organization's accounting system.

Osmond et al. (1995) developed the WATERSHEDSS (Water, Soil, and HydroEnvironmental Decision Support System), the primary objective of which is to transfer water quality and land treatment information to watershed managers. The goal is to assist them in: 1) to make appropriate land management and treatment decisions; and 2) to assess and evaluate water sources, environmental impacts, and potential management options.

The Department of Defense (1998) has developed a Civilian Personnel Management Service expert system using Multilogic's EXSYS Internet-based expert system software. Different modules in the expert system are used to determine employee status, records of leave and absences, setting rates of pay, etc.

Proffer (1998) developed a number of Internet/Intranet based traffic management systems for real-time traffic displays for the city of San Jose. These displays were developed using the Java programming language and were embedded in HTML web pages. At time of this publication, they are developing traffic displays that would run in a dynamic HTML 
environment using ECMAScript or VBScript for real-time monitoring. Implementations are also in progress towards delivering these displays to wireless hand-held devices such as palmtops, for individuals who can then accordingly decide their route of travel based on the traffic display in the vicinity.

A few of the widely employed commercial software for DSS development were also reviewed. These software are capable of rational and analytical decision making and incorporate design tools such as graphics, spreadsheets, automated reports, graphs and web pages. ERGO is a DSS software developed by Arlington software corporation (Arlington Software Corporation, 1997) that simplifies arranging, prioritizing, and evaluating criteria. It helps structure and compare relevant variables during decision-making process. Analytica, a DSS development tool from Lumina (1998), uses influence diagrams to form a "visual environment for creating, analyzing and communicating probabilistic models for business, risk and decision analysis". These software are found to be more applicable to problems where there are a large number of decision making variables and wherein a lot of data had to be analyzed and manipulated.

\subsubsection{Need for Selection of Web Browser as the DSS Environment}

One of the advantages of Web-based applications is the interpreted type programming language. With respect to the current problem, the system development will be of an evolving nature, which will require future knowledge refinements and program reasoning modifications and extensions. Hence, to develop this system as a stand-alone application may pose certain disadvantages. To understand this, one must delve into the realms of programming language fundamentals. 
Programming languages are classified as compiled languages and interpreted languages. Languages such as C, Visual Basic, or an AI language such as Lisp, are all compiled languages, wherein a compiler takes the code and generates executable files, which is essentially a machine language that the CPU can understand (Foghlu, 1996). This executable file can then be run or be copied to other computers, without the need for the program source code. The file size of a compiled program is generally considerably larger than the original. Once compiled and distributed for use, the source code of the program is not visible. However, the resulting machine language code is specific to the processor on which it was compiled. If the code needs to be used on another processor, the code must be recompiled on, and often rewritten, for the new machine (Stapleton, 1998). For future modifications and expansions, the source code requires separate distribution and compilation in its development environment. Separate licensed software will have to be purchased for all future program development related activity.

An interpreter program, on the other hand, translates the program statements into machine language one line at a time. An interpreted program is smaller than a compiled one but might take longer to execute and uses less memory than a corresponding program written in a compiled language (Stapleton, 1998). Scripting languages such as PERL, JavaScript, VbScript and Shell Scripts are all languages of the interpreted kind, wherein the source code of the program is distributed along with the application. It can be viewed and modified by individuals having administrative privileges to the servers on which these programs reside. 


\subsubsection{Suitability of Development of DSS as Web-Based Application}

For current problem, the AVLBs, being mobile (Chapter 1), could be stationed at any army base or battle zone location anywhere in the world. The testing facility for inspection of the bridge could be extended to multiple army depots. These scenarios make the system ideally suited for Internet-based development.

Being Internet-based, the database as well as the expert system, can be maintained and run from a web server. Any high capacity server, such as Netscape Live Wire or Microsoft SQL Server, can be used to provide database connectivity between the web browser and a relational database system.

The web-based system would ensure that data can be updated and accessed from one central database, rather than data collection on standalone systems and later data transfer for database updating. To maintain privacy of the information, security features can be incorporated in the system to make it accessible to the authorized personnel. The development of this expanded prototype DSS has been described in Chapter 4.

\subsection{Summary of Literature Review}

Several literatures indicate decision support systems incorporating expert system concepts, database and other ancillary features have been developed for structural condition assessment. In most cases, knowledge bases have been collected from available historical structural data, test data and the knowledge and experience of structural experts. Certain systems also employed an integrated database facility for test data storage that could be utilized in future to refine the system. 
Expert systems are evolutionary systems wherein initial designs and implementations rarely last. Feedback from expert collaborators and users and further incorporation of knowledge based on future inspections and tests are crucial for improving system design and performance.

Internet based applications are an emerging and rapidly growing trend in computer applications and represents a paradigm shift from stand alone desktop applications to webbased applications available remotely to authorized individuals. Web-based applications running from a network server ensure enterprise-wide availability of identical decision making tools and criteria and provide centralized information that can be remotely updated. 


\section{CHAPTER 3}

\section{KNOWLEDGE ACQUISITION AND SYNTHESIS}

\subsection{Introduction}

This chapter deals with the knowledge-base generation of the expert system as part of the decision support system for the AVLB inspection system. A knowledge-based expert system can not exist unless expert knowledge from some sources are elicited or acquired. This acquired knowledge is then synthesized and transformed into rule base from which questions may be framed, in order to develop the expert system procedure. In developing the AVLB knowledge base, due to limited physical data on the AVLB, expert opinions are largely collected through army personnel and available literatures. The available information formed the basis for the development of the expert system. Further refinements are needed, based on carefully recorded physical data on the AVLB damage state, and bridge conditions.

\subsection{Knowledge Acquisition}

Two key modules are included in the Knowledge-Based System (KBS) for the inspection of the AVLB, namely: visual inspection and vibration inspection procedures (Section 1.3). The knowledge-base required for developing the visual inspection module of the system was basically acquired from three main sources: the Army Preventive Maintenance Checks and Services (PMCS) Manual (TM 5-5420-203-14, U.S. Army, 1990); interviews with army technical personnel who have worked on or managed the AVLB; and engineering intuition from structural engineers. The knowledge and rule base for the vibration inspection module of the system was acquired through carrying out vibration tests on the AVLB and simulating damage scenarios on validated Finite Element (FE) models. 
The knowledge elicitation from the US Army technical personnel, through interviews regarding issues relevant to the development of the inspection procedure, is established through a questionnaire (Appendix B). The questionnaire was developed to extract information necessary to develop a knowledge base for the expert system module.

Based on the answers received from the US Army technical personnel and the original PMCS (US Army, 1990), a visual inspection procedure was developed. The decision about the frequency of consulting the decision support system for carrying out the inspection is left to the users depending on the usage and location of the bridge. However, the system is programmed to ask the user for inspection data, which are compiled into a database.

Full-scale modal testing of the AVLB was conducted to determine the dynamic characteristics of the bridge (Chen et al., 1997, SDRC, 1997). These data formed the baseline values for the damage parameters used in vibration inspection evaluation procedures (Section 3.4).

\subsection{Visual Inspection Knowledge Analysis}

\subsubsection{Classification of Components}

Based on descriptions in the PMCS manual (US Army, 1990), the inspection procedure may be separated into functional inspection or structural inspection. The functional inspection deals with nonstructural components, which are related to the mechanical and hydraulic system of the AVLB. For example, the hydraulic hose assembly, scissoring cylinder and pipeline. The structural inspection is related to the different components that may contribute to the overall structural strength or stiffness. Hence, the 
different components of the AVLB (Table 2-2 of the revised PMCS manual) have been classified into either functional components or structural components. Table 3.1 shows the list of AVLB components. Item numbers listed in the tables in this chapter correspond to the item numbers in the PMCS manual. Except for a few items, the revised PMCS manual is applicable for both models M60 and M70 of the AVLB. 
Table 3.1 Categorization of Components on Functional and Structural Bases

\begin{tabular}{|c|c|c|c|}
\hline Item No. & Description & Functional & Structural \\
\hline 1 & tie-rod assemblies & $\mathrm{X}$ & \\
\hline $2 \mathrm{a}$ & Deck Extrusions & & $\mathrm{X}$ \\
\hline $2 b$ & deck Curbing & & $\mathrm{X}$ \\
\hline 3 & Hydraulic fluid leaks & $\mathrm{X}$ & \\
\hline 4 & pin rivets, hot-rivets of all parts & & $\mathrm{X}$ \\
\hline 5 & Attaching hardware, i.e. Nuts/Bolts/Washers & & $\mathrm{X}$ \\
\hline 6 & Top center connector pins (Model 70 and 60) & & $\mathrm{X}$ \\
\hline $7 \mathrm{a}$ & Top connector pins (end to center panels) (AVLB 60) & & $\mathrm{X}$ \\
\hline $7 \mathrm{~b}$ & Bottom connector pins (end to center panels) & & $\mathrm{X}$ \\
\hline $8 \mathrm{a}$ & center hinge & & $\mathrm{X}$ \\
\hline $8 \mathrm{~b}$ & center hinge pin and retainer clip & & $\mathrm{X}$ \\
\hline $9 \mathrm{a}$ & Main aluminum angles along top chords & & $\mathrm{X}$ \\
\hline $9 \mathrm{~b}$ & Main aluminum angles along bottom chords & & $\mathrm{X}$ \\
\hline 10 & Connector area along the bottom chord & & $\mathrm{X}$ \\
\hline 11 & Press fit pins along the top chord (AVLB 70) & & $\mathrm{X}$ \\
\hline 12 & splice doubler angles in bottom chord & & $\mathrm{X}$ \\
\hline 13 & splice plate along bottom of each girder & & $\mathrm{X}$ \\
\hline 14 & main aluminum angle extensions & & $\mathrm{X}$ \\
\hline 15 & cross bracing under treadways of center/end panels/ of sections & & $\mathrm{X}$ \\
\hline 16 & Launching diaphragm & $\mathrm{X}$ & \\
\hline 17 & hose assemblies and quick disconnects & $\mathrm{X}$ & \\
\hline 18 & Hydraulic piping/fitting/connections & $\mathrm{X}$ & \\
\hline 19 & Cylinder beam and cable beam & $\mathrm{X}$ & \\
\hline 20 & Scissoring cylinder and cylinder seat brackets & $\mathrm{X}$ & \\
\hline 21 & Scissoring/launching cables and equalizer plates and pins & $\mathrm{X}$ & \\
\hline 22 & Quadrant and quadrant struts & $\mathrm{X}$ & \\
\hline 23 & cross pin socket on the inboard side of the ramps & $\mathrm{X}$ & \\
\hline 24 & Lateral cross braces & & $\mathrm{X}$ \\
\hline 25 & Transverse braces between center/end panels, or sections & & $\mathrm{X}$ \\
\hline 26 & web girder plate & & $\mathrm{X}$ \\
\hline
\end{tabular}




\subsubsection{Functional Components}

Functional components include different structural parts that may constitute the hydraulic system and the mechanical systems that are involved in the launching operation. The effectiveness of the bridge launching, opening and folding is governed by the ability of these elements to function effectively. The ability of the AVLB to sustain a tank load during tank crossing, however, is almost independent of the working condition of these functional components. As the current effort of this thesis is largely dedicated to assess the structural integrity of the bridge, the working aspects of the bridge have not been considered in the present KBS system.

\subsubsection{Structural Components}

Structural components are parts of the AVLB that directly contribute to the overall integrity of the system and have been distinguished into "primary" and "secondary" components (Table 3.2). As outlined in the PMCS manual (US Army, 1990), damages to secondary components do not necessarily deem the bridge - "non-mission capable". "Nonmission capable" usually leads to a decision of "deadlining" of the bridge. However, observation of damages on secondary components may indicate the type of damage mechanisms that the structure may be experiencing. Damage to primary components has more significant and direct implication on the structural conditions than secondary members.

Typical damages in the AVLB may result from overloading or corrosion induced deterioration in the load carrying bottom chords and other structural members. Battle damage, damage sustained during shipping and damage due to launch and retrieve operations are other possible sources of damage (Henry, 1996). 
Factors such as frequency of tank crossing, age, loading history, development of high stresses during launch and retrieval operations, and material fracture toughness are essential considerations as they contribute towards the development fatigue crack, which may lead to catastrophic failures. From a series of tank crossing tests conducted at Aberdeen Proving Grounds, cracks and defects were observed in angle splices above and below rivets located in the bottom chord (Cho, 1994). Damages observed on a bracing and a rivet are shown in Figures 3.1 and 3.2, respectively.

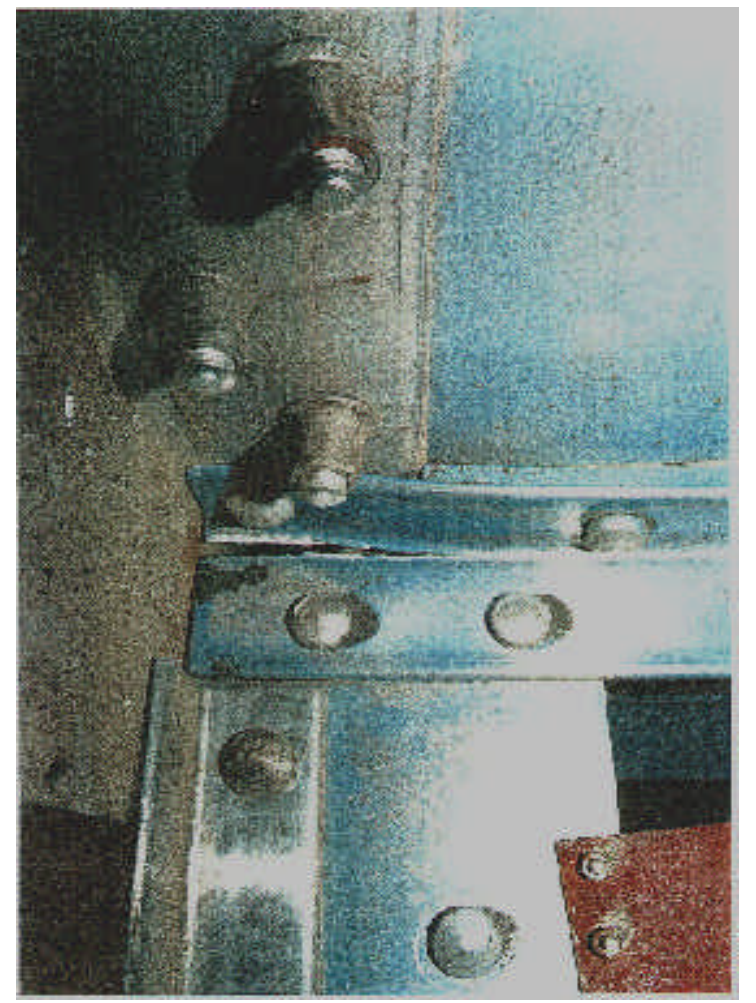

Figure 3.1 Damaged Bracing on AVLB from Static Tests (Henry et al., 1996)

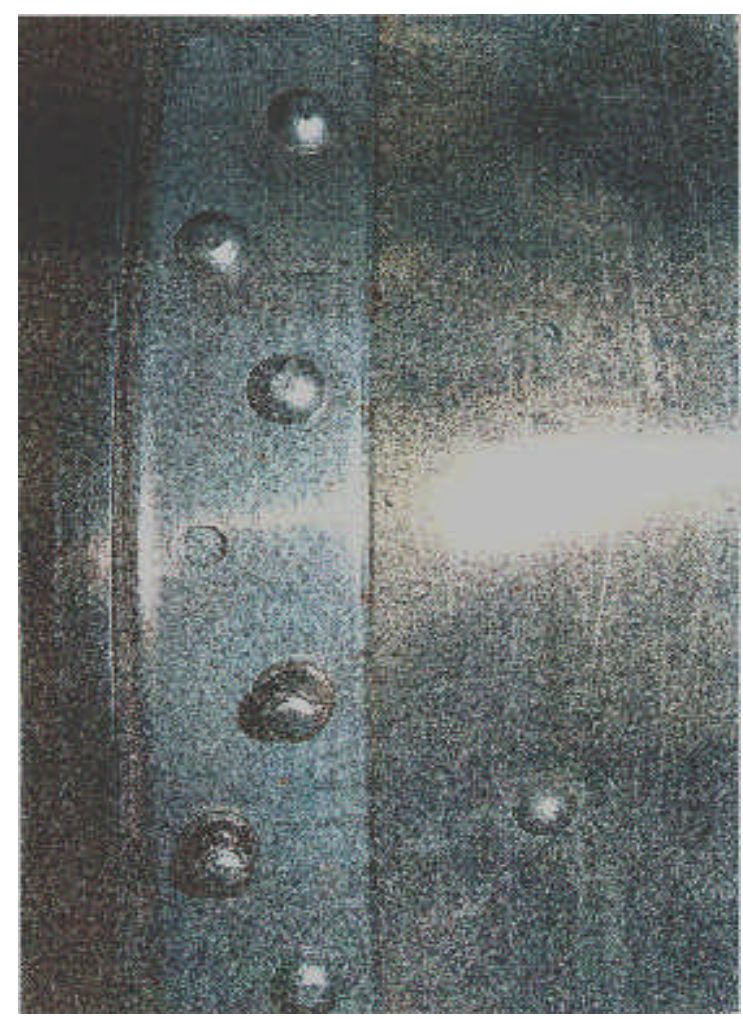

Figure 3.2 Damaged Rivet on AVLB from Static Tests (Henry et al., 1996) 
Table 3.2 Classification of Components into Primary and Secondary Elements

\begin{tabular}{|c|c|c|c|}
\hline $\begin{array}{l}\text { PMCS } \\
\text { item } \\
\text { number }\end{array}$ & Component name & Primary & Secondary \\
\hline $2 \mathrm{a}$ & Deck extrusions & & $\mathrm{X}$ \\
\hline $4 a$ & $\begin{array}{l}\text { Pin rivets, hot-rivets of all parts other than at hinge, connector areas, } \\
\text { spliced areas, at bottom chord and at cross bracing }\end{array}$ & & $\mathrm{X}$ \\
\hline $4 \mathrm{~b}$ & $\begin{array}{l}\text { pin rivets, hot-rivets at hinge, connector areas, spliced areas, at bottom } \\
\text { chord and at cross bracing }\end{array}$ & $\mathrm{X}$ & \\
\hline 5 & $\begin{array}{l}\text { Attaching hardware, i.e. Nuts/Bolts/Washers used to secure the braces. } \\
\text { That hold the treadways and hydraulic components together }\end{array}$ & & $\mathrm{X}$ \\
\hline 6 & Top center connector pins (AVLB 60 and 70) & & $\mathrm{X}$ \\
\hline $7 \mathrm{a}$ & Top connector pins (end to center panels) (AVLB 60) & & $\mathrm{X}$ \\
\hline $7 b$ & Bottom connector pins (end to center panels) & $\mathrm{X}$ & \\
\hline $8 \mathrm{a}$ & Center hinge & $\mathrm{X}$ & \\
\hline $8 b$ & Center hinge pin and retainer clip & $\mathrm{X}$ & \\
\hline $9 \mathrm{a}$ & Main aluminum angles along top chords & $\mathrm{X}$ & \\
\hline $9 b$ & Main aluminum angles along bottom chords & $\mathrm{X}$ & \\
\hline 10 & $\begin{array}{l}\text { Connector area along the bottom chord (connectors for AVLB } \\
60 \text { and splice bars and spacers for AVLB-70) }\end{array}$ & $\mathrm{X}$ & \\
\hline 11 & Press fit pins along the top chord (AVLB 70) & $\mathrm{X}$ & \\
\hline 12 & Splice doubler angles in bottom chord & $\mathrm{X}$ & \\
\hline 13 & splice plate along bottom of each girder & $\mathrm{X}$ & \\
\hline 14 & main aluminum angle extensions & $\mathrm{X}$ & \\
\hline 15 & cross bracing under the treadways of center/end panels/ of sections & & $\mathrm{X}$ \\
\hline 24 & Lateral cross braces & & $\mathrm{X}$ \\
\hline 25 & Transverse braces between center and end panels, or between sections & & $\mathrm{X}$ \\
\hline 26 & web girder plate & $\mathrm{X}$ & \\
\hline
\end{tabular}


The damage states of a component as mentioned in the manual, are not quantitative, and are typically employed by words such as: loose, broken, cracking or damage. These languages are objective and do not provide a clear instruction for identifying potential danger. A more descriptive language, which includes description of damage mechanism, is needed for the decision support system. Since no physical data are available that correlates visually observed crack size with the fracture criticality of these cracks, the damage states will be identified in the visual inspection module of the DSS, as either complete damage or partial damage. A through crack on a critical component would be considered as a complete damage, whereas a stable single crack or many cracks of less than an inch on a large component would be considered a partial damage. A partial damage, however, is not an indication of less danger. For instance, in the case of a component such as a rivet that is corroded, it may fall out without being completely corroded, rusted or reduced to zero diameter. Even though the damage description used in the DSS is more concise, but it should not be regarded as a replacement of damage states described in the PMCS manual. Caution should be practiced in identifying critical damages.

\subsubsection{Damage Scenarios}

Since different bridge components are designed to resist different kinds of loading conditions, different damage conditions need to be considered for typical bridge components. Modified from the Bridge Inspectors' manual (AASHTO, 1990), the following conditions have been identified for the AVLB components and has been used to formulate the damage scenarios listed in Table 3.3. 
1. Primary girder - shear zone, flexural zone, crippling due to overload, buckling fracture, battle damage, fatigue crack, bent, buckling.

2. Secondary member - fracture cracking, loose fasteners, battle damage, fatigue crack, bent.

3. Tension members - corrosion and cracks, local buckling, misalignment, wrinkles or waves in flanges, webs.

4. Girder plates, gusset plates - loose rivets, bent, crack, fatigue crack.

5. Pin or rivet connectors - fracture critical, lose in sections.

For an AVLB, typical damage mechanisms may include, battle damages, fatigue cracking, large deformation (plastic deformation), plastic cracking (large stress cycles), missing components, environmental damage (corrosions) and separation of components. The likely damage modes of the primary and secondary components are identified and listed in Tables 3.3 and 3.4 . 
Table 3.3 Likely Damage Modes of Primary Components (Complete to Partial)

\begin{tabular}{|c|c|c|}
\hline $\begin{array}{l}\text { Item } \\
\text { no. }\end{array}$ & Component name & Damage Scenarios \\
\hline $4 \mathrm{~b}$ & $\begin{array}{l}\text { Pin rivets, hot-rivets at hinge, } \\
\text { connector areas, spliced areas, at } \\
\text { bottom chord and at cross bracing }\end{array}$ & $\begin{array}{l}\text { 1. Completely or significant amount missing } \\
\text { 2. Completely/ significant amount completely sheared } \\
\text { 3. Completely or significant amount corroded or wear (loss } \\
\text { of sectional area) } \\
\text { 4. Partially missing } \\
\text { 5. Partially sheared } \\
\text { 6. Partially corroded }\end{array}$ \\
\hline $7 \mathrm{a}$ & $\begin{array}{l}\text { Top connector pins (end to center } \\
\text { panels) (AVLB 60) }\end{array}$ & $\begin{array}{l}\text { 1. Missing } \\
\text { 2. Completely sheared off } \\
\text { 3. Significantly corroded or wear (loss of sectional area) } \\
\text { 4. Bent } \\
\text { 5. Cracked } \\
\text { 6. Partially sheared } \\
\text { 7. Some corrosion }\end{array}$ \\
\hline $7 \mathrm{~b}$ & $\begin{array}{l}\text { Bottom connector pins (end to center } \\
\text { panels) }\end{array}$ & $\begin{array}{l}\text { 1. Missing } \\
\text { 2. Completely sheared off } \\
\text { 3. Corrosion or wear (loss of sectional area) } \\
\text { 4. Bent } \\
\text { 5. Cracked } \\
\text { 6. Partially sheared } \\
\text { 7. Some corrosion }\end{array}$ \\
\hline $8 \mathrm{a}$ & Center hinge & $\begin{array}{l}\text { 1. Complete cracked through } \\
\text { 2. Pin holes experience enlargement due to corrosion or wear } \\
\text { 2. Partial cracking } \\
\text { 3. Multiple cracks } \\
\text { 4. Bent or deformed }\end{array}$ \\
\hline $8 b$ & Center hinge pin and retainer clip & $\begin{array}{l}\text { 1. Missing } \\
\text { 2. Completely sheared-off } \\
\text { 3. Significant corrosion or wear (loss of sectional area) } \\
\text { 4. Bent } \\
\text { 5. Cracked } \\
\text { 6. Partially sheared } \\
\text { 7. Complete corrosion }\end{array}$ \\
\hline $9 \mathrm{a}$ & $\begin{array}{l}\text { Main aluminum angles along top } \\
\text { chords }\end{array}$ & $\begin{array}{l}\text { 1. Completely cracked through } \\
\text { 2. Partial cracking } \\
\text { 3. Multiple cracks } \\
\text { 4. Deformed }\end{array}$ \\
\hline $9 b$ & $\begin{array}{l}\text { Main aluminum angles along bottom } \\
\text { chords }\end{array}$ & 1. Completely cracked through \\
\hline
\end{tabular}




\begin{tabular}{|c|c|c|}
\hline & & $\begin{array}{l}\text { 2. Sheared } \\
\text { 3. Partial cracking } \\
\text { 4. Multiple cracks } \\
\text { 5. Deformed }\end{array}$ \\
\hline 10 & $\begin{array}{l}\text { Connector area along the bottom } \\
\text { chord (connectors for AVLB } 60 \text { and } \\
\text { splice bars and spacers for AVLB- } \\
70 \text { ) }\end{array}$ & $\begin{array}{l}\text { 1. Complete cracked through } \\
\text { 2. Pin holes experience enlargement due to corrosion or wear } \\
\text { 2. Partial cracking } \\
\text { 3. Multiple cracks } \\
\text { 4. Bent or deformed }\end{array}$ \\
\hline 11 & $\begin{array}{l}\text { Press fit pins along the top chord } \\
\text { (AVLB 70) }\end{array}$ & $\begin{array}{l}\text { 1. Missing } \\
\text { 2. Completely sheared-off } \\
\text { 3. Significant corrosion and wear (sectional area loss) } \\
\text { 4. Bent } \\
\text { 5. Cracked } \\
\text { 6. Partially sheared } \\
\text { 7. Somewhat corroded } \\
\text { 8. Somewhat bent }\end{array}$ \\
\hline 12 & $\begin{array}{l}\text { Splice doubler angles in bottom } \\
\text { chord }\end{array}$ & $\begin{array}{l}\text { 1. Completely cracked through } \\
\text { 2. Sheared } \\
\text { 3. Partial cracking } \\
\text { 4. Multiple cracks } \\
\text { 5. Deformed }\end{array}$ \\
\hline 13 & $\begin{array}{l}\text { Splice plate along bottom of each } \\
\text { girder }\end{array}$ & $\begin{array}{l}\text { 1. Completely cracked through } \\
\text { 2. Sheared } \\
\text { 3. Partial cracking } \\
\text { 4. multiple cracks } \\
\text { 5. Bent or deformed }\end{array}$ \\
\hline 14 & Main aluminum angle extensions & $\begin{array}{l}\text { 1. Completely cracked through } \\
\text { 2. Sheared } \\
\text { 3. Partial cracking } \\
\text { 4. Bent } \\
\text { 5. Multiple cracks }\end{array}$ \\
\hline 26 & Web girder plate & $\begin{array}{l}\text { 1. Completely cracked through } \\
\text { 2. Sheared } \\
\text { 3. Partial cracking } \\
\text { 4. Multiple cracks } \\
\text { 5. Bent, twisted or deformed }\end{array}$ \\
\hline
\end{tabular}

Table 3.3 (continued) 
Table 3.4 Likely Damage Mode of Secondary Components (Complete to Partial)

\begin{tabular}{|c|c|c|}
\hline Item No. & Component name & Damage Scenarios \\
\hline $2 a$ & Deck extrusions & $\begin{array}{l}\text { 1. Completely cracked through } \\
\text { 2. Partial cracking } \\
\text { 3. Multiple cracks } \\
\text { 4. Bent, twisted or deformed }\end{array}$ \\
\hline $4 a$ & $\begin{array}{l}\text { Pin rivets, hot-rivets of } \\
\text { all parts other than at } \\
\text { hinge, connector areas, } \\
\text { spliced areas, at bottom } \\
\text { chord and at cross } \\
\text { bracing }\end{array}$ & $\begin{array}{l}\text { 1. Completely or significant amount missing } \\
\text { 2. Completely or significant amount completely sheared } \\
\text { 3. Completely or significant amount Corroded or wear (loss of } \\
\text { sectional area) } \\
\text { 4. Partially missing (more than a quarter missing) } \\
\text { 5. Partially sheared } \\
\text { 6. Partially corroded }\end{array}$ \\
\hline 5 & $\begin{array}{l}\text { Attaching hardware, i.e. } \\
\text { Nuts/Bolts/Washers } \\
\text { used to secure the } \\
\text { braces. }\end{array}$ & $\begin{array}{l}\text { 1. Missing } \\
\text { 2. Completely sheared } \\
\text { 3. Significant corrosion and wear (loss of sectional area) } \\
\text { 4. Partially damaged of any type }\end{array}$ \\
\hline 6 & $\begin{array}{l}\text { Top center connector } \\
\text { pins (AVLB } 60 \text { and 70) }\end{array}$ & $\begin{array}{l}\text { 1. Missing } \\
\text { 2. Completely sheared } \\
\text { 3. Corrosion and wear (loss of sectional area) } \\
\text { 4. Bent } \\
\text { 5. Cracked } \\
\text { 6. Partially sheared } \\
\text { 7. Some corrosion } \\
\text { 8. Somewhat bent }\end{array}$ \\
\hline 15 & $\begin{array}{l}\text { Cross bracing under the } \\
\text { treadways of center/end } \\
\text { panels/ of sections }\end{array}$ & $\begin{array}{l}\text { 1. Completely cracked through } \\
\text { 2. Shear failure } \\
\text { 3. Partial crack } \\
\text { 4. Multiple cracks } \\
\text { 5. Bent or deformed }\end{array}$ \\
\hline 24 & Lateral cross braces & $\begin{array}{l}\text { 1. Completely cracked through } \\
\text { 2. Shear failure } \\
\text { 3. Partial crack } \\
\text { 4. Multiple cracks } \\
\text { 5. Bent or deformed }\end{array}$ \\
\hline 25 & $\begin{array}{l}\text { Transverse braces } \\
\text { between center and end } \\
\text { panels, or between } \\
\text { sections }\end{array}$ & $\begin{array}{l}\text { 1. Completely cracked through } \\
\text { 2. Shear failure } \\
\text { 3. Partial crack } \\
\text { 4. Multiple cracks } \\
\text { 5. Bent or deformed }\end{array}$ \\
\hline
\end{tabular}




\subsubsection{Hierarchy Criteria for Determining Criticality of Components}

Based on the different damage scenarios (Tables 3.3 and 3.4), it is possible to establish a hierarchy among the damage states of each component. Hierarchy in defining criticality of components is set such that structural criticality always precedes functional criticality. For instance, a deck extrusion failure will cause immediate deadline of bridge, however it would have any significant influence on the overall strength of the structure. Based on Worst Scenario Approach, the following criteria are set to establish the hierachy for determining the criticality of components:

A: If a component failed, will cause immediate collapse of structure (i.e. web girder plate cracked through or had very large cracks $(1 / 2$ of the depth of girder), center hinge sheared through, center hinge pin missing or sheared through).

B: If a component failure leads to other component failures, which may cause immediate collapse of structure (i.e. significant amount of hinge rivets missing).

C: If component failure leads to immediate dysfunction of structure, but not structural failure (i.e. bridge deck damaged will not weaken structure, but will not allow tank crossing).

D: If component failure leads to other components to fail, but will not lead to immediate collapse of structure (i.e. splice doubler angles failed will induce damage at the splice plates and the girder plate).

E: If a component failure does not have significant impact on structure and can be replaced much later. 
The visual inspection procedure is established first by generating the component criticality list (Table 3.5), and then combined it with a top-down scenario for each component. This results in a single-way, top-down inspection procedure (Table 3.6).

Table 3.5 Prioritization of Structural Elements

\begin{tabular}{|l|l|l|}
\hline Item no & Component name & Priority \\
\hline $2 \mathrm{a}$ & Deck extrusions & 17 \\
\hline $4 \mathrm{a}$ & $\begin{array}{l}\text { Pin rivets, hot-rivets of all parts other than at hinge, connector areas, spliced areas, } \\
\text { at bottom chord and at cross bracing }\end{array}$ & 20 \\
\hline $4 \mathrm{~b}$ & $\begin{array}{l}\text { Pin rivets, hot-rivets at hinge, connector areas, spliced areas, at bottom chord and } \\
\text { at cross bracing }\end{array}$ & 10 \\
\hline 5 & $\begin{array}{l}\text { Attaching hardware, i.e. Nuts/Bolts/Washers used to secure the braces. That hold } \\
\text { the treadways and hydraulic components together }\end{array}$ & 18 \\
\hline 6 & Top center connector pins & 19 \\
\hline $7 \mathrm{a}$ & Top connector pins (end to center panels) & 13 \\
\hline $7 \mathrm{~b}$ & Bottom connector pins (end to center panels) & 8 \\
\hline $8 \mathrm{a}$ & Center Hinge & 1 \\
\hline $8 \mathrm{~b}$ & Center hinge pin and retainer clip & 2 \\
\hline $9 \mathrm{a}$ & Main aluminum angles along bottom chords & 9 \\
\hline $9 \mathrm{~b}$ & Main aluminum angles along top chords & 11 \\
\hline 10 & $\begin{array}{l}\text { Connector area along the bottom chord (connectors for AVLB 60 and splice bars } \\
\text { and spacers for AVLB-70) }\end{array}$ & 3 \\
\hline 11 & Press fit pins along the top chord & 12 \\
\hline 12 & Splice doubler angles in bottom chord & 5 \\
\hline 13 & Splice plate along bottom of each girder & 6 \\
\hline 14 & Main aluminum angle extensions & 7 \\
\hline 15 & Cross bracing under the treadways of center/end panels/ of sections & 14 \\
\hline 24 & Lateral cross braces & 16 \\
\hline 25 & Transverse braces between center and end panels, or between sections & 15 \\
\hline 26 & Web girder plate & 4 \\
\hline
\end{tabular}




\subsubsection{Visual Inspection Procedure Development}

Table 3.6 summarizes the final visual inspection procedure, which is adopted and integrated into the expert KBS system. One of the key functions of the inspection is to identify potential hazards, and to establish a criticality rating for the bridge. Table 3.6 shows the steps in bridge evaluation, including damage states for visual observation, and the possible consequences of observed damage, recommended actions, and the bridge rating based on the damaged state. The bridge rating system is based on levels A-E, which was identified in Section 3.3.3 
Table 3.6 Final Visual Inspection Procedure

\begin{tabular}{|c|c|c|c|c|c|c|}
\hline & $\begin{array}{l}\text { Item } \\
\text { No. }\end{array}$ & Component & Damage & Possible danger & Action & $\begin{array}{l}\text { Damage } \\
\text { level }\end{array}$ \\
\hline 1 & & Whole bridge & $\begin{array}{l}\text { Significant sagging } \\
\text { (>1ft), deformation, } \\
\text { twisted }\end{array}$ & $\begin{array}{l}\text { Total collapse of } \\
\text { bridge }\end{array}$ & $\begin{array}{l}\text { Stop analysis, } \\
\text { bridge may } \\
\text { fail }\end{array}$ & A \\
\hline 2 & & Whole bridge & $\begin{array}{l}\text { Deck completely } \\
\text { gone, } 60 \% \text { of bridge } \\
\text { visible surface are } \\
\text { gone (bombed) }\end{array}$ & $\begin{array}{l}\text { Total collapse of } \\
\text { bridge }\end{array}$ & $\begin{array}{l}\text { Stop analysis, } \\
\text { bridge may } \\
\text { fail }\end{array}$ & A \\
\hline 3 & $8 \mathrm{a}$ & Center hinge area & $\begin{array}{l}\text { Significantly large } \\
\text { cracking or cracked } \\
\text { through }\end{array}$ & $\begin{array}{l}\text { Total collapse of } \\
\text { bridge }\end{array}$ & $\begin{array}{l}\text { Stop analysis, } \\
\text { bridge may } \\
\text { fail }\end{array}$ & $\mathrm{A}$ \\
\hline 4 & $8 b$ & $\begin{array}{l}\text { Center hinge pin } \\
\text { and retainer clip }\end{array}$ & $\begin{array}{l}\text { Missing, sheared or } \\
\text { crack through }\end{array}$ & $\begin{array}{l}\text { Total collapse of } \\
\text { bridge }\end{array}$ & $\begin{array}{l}\text { Stop analysis, } \\
\text { bridge may } \\
\text { fail }\end{array}$ & $\mathrm{A}$ \\
\hline 5 & 10 & $\begin{array}{l}\text { Connector area } \\
\text { (bottom) }\end{array}$ & $\begin{array}{l}\text { Significantly large } \\
\text { cracking or cracked } \\
\text { through }\end{array}$ & $\begin{array}{l}\text { Total collapse of } \\
\text { bridge }\end{array}$ & $\begin{array}{l}\text { Stop analysis, } \\
\text { bridge may } \\
\text { fail }\end{array}$ & A \\
\hline 6 & 26 & Web girder plate & Buckled & $\begin{array}{l}\text { Unpredictable } \\
\text { strength and will } \\
\text { lead to total } \\
\text { collapse of } \\
\text { bridge }\end{array}$ & $\begin{array}{l}\text { Stop analysis, } \\
\text { bridge may } \\
\text { fail }\end{array}$ & A \\
\hline 7 & 26 & Web girder plate & $\begin{array}{l}\text { Significantly large } \\
\text { cracking (over } 60 \% \text { ) } \\
\text { or cracked through }\end{array}$ & $\begin{array}{l}\text { Total collapse of } \\
\text { bridge }\end{array}$ & $\begin{array}{l}\text { Stop analysis, } \\
\text { bridge may } \\
\text { fail }\end{array}$ & A \\
\hline 8 & 12 & $\begin{array}{l}\text { Splice doubler } \\
\text { angles in bottom } \\
\text { chord }\end{array}$ & Through crack & $\begin{array}{l}\text { Separation of end } \\
\text { panel and center } \\
\text { panel }\end{array}$ & $\begin{array}{l}\text { Continue } \\
\text { analysis, } \\
\text { replace }\end{array}$ & A \\
\hline 9 & 13 & $\begin{array}{l}\text { Splice plate } \\
\text { along bottom of } \\
\text { each girder }\end{array}$ & Through crack & $\begin{array}{l}\text { Separation of end } \\
\text { panel and center } \\
\text { panel }\end{array}$ & $\begin{array}{l}\text { Continue } \\
\text { analysis, } \\
\text { replace }\end{array}$ & A \\
\hline 10 & 14 & $\begin{array}{l}\text { Main aluminum } \\
\text { angle extensions }\end{array}$ & $\begin{array}{l}\text { Through crack, } \\
\text { bending, more than } \\
50 \% \text { rivets fall out }\end{array}$ & $\begin{array}{l}\text { May lead to } \\
\text { girder cracking, } \\
\text { deforming }\end{array}$ & $\begin{array}{l}\text { Continue } \\
\text { analysis, } \\
\text { repair }\end{array}$ & A \\
\hline 11 & $7 \mathrm{~b}$ & $\begin{array}{l}\text { Bottom } \\
\text { connector pins } \\
\text { (end to center } \\
\text { panels) }\end{array}$ & $\begin{array}{l}\text { Through crack or } \\
\text { broken, missing }\end{array}$ & $\begin{array}{l}\text { Total collapse of } \\
\text { bridge }\end{array}$ & $\begin{array}{l}\text { Stop analysis, } \\
\text { replace }\end{array}$ & A \\
\hline 12 & $9 \mathrm{a}$ & $\begin{array}{l}\text { Main aluminum } \\
\text { angles along } \\
\text { bottom chords }\end{array}$ & $\begin{array}{l}\text { Through crack, } \\
\text { buckling or bending }\end{array}$ & $\begin{array}{l}\text { May lead to } \\
\text { girder cracking, } \\
\text { deformation, } \\
\text { instability }\end{array}$ & $\begin{array}{l}\text { Continue } \\
\text { analysis, } \\
\text { replace }\end{array}$ & B \\
\hline
\end{tabular}




\begin{tabular}{|c|c|c|c|c|c|c|}
\hline 13 & $4 \mathrm{~b}$ & $\begin{array}{l}\text { Pin rivets, hot- } \\
\text { rivets at hinge, } \\
\text { connector areas, } \\
\text { at bottom chord } \\
\text { and at cross } \\
\text { bracing }\end{array}$ & $\begin{array}{l}\text { More than } 50 \% \\
\text { cracked or missing }\end{array}$ & $\begin{array}{l}\text { May cause } \\
\text { bridge } \\
\text { disintegration }\end{array}$ & $\begin{array}{l}\text { Continue } \\
\text { analysis, } \\
\text { replace }\end{array}$ & B \\
\hline 14 & $9 b$ & $\begin{array}{l}\text { Main aluminum } \\
\text { angles along top } \\
\text { chord }\end{array}$ & $\begin{array}{l}\text { Through crack, } \\
\text { bending, large } \\
\text { deformation }\end{array}$ & $\begin{array}{l}\text { May weaken } \\
\text { girders }\end{array}$ & $\begin{array}{l}\text { Continue } \\
\text { analysis, } \\
\text { replace }\end{array}$ & B \\
\hline 15 & 11 & $\begin{array}{l}\text { Press fit pins } \\
\text { along the top } \\
\text { chord }\end{array}$ & $\begin{array}{l}\text { Large crack, large } \\
\text { amount missing }\end{array}$ & May loosen deck & $\begin{array}{l}\text { Continue } \\
\text { analysis, } \\
\text { replace }\end{array}$ & $\mathrm{C}$ \\
\hline 16 & $7 \mathrm{a}$ & $\begin{array}{l}\text { Top connector } \\
\text { pins (end to } \\
\text { center panels) }\end{array}$ & $\begin{array}{l}\text { Through crack, } \\
\text { missing }\end{array}$ & $\begin{array}{l}\text { No imminent } \\
\text { danger }\end{array}$ & $\begin{array}{l}\text { Continue } \\
\text { analysis, } \\
\text { replace }\end{array}$ & $\mathrm{C}$ \\
\hline 17 & 15 & $\begin{array}{l}\text { Cross bracing } \\
\text { under the } \\
\text { treadways of } \\
\text { center/end } \\
\text { panels/sections }\end{array}$ & $\begin{array}{l}\text { Through crack or } \\
\text { buckling }\end{array}$ & $\begin{array}{l}\text { May lead to } \\
\text { bending of girder } \\
\text { web }\end{array}$ & $\begin{array}{l}\text { Continue } \\
\text { analysis, } \\
\text { replace }\end{array}$ & $\mathrm{C}$ \\
\hline 18 & 25 & $\begin{array}{l}\text { Transverse } \\
\text { Braces between } \\
\text { center and end } \\
\text { panels, or } \\
\text { between sections }\end{array}$ & $\begin{array}{l}\text { Through crack or } \\
\text { buckling, bending }\end{array}$ & $\begin{array}{l}\text { May lead to } \\
\text { connector failure }\end{array}$ & $\begin{array}{l}\text { Continue } \\
\text { analysis, } \\
\text { replace }\end{array}$ & $\mathrm{C}$ \\
\hline 19 & 24 & $\begin{array}{l}\text { Lateral cross } \\
\text { braces }\end{array}$ & $\begin{array}{l}\text { Through crack, } \\
\text { buckling or bending }\end{array}$ & $\begin{array}{l}\text { Change distance } \\
\text { between the two } \\
\text { treadways }\end{array}$ & $\begin{array}{l}\text { Continue } \\
\text { analysis, } \\
\text { replace }\end{array}$ & $\mathrm{C}$ \\
\hline 20 & 42 & Deck plating & $\begin{array}{l}\text { Bend, separated } \\
\text { from the girder }\end{array}$ & $\begin{array}{l}\text { May cause } \\
\text { immediate } \\
\text { dysfunction }\end{array}$ & $\begin{array}{l}\text { Continue } \\
\text { analysis, } \\
\text { replace }\end{array}$ & $\mathrm{C}$ \\
\hline 21 & 5 & $\begin{array}{l}\text { Attaching } \\
\text { hardware, } \\
\text { Nuts/Bolts/ } \\
\text { Washers to } \\
\text { secure the braces. } \\
\text { That hold the } \\
\text { treadways and } \\
\text { hydraulic } \\
\text { components } \\
\text { together }\end{array}$ & $\begin{array}{l}\text { Missing parts, } \\
\text { severely damaged } \\
\text { parts }\end{array}$ & $\begin{array}{l}\text { May change } \\
\text { distance between } \\
\text { the two } \\
\text { treadways }\end{array}$ & $\begin{array}{l}\text { Continue } \\
\text { analysis, } \\
\text { replace }\end{array}$ & $\mathrm{D}$ \\
\hline 22 & 6 & $\begin{array}{l}\text { Top center } \\
\text { connector pins }\end{array}$ & $\begin{array}{l}\text { Through crack, } \\
\text { missing }\end{array}$ & $\begin{array}{l}\text { No imminent } \\
\text { danger }\end{array}$ & $\begin{array}{l}\text { Continue } \\
\text { analysis, } \\
\text { replace }\end{array}$ & $\mathrm{E}$ \\
\hline 23 & 8 & $\begin{array}{l}\text { Center hinge area } \\
\text { at the bottom } \\
\text { chord }\end{array}$ & Fatigue cracks, dent, & $\begin{array}{l}\text { No imminent } \\
\text { danger }\end{array}$ & $\begin{array}{l}\text { Continue } \\
\text { analysis, } \\
\text { bridge failed }\end{array}$ & $\mathrm{E}$ \\
\hline
\end{tabular}




\begin{tabular}{|c|c|c|c|c|c|c|}
\hline 24 & 10 & $\begin{array}{l}\text { Connector area } \\
\text { (bottom) }\end{array}$ & $\begin{array}{l}\text { Significantly large } \\
\text { cracking or cracked } \\
\text { through }\end{array}$ & $\begin{array}{l}\text { Total collapse of } \\
\text { bridge }\end{array}$ & $\begin{array}{l}\text { Stop analysis, } \\
\text { bridge failed }\end{array}$ & A \\
\hline 25 & 26 & Girder web plate & Buckled & $\begin{array}{l}\text { Unpredictable } \\
\text { strength and will } \\
\text { lead to total } \\
\text { collapse of } \\
\text { bridge }\end{array}$ & $\begin{array}{l}\text { Stop analysis, } \\
\text { bridge failed }\end{array}$ & A \\
\hline 26 & 26 & Girder web plate & $\begin{array}{l}\text { Significantly large } \\
\text { cracking or cracked } \\
\text { through }\end{array}$ & $\begin{array}{l}\text { Total collapse of } \\
\text { bridge }\end{array}$ & $\begin{array}{l}\text { Stop analysis, } \\
\text { bridge failed }\end{array}$ & A \\
\hline 27 & $7 b$ & $\begin{array}{l}\text { Bottom } \\
\text { connector pins } \\
\text { (end to center } \\
\text { panels) }\end{array}$ & $\begin{array}{l}\text { Through crack or } \\
\text { broken }\end{array}$ & $\begin{array}{l}\text { Total collapse of } \\
\text { bridge }\end{array}$ & $\begin{array}{l}\text { Stop analysis, } \\
\text { replace }\end{array}$ & A \\
\hline 28 & 12 & $\begin{array}{l}\text { Splice doubler } \\
\text { angles in bottom } \\
\text { chord }\end{array}$ & Through crack & $\begin{array}{l}\text { Separation of end } \\
\text { panel and center } \\
\text { panel }\end{array}$ & $\begin{array}{l}\text { Continue } \\
\text { analysis, } \\
\text { replace }\end{array}$ & B \\
\hline 29 & 13 & $\begin{array}{l}\text { Splice plate } \\
\text { along bottom of } \\
\text { each girder }\end{array}$ & Through crack & $\begin{array}{l}\text { Separation of end } \\
\text { panel and center } \\
\text { panel }\end{array}$ & $\begin{array}{l}\text { Continue } \\
\text { analysis, } \\
\text { replace }\end{array}$ & B \\
\hline 30 & 15 & $\begin{array}{l}\text { Cross bracing } \\
\text { under the } \\
\text { treadways of } \\
\text { center/end } \\
\text { panels/sections }\end{array}$ & $\begin{array}{l}\text { Through crack or } \\
\text { buckling }\end{array}$ & $\begin{array}{l}\text { May lead to } \\
\text { bending of girder } \\
\text { web }\end{array}$ & $\begin{array}{l}\text { Continue } \\
\text { analysis, } \\
\text { replace }\end{array}$ & B \\
\hline 31 & 25 & $\begin{array}{l}\text { Transverse } \\
\text { Braces between } \\
\text { center and end } \\
\text { panels, or } \\
\text { between sections }\end{array}$ & $\begin{array}{l}\text { Through crack or } \\
\text { buckling, bending }\end{array}$ & $\begin{array}{l}\text { May lead to } \\
\text { connector failure }\end{array}$ & $\begin{array}{l}\text { Continue } \\
\text { analysis, } \\
\text { replace }\end{array}$ & B \\
\hline 32 & 14 & $\begin{array}{l}\text { Main aluminum } \\
\text { angle extensions }\end{array}$ & $\begin{array}{l}\text { Through crack, } \\
\text { bending, more than } \\
50 \% \text { rivets fall out }\end{array}$ & $\begin{array}{l}\text { May lead to } \\
\text { girder cracking, } \\
\text { deforming }\end{array}$ & $\begin{array}{l}\text { Continue } \\
\text { analysis, } \\
\text { repair }\end{array}$ & $\mathrm{C}$ \\
\hline 33 & 24 & $\begin{array}{l}\text { Lateral cross } \\
\text { braces }\end{array}$ & $\begin{array}{l}\text { Through crack, } \\
\text { buckling or bending }\end{array}$ & $\begin{array}{l}\text { Change distance } \\
\text { between the two } \\
\text { treadways }\end{array}$ & $\begin{array}{l}\text { Continue } \\
\text { analysis, } \\
\text { replace }\end{array}$ & $\mathrm{C}$ \\
\hline 34 & $9 a$ & $\begin{array}{l}\text { Main aluminum } \\
\text { angles along } \\
\text { bottom chords }\end{array}$ & $\begin{array}{l}\text { Through crack, } \\
\text { buckling or bending }\end{array}$ & $\begin{array}{l}\text { May lead to } \\
\text { girder cracking, } \\
\text { deformation, } \\
\text { instability }\end{array}$ & $\begin{array}{l}\text { Continue } \\
\text { analysis, } \\
\text { replace }\end{array}$ & $\mathrm{C}$ \\
\hline 35 & 42 & Deck plating & $\begin{array}{l}\text { Bend, separated } \\
\text { from the girder }\end{array}$ & $\begin{array}{l}\text { May cause } \\
\text { immediate } \\
\text { dysfunction }\end{array}$ & $\begin{array}{l}\text { Continue } \\
\text { analysis, } \\
\text { replace }\end{array}$ & $\mathrm{C}$ \\
\hline 36 & $4 b$ & $\begin{array}{l}\text { Pin rivets, hot- } \\
\text { rivets at hinge, }\end{array}$ & $\begin{array}{l}\text { More than } 50 \% \\
\text { cracked or missing }\end{array}$ & $\begin{array}{l}\text { May cause } \\
\text { bridge }\end{array}$ & $\begin{array}{l}\text { Continue } \\
\text { analysis, }\end{array}$ & $\mathrm{C}$ \\
\hline
\end{tabular}




\begin{tabular}{|c|c|c|c|c|c|c|}
\hline & & $\begin{array}{l}\text { connector areas, } \\
\text { at bottom chord } \\
\text { and at cross } \\
\text { bracing }\end{array}$ & & disintegration & replace & \\
\hline 37 & 5 & $\begin{array}{l}\text { Attaching } \\
\text { hardware, i.e. } \\
\text { Nuts/Bolts/Wash } \\
\text { ers used to } \\
\text { secure the braces. } \\
\text { That hold the } \\
\text { treadways and } \\
\text { hydraulic } \\
\text { components } \\
\text { together }\end{array}$ & $\begin{array}{l}\text { Missing parts, } \\
\text { severely damaged } \\
\text { parts }\end{array}$ & $\begin{array}{l}\text { May change } \\
\text { distance between } \\
\text { the two } \\
\text { treadways }\end{array}$ & $\begin{array}{l}\text { Continue } \\
\text { analysis, } \\
\text { replace }\end{array}$ & $\mathrm{D}$ \\
\hline 38 & $9 b$ & $\begin{array}{l}\text { Main aluminum } \\
\text { angles along top } \\
\text { chord }\end{array}$ & $\begin{array}{l}\text { Through crack, } \\
\text { bending, large } \\
\text { deformation }\end{array}$ & $\begin{array}{l}\text { May loosen } \\
\text { curbing }\end{array}$ & $\begin{array}{l}\text { Continue } \\
\text { analysis, } \\
\text { replace }\end{array}$ & $\mathrm{D}$ \\
\hline 39 & 11 & $\begin{array}{l}\text { Press fit pins } \\
\text { along the top } \\
\text { chord }\end{array}$ & $\begin{array}{l}\text { Large crack, large } \\
\text { amount missing }\end{array}$ & May loosen deck & $\begin{array}{l}\text { Continue } \\
\text { analysis, } \\
\text { replace }\end{array}$ & D \\
\hline 40 & 6 & $\begin{array}{l}\text { Top center } \\
\text { connector pins }\end{array}$ & $\begin{array}{l}\text { Through crack, } \\
\text { missing }\end{array}$ & $\begin{array}{l}\text { No imminent } \\
\text { danger }\end{array}$ & $\begin{array}{l}\text { Continue } \\
\text { analysis, } \\
\text { replace }\end{array}$ & $\mathrm{E}$ \\
\hline 41 & 7 & $\begin{array}{l}\text { Top connector } \\
\text { pins (end to } \\
\text { center panels) }\end{array}$ & $\begin{array}{l}\text { Through crack, } \\
\text { missing }\end{array}$ & $\begin{array}{l}\text { No imminent } \\
\text { danger }\end{array}$ & $\begin{array}{l}\text { Continue } \\
\text { analysis, } \\
\text { replace }\end{array}$ & E \\
\hline 42 & 22 & $\begin{array}{l}\text { Quadrant and } \\
\text { quadrant struts }\end{array}$ & $\begin{array}{l}\text { Through crack, } \\
\text { missing }\end{array}$ & $\begin{array}{l}\text { No imminent } \\
\text { danger }\end{array}$ & $\begin{array}{l}\text { Continue } \\
\text { analysis, } \\
\text { replace }\end{array}$ & E \\
\hline
\end{tabular}




\subsection{Knowledge Acquisition for Vibration Inspection}

As mentioned in Section 3.2, the knowledge acquisition for the development of the expert system procedure for the vibration inspection is based on actual evaluation of the AVLB dynamic characteristics. Current vibration inspection approach, including some qualitative damage is based on a response-based technique, uses a strain energy-based damage detection algorithm (Venkatappa, 1997). This approach requires the physical extraction of modal parameters, i.e. modal frequency shift, change in strain energy before and after damage, Strain Energy Damage Index (SEDI) and Modal Assurance Criteria (MAC). These parameters have been experimentally proved to be good indicators of damage in a structure, from which \% strain energy is found to be more sensitive to damage than other parameters (Venkatappa, 1997). A systematic algorithm, including data acquisition, signal processing and computation of strain energy distribution, has been developed and automated for later system integration. The automated procedure was developed on the virtual instrumentation package LabVIEW (National Instruments). The algorithm consists of four modules, as shown in Figure 3.3 (Venkatappa, 1997):

1. Data acquisition

2. Signal processing and frequency domain transformation

3. Modal parameter extraction and refinement

4. Strain energy distribution. 


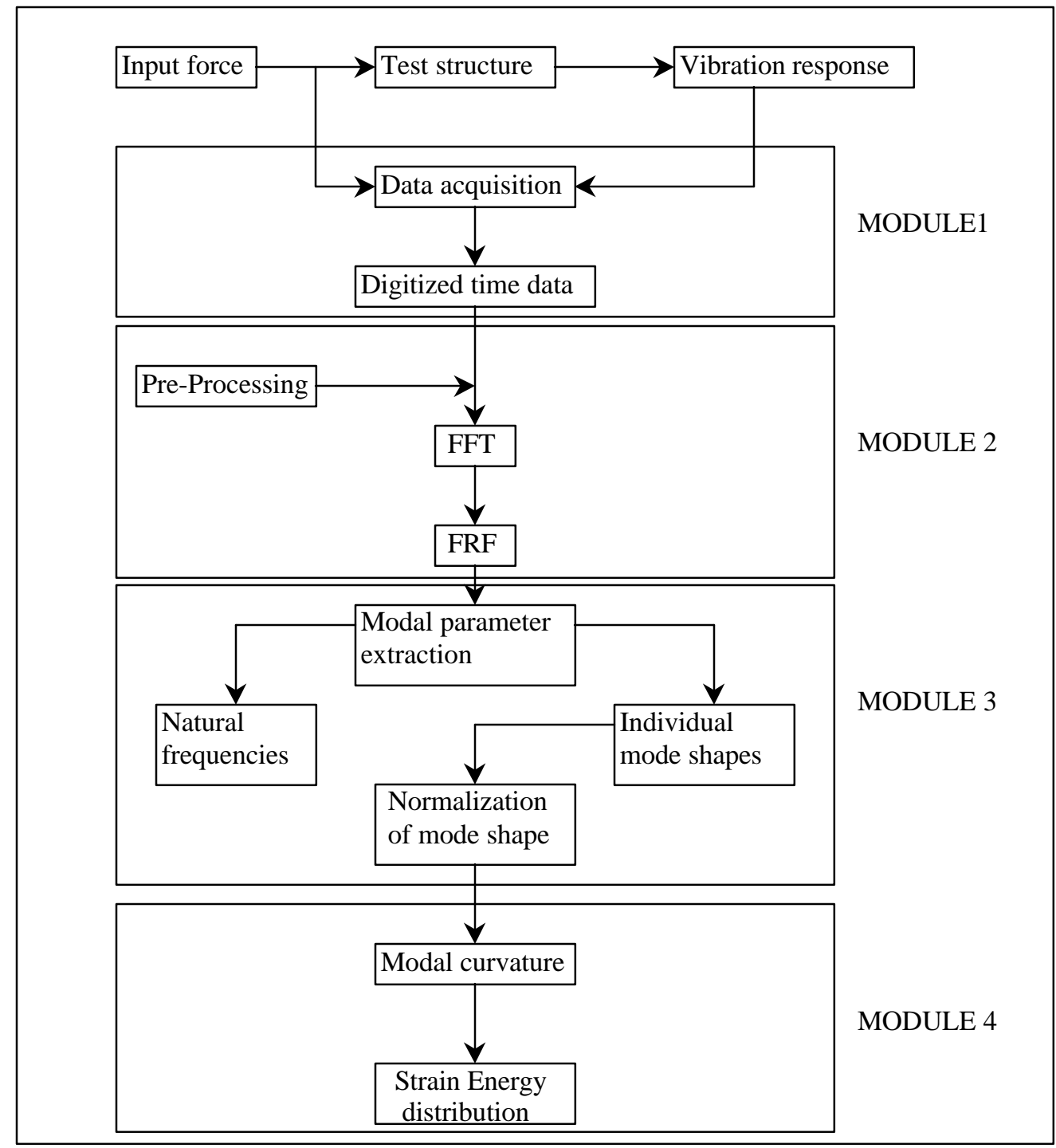

Figure 3.3 The Automated Damage Detection Algorithm (Venkatappa, 1997) 
To establish baseline values of the modal parameters for the AVLB, two full-scale modal tests have been conducted on the AVLB. The objectives of these tests are: 1) to understand the dynamic behavior of the AVLB; 2) to establish limits based on global dynamic characteristics, such as the natural vibration frequencies and the mode shapes; and 3) to determine viable inspection approach.

An impact test and a shaker test were conducted on the AVLB. Two different boundary conditions have also been studied. Details about the two tests can be found in Venkattapa (1997) and SDRC (1997). The natural frequencies of the first three bending modes are summarized in the following table:

Table 3.7 Comparison of Modal Frequencies (Hz) of the AVLB

\begin{tabular}{|c|c|c|c|c|}
\hline Mode & \multicolumn{2}{|c|}{ Free-Free } & \multicolumn{2}{c|}{ Simple Support } \\
& & FE & Exp. & FE \\
\hline & Exp. & & & \\
\hline 1 & 8.84 & 9.30 & 3.93 & 4.25 \\
\hline 2 & 19.00 & 22.20 & 12.86 & 14.79 \\
\hline 3 & 37.40 & 40.40 & 31.60 & 32.82 \\
\hline
\end{tabular}

Also included in Table 3.7, are the results from Finite Element Analysis (FE). The FE model is provided by the US Army. As is shown, the frequency values are very close between the experimental and analytical results. However, due to the selection of large element size for FE modeling, the model may not accurately represent realistic damage scenarios. In the present study, no parametric work has been done in generating damage data from the FE model. Based on the results of this study, several issues related to the over-all 
inspection methodology have been resolved. The following section describes the inspection methodology for the AVLB system.

\subsection{Inspection Methodology}

The decision support system developed is proposed to be a part of an overall automated AVLB inspection system. The AVLB inspection system is proposed to be a permanent installment at one or more US Army depots. The inspection system consists of an automated gantry, test setup, a laser vibration sensing system, a master console for system control, and a web-link expert system for bridge evaluation and database management. Figure 3.4 shows a schematic drawing of the proposed system concept. The depot setup will be in-door, hence, eliminate all possible environmental impact and potential interruptions of testing. An automated robotic gantry system will house the necessary testing setup including laser movement, four to eight shakers, and eight airbags for bridge support. The automated gantry system will be used to move a non-contact laser vibrometer to different locations of the bridge. This system is a state-of-the-art computer controlled system, which has a high precision positioning capability and with minimum sliding problem $(<1$ inch). The shakers will be placed underneath the bridge to provide pure bending vibration. Four shakers are used such that the bridge would behave as four independent or lightly coupled beams.

The laser vibrometer is a highly sensitive tool for non-contact vibration measurements. The laser vibrometer, based on the measurement of Doppler frequency shifts, can provide accurate measurement of vibration velocity along the line of sight (Drain, 1980.) In the current approach, a high-power, $\mathrm{CO}_{2}$ laser system from Litton Technology Co. will be implemented. The $\mathrm{CO}_{2}$ laser system has an aperture of 2 inches, which could average out 
errors due to surface ruggedness of the AVLB. The high power laser system can also guarantee adequate energy return for clean and accurate signals.

A master control program will be used to control and automate the vibration inspection procedure. The collected vibration data will be analyzed by the system to determine the different vibration parameters, which are then used for damage detection. The master control software consists of four modules: a shaker control module; a data acquisition module; a signal analysis module that will determine Frequency Response Function (FRF), which will be used to construct the mode shape; the vibration parameter abstractions module; and finally, a damage detection module. The results of damage detection are then transferred to the decision support system, developed in this thesis, for overall bridge evaluation and recommendation.

Figure 3.5 shows a system functional diagram. Two key component of the inspection system are data collection and data processing. The automated gantry system, the SLV, the shakers and the master control program constitute the data collection component of the system. Signal processing, damage detection and the expert system constitute the data processing component. The final goal of the inspection system is to determine with certainty, whether green light (go) or yellow light (caution) or red light (no-go) for tank crossings, should be issued. A system interface is provided to connect the master control program to the data processing component and the web-based decision support system.

The AVLB inspection procedure starts with visual inspection at the depot, which is proceeded with a full-field modal analysis with the suspended laser vibrometer. Sinusoidal excitation is first used to determine the bending vibration frequencies. A complete mode shape construction is then followed. Four vibration parameters are extracted from the 
vibration test results: \% Frequency Shift (FS), Mode Assurance Criteria (MAC), Strain Energy Modal Assurance Criteria (SEMAC) and \% Strain Energy Difference (SED) at damage location. The methodology treats the four girders of the bridge as lightly coupled members, which can be isolated by proper excitation. The vibration inspection is done in girder-by-girder and mode-by-mode manner. At least four bending modes will be used for damage identification and location. 


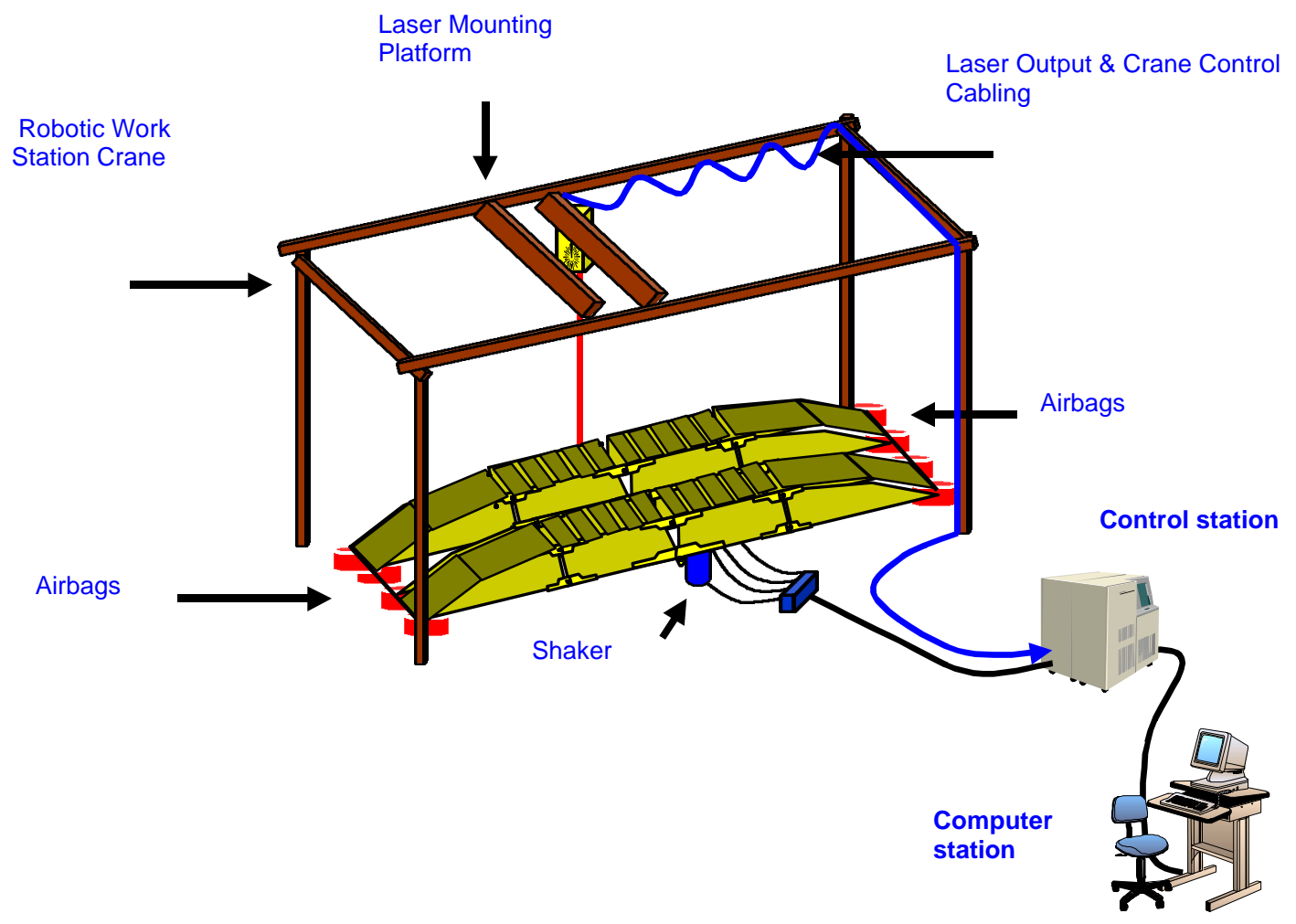

Figure 3.4 Schematic Drawing of the Inspection System Concept 


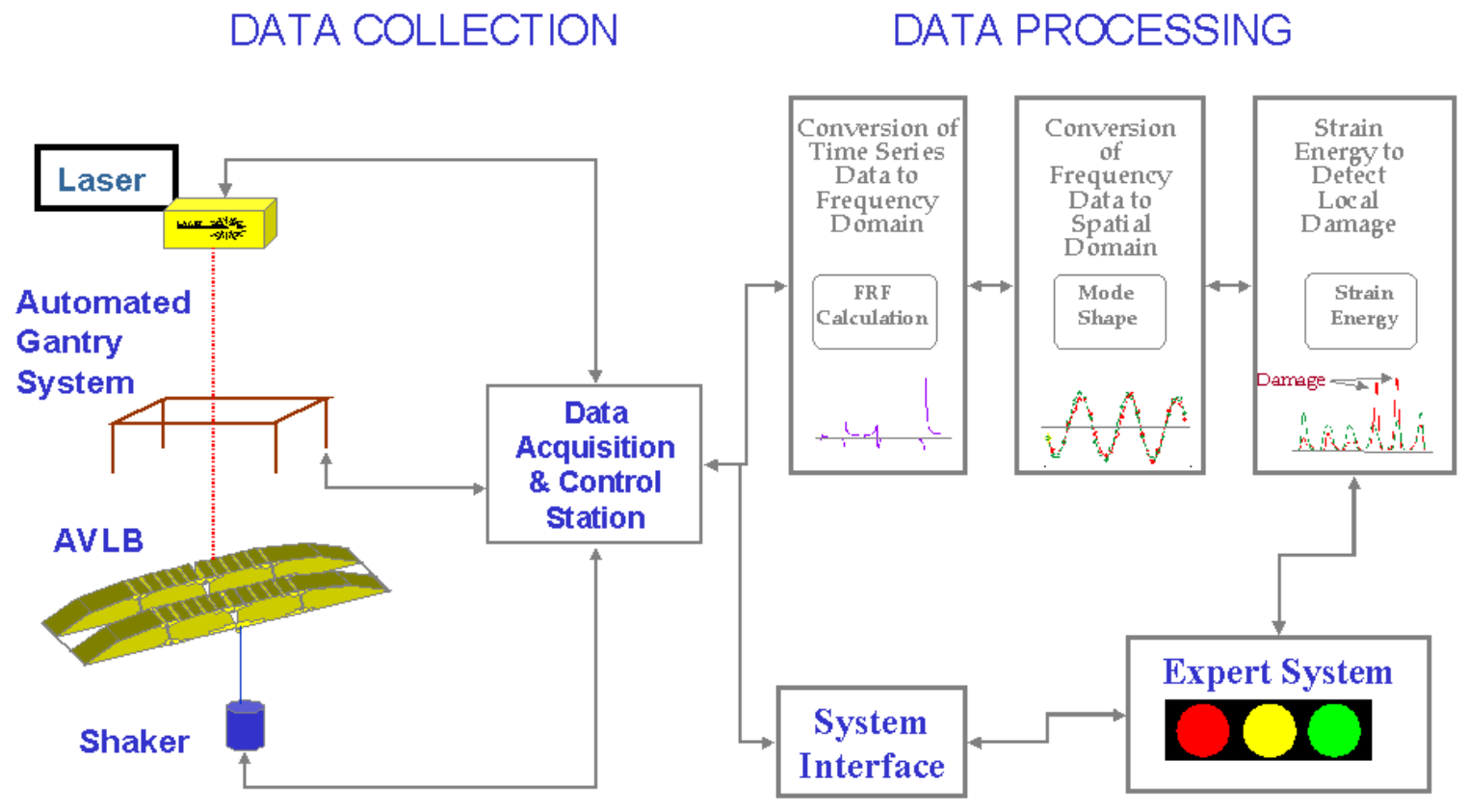

Figure 3.5 System Functional Diagram 


\section{CHAPTER 4}

\section{DECISION SUPPORT SYSTEM DEVELOPMENT}

\subsection{Introduction}

The AVLB Decision Support System (AVLB-DSS) was developed incorporating expert system concepts, database capabilities and online maintenance manual. The AVLBDSS is an Internet-based application running from a web server and has incorporated refinements over the initial prototype system developed using VP-Expert (Chapter 2). The system consists of four key modules, which can be independently consulted. This chapter describes the system development environment and the design and development of the four modules.

\subsection{The AVLB Decision Support System Structure}

The AVLB decision support system has a main page and four modules. The main page introduces the AVLB-DSS and asks a password to enter the consultation mode. Figure 4.1 gives a general framework for the AVLB DSS, which shows its various modules for carrying out different tasks. The consultation consists of the following program modules:

- 1. AVLB Introduction Module: This section consists of a brief description about the history of AVLB. It presents a comparison between AVLB models M60 and M70.

- 2. Expert System Inspection Module: This module consists of visual inspection and vibration testing procedure directives: the users run the consultation, respond to queries on various aspects of visual inspection, and input the results of the vibration test results. More details about this module is given in Section 4.3. 
- 3. Checks and Maintenance Module: The Army Technical Manual TM 5-5420-203-14 for the AVLB Scissoring Type of Class 60 and 70, documents the inspection and service procedures to be carried out on the bridge. These procedures are integrated in to the DSS with online descriptions, including an image map of the AVLB. The image is hotspotted, such that the user can click on any individual component on the image map to view the inspection plan for that component. Section 4.4 provides more descriptions on this module.

- 4. Database Module: A database, which includes detailed past test results of the AVLB, is maintained in Microsoft Access Database file. The database consists of tables of data related to each individual AVLB and the results of inspection. The database module permits storage and retrieval of data from within the web browser interface. This module is elaborated in Section 4.5.

The system is designed accessible through the Internet via a given Internet address. Once contacted by a user, the main page would appear as the Homepage for the system. Once the user provides the valid password, the system would allow him/her to enter the main menu, which acts as a gateway to the individual modules. The main menu appears as a split frame on the left side of the browser window. 


\section{DECISION SUPPORT SYSTEM}

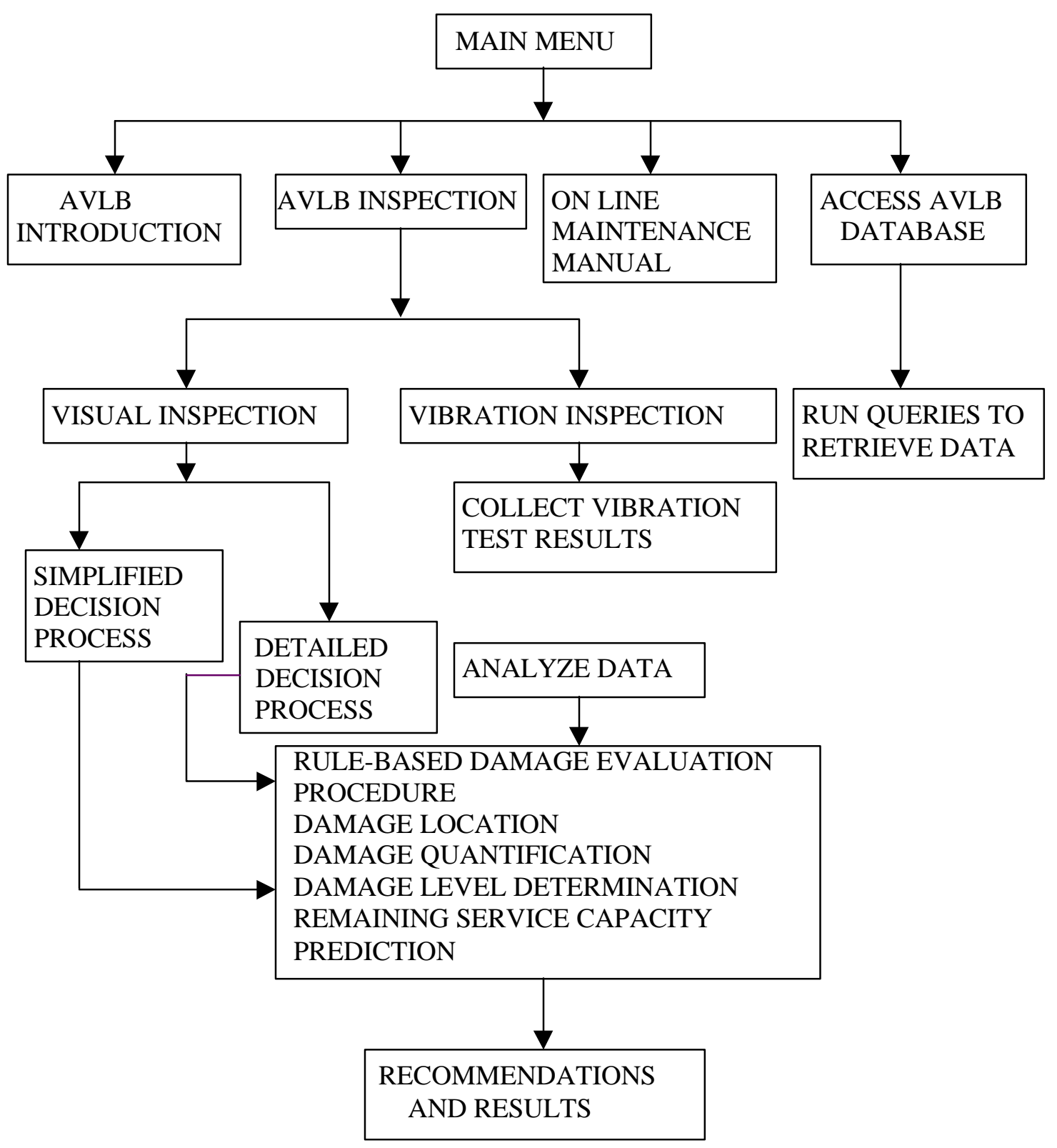

Figure 4.1 AVLB Decision Support System Structure 


\subsection{Expert System Module}

This module consists of two sections: the visual inspection section and the vibration inspection section. Expert system concept is used to draw inference over the condition of the AVLB when consulted.

\subsubsection{Visual Inspection Program Development}

The development of the visual inspection module of the system involved eliciting, analyzing and interpreting the knowledge required for solving the problem - that of diagnosis of the bridge condition, and in this case, transforming this knowledge to a suitable program representation.

The visual inspection section consists of a simplified inspection procedure and a detailed inspection procedure. The simplified procedure consists mainly of conditions that would immediately deadline the bridge including condition assessment of primary structural components (Figure 4.2). These components are center hinge, web girder, deck extrusion plates, lower cross bracing angles, splice plate. The questions are directed towards ascertaining whether any of these components are damaged or missing to the state that would render the bridge unsafe for tank crossing.

The detailed visual inspection module is consulted when a thorough visual inspection procedure has to be employed to assess the bridge condition. The first thing to appear, after selecting this option, is a brief introduction to the underlying philosophy. This module has been developed to determine the structural integrity progressively from the most critical component to the least critical one. Hence, several pages of questions would direct the user to arrive at a logical conclusion. 


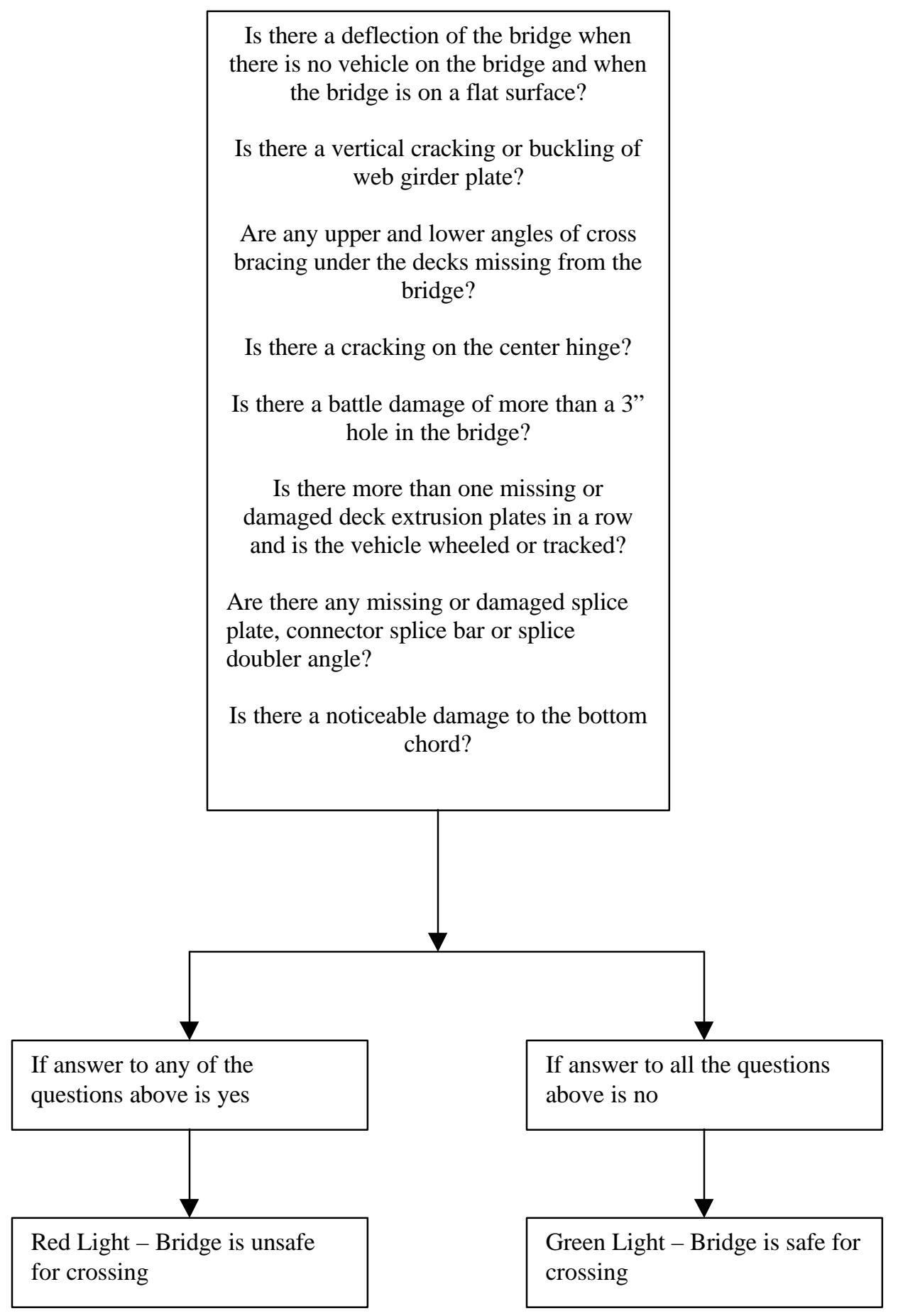

Figure 4.2 Simplified Visual Inspection Procedure 
A detailed flow chart of the visual inspection procedure is shown in Figure 4.3. The procedure can be divided into four stages. Stage 1 checks for the structural fitness of the most critical or primary structural components - the failure of any of these components would cause immediate failure of the structure. This corresponds to Class A components of the component hierarchy (Section 3.3.3). Positive response to any of the questions in Stage 1, indicates the bridge is unsafe for crossing. Stage 2 questions the integrity of "Class B" components whose failure would cause primary components to fail which may lead to immediate collapse of the bridge structure. Class $\mathrm{C}$ components whose failure would not cause failure of the bridge structure but would hinder tank crossing are investigated in Stage 3. Finally, Stage 4 lists Class D or Class E components whose failure may cause failure of other secondary components but does not have significant impact on the structure. There is a provision for entering confidence factors for each query asked by the system. Application of confidence factors is discussed in Section 4.3.3. Based on the responses to the questions posed, the expert system decides the status of the bridge from the production rule base. 


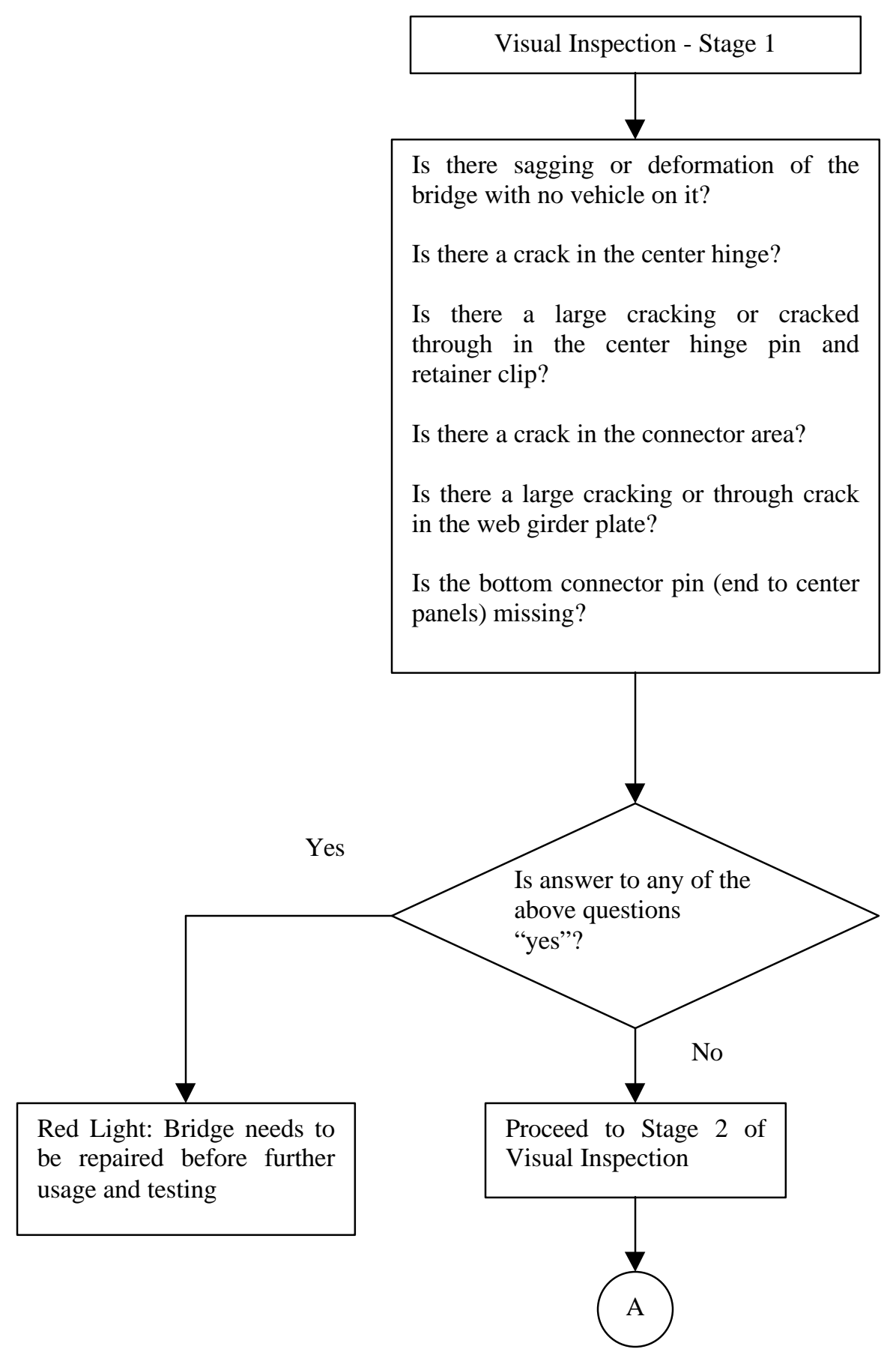

Figure 4.3 Flowchart of the Detailed Visual Inspection Procedure 


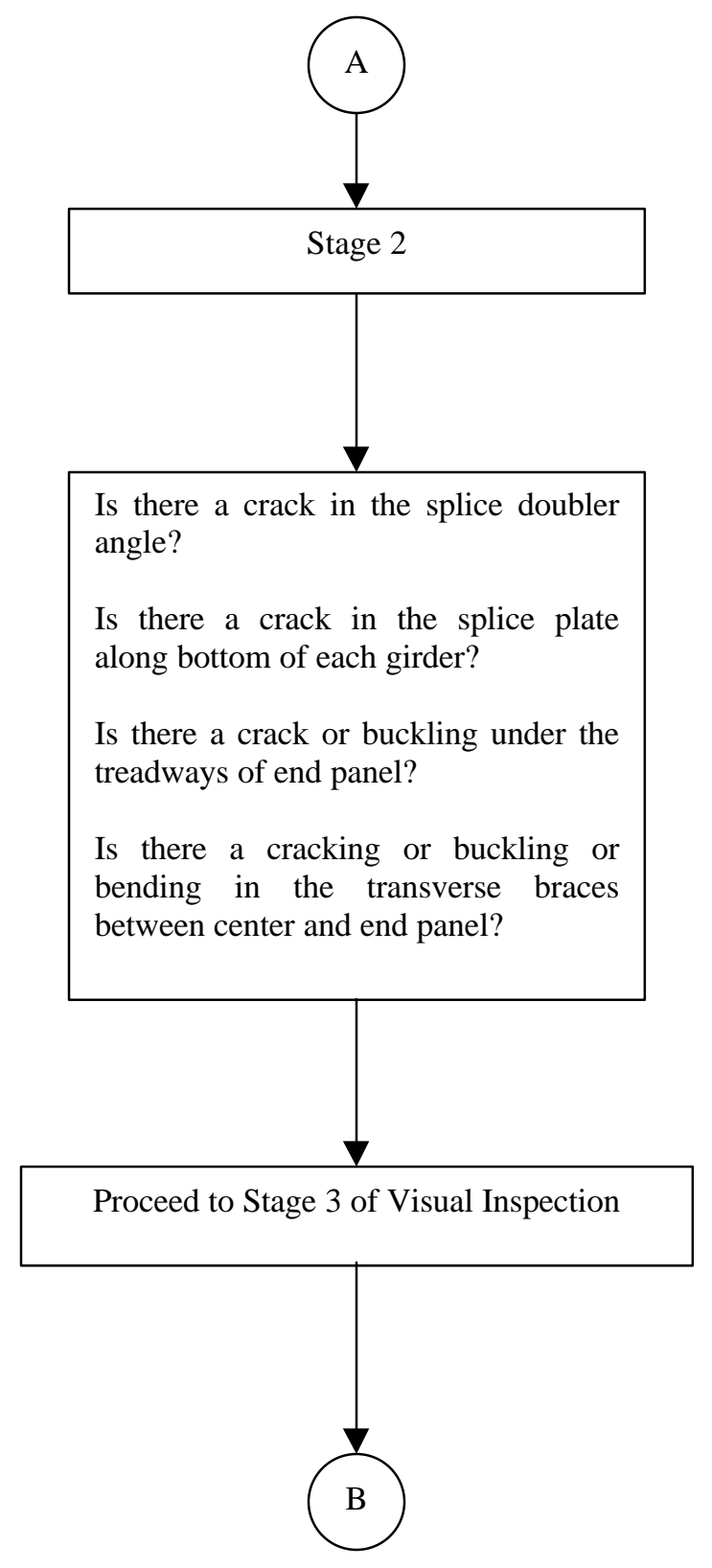

Figure 4.3 (continued) 


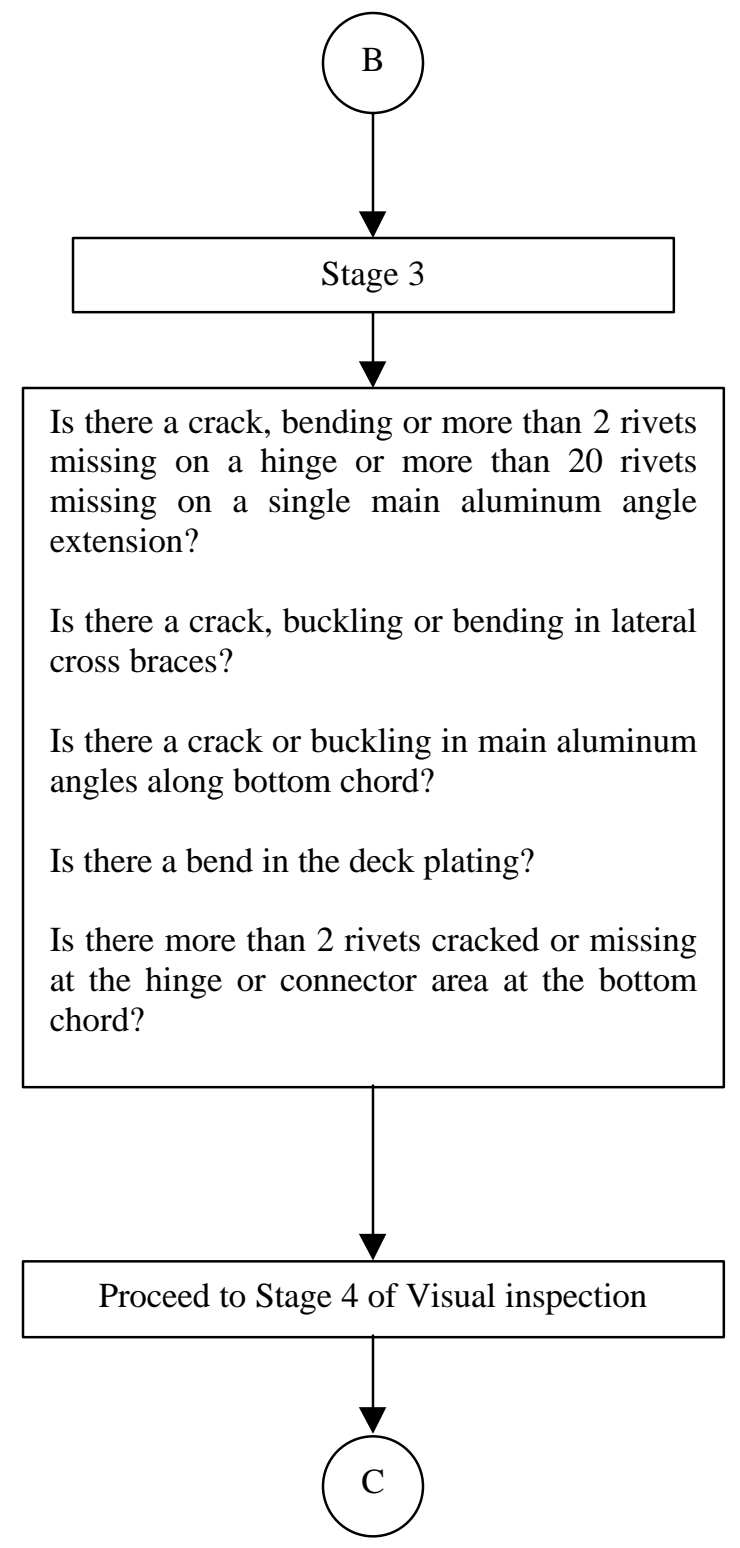

Figure 4.3 (continued) 


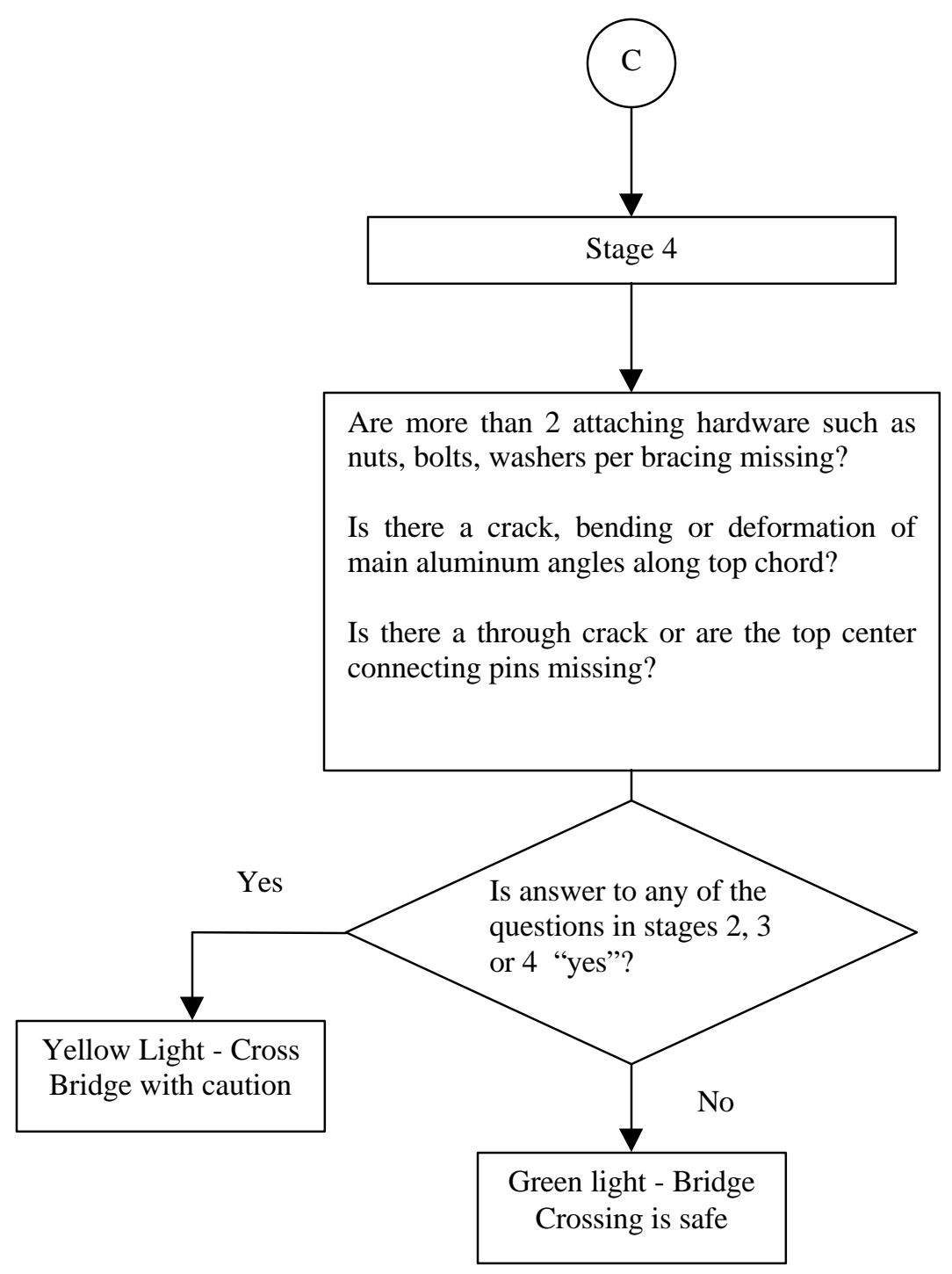

Figure 4.3 (continued) 


\section{Table 4.1 Visual Inspection Decision-making Rules}

\begin{tabular}{|c|c|c|}
\hline AVLB-DSS Visual Inspection Stages & Reply & Result \\
\hline $\begin{array}{l}\text { Stage } 1 \\
\text { Is there sagging or deformation of the bridge with no vehicle on it? } \\
\text { Is there a crack in the center hinge? } \\
\text { Is there a large cracking or cracked through in the center hinge pin } \\
\text { and retainer clip? } \\
\text { Is there a crack in the connector area? } \\
\text { Is there a large cracking or through crack in the web girder plate? } \\
\text { Is the bottom connector pin (end to center panels) missing? }\end{array}$ & $\begin{array}{l}\text { Answer to any of } \\
\text { the questions in } \\
\text { Stage } 1 \text { is Yes }\end{array}$ & Red Light \\
\hline $\begin{array}{l}\text { Stage } 2 \\
\text { Is there a crack in the splice doubler angle? } \\
\text { Is there a crack in the splice plate along bottom of each girder? } \\
\text { Is there a crack or buckling under the treadways of end panel? } \\
\text { Is there a cracking or buckling or bending in the transverse braces } \\
\text { between center and end panel? } \\
\text { Stage } 3 \\
\text { Is there a crack, bending or more than } 2 \text { rivets missing on a hinge or } \\
\text { more than } 20 \text { rivets missing on a single main aluminum angle } \\
\text { extension? } \\
\text { Is there a crack, buckling or bending in lateral cross braces? } \\
\text { Is there a crack or buckling in main aluminum angles along bottom } \\
\text { chord? } \\
\text { Is there a bend in the deck plating? } \\
\text { Is there more than } 2 \text { rivets cracked or missing at the hinge or } \\
\text { connector area at the bottom chord? } \\
\text { Stage } 4 \\
\text { Are more than } 2 \text { attaching hardware such as nuts, bolts, washers } \\
\text { per bracing missing? } \\
\text { Is there a crack, bending or deformation of main aluminum angles } \\
\text { along top chord? } \\
\text { Is there a through crack or are the top center connecting pins } \\
\text { missing? }\end{array}$ & $\begin{array}{l}\text { Answer to any } \\
\text { question in Stage 2, } \\
\text { Stage } 3 \text { or Stage } 4 \\
\text { is Yes }\end{array}$ & Yellow Light \\
\hline All 4 Stages inspected & $\begin{array}{l}\text { Answer to all } \\
\text { questions in Stages } \\
1,2,3 \text { and } 4 \text { is No }\end{array}$ & Green Light \\
\hline
\end{tabular}


Table 4.1 lists the decision criteria employed by the detailed visual inspection procedure, as shown in Figure 4.3.

The main parts of the program - the rule base, the data evaluation and the inference processing, are coded in Microsoft ${ }^{\circledR}$ Visual Basic ${ }^{\circledR}$ Scripting Edition (VBScript). VBScript is a subset of the Microsoft ${ }^{\circledR}$ Visual Basic $®$ programming language, which is a fast, portable, lightweight interpreter for use in World Wide Web browsers and other applications (Borphy, 1996). Parts of the program, the form containing the text boxes and check boxes and the form validation, are coded in JavaScript, which is a programming language developed by Netscape Communications ${ }^{\circledR}$ for programming on the World Wide Web. A sample code of the rule base is shown below:

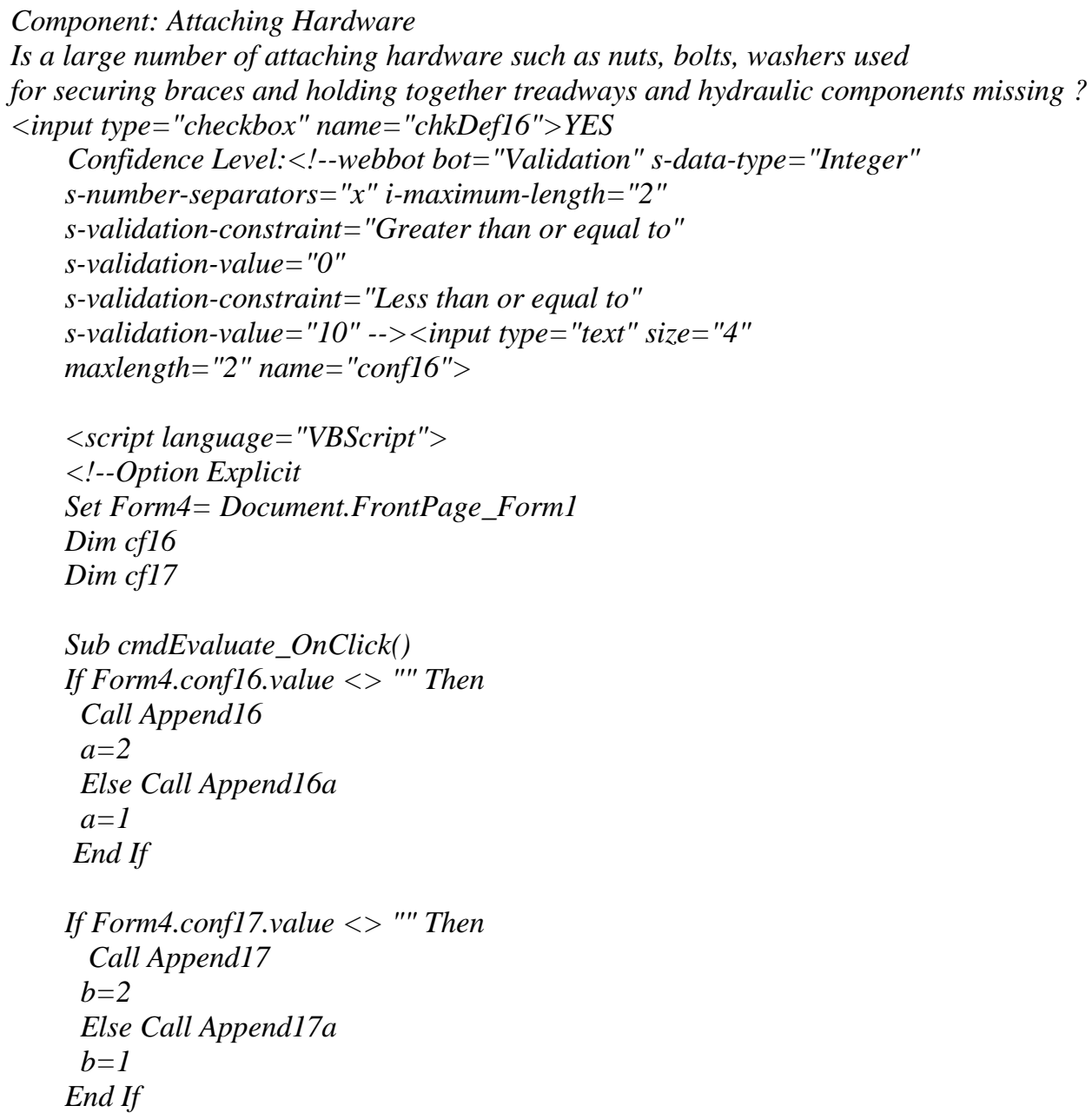




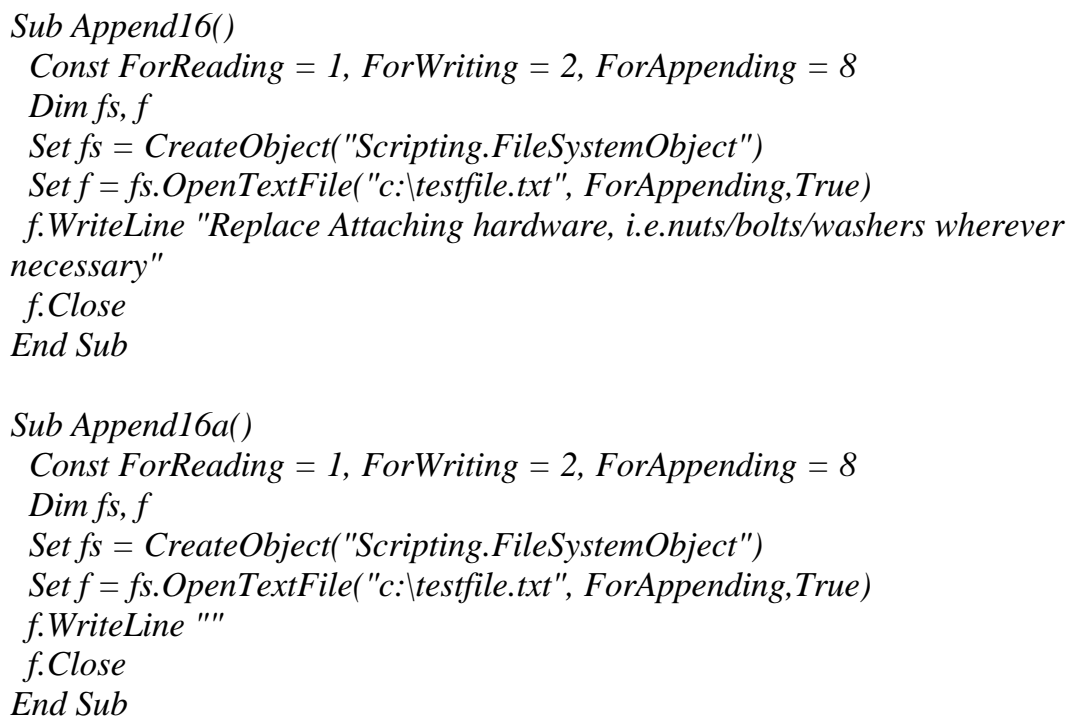

In the above section of the program code, the user is presented with a question, which has to be answered by checking the check box (chkDef16). The confidence that the user has in answering the question is to be entered in the text box field (conf16). The program also ensures that the value entered in the text box is within the expected range of values and only text values are entered in the field. The next section of the program is the rule base of the expert system that processes the input provided by the user and stores the information in a text file (testfile.txt).

The program uses forward chaining mechanism, which is also known as data driven or event driven mechanism. This method of reasoning is used when data or facts are available and works towards conclusions (Chapter 2). The rules, whose "if" parts are true, are activated and the system infers towards a solution. This inference logic ensures that the system would deadline the bridge if any of the major structural components were found weak, and subsequently check for the fitness of secondary components. 


\subsubsection{Vibration Inspection Program Development}

Vibration inspection is expected to be carried out with the AVLB resting on eight airbags and excited by four shakers, with a scanning laser vibrometer acquiring the vibration responses. The laser vibrometer will scan the AVLB girder by girder. Four bending modes of each girder will be investigated. After analysis and processing the data, modal parameters such as frequency shift, SEMAC, SEDI and MAC will be extracted and fed into the system. Other important data such as location of the major crack or damage on the bridge would also be collected. Figure 4.4 shows the flowchart of the vibration inspection procedure. 


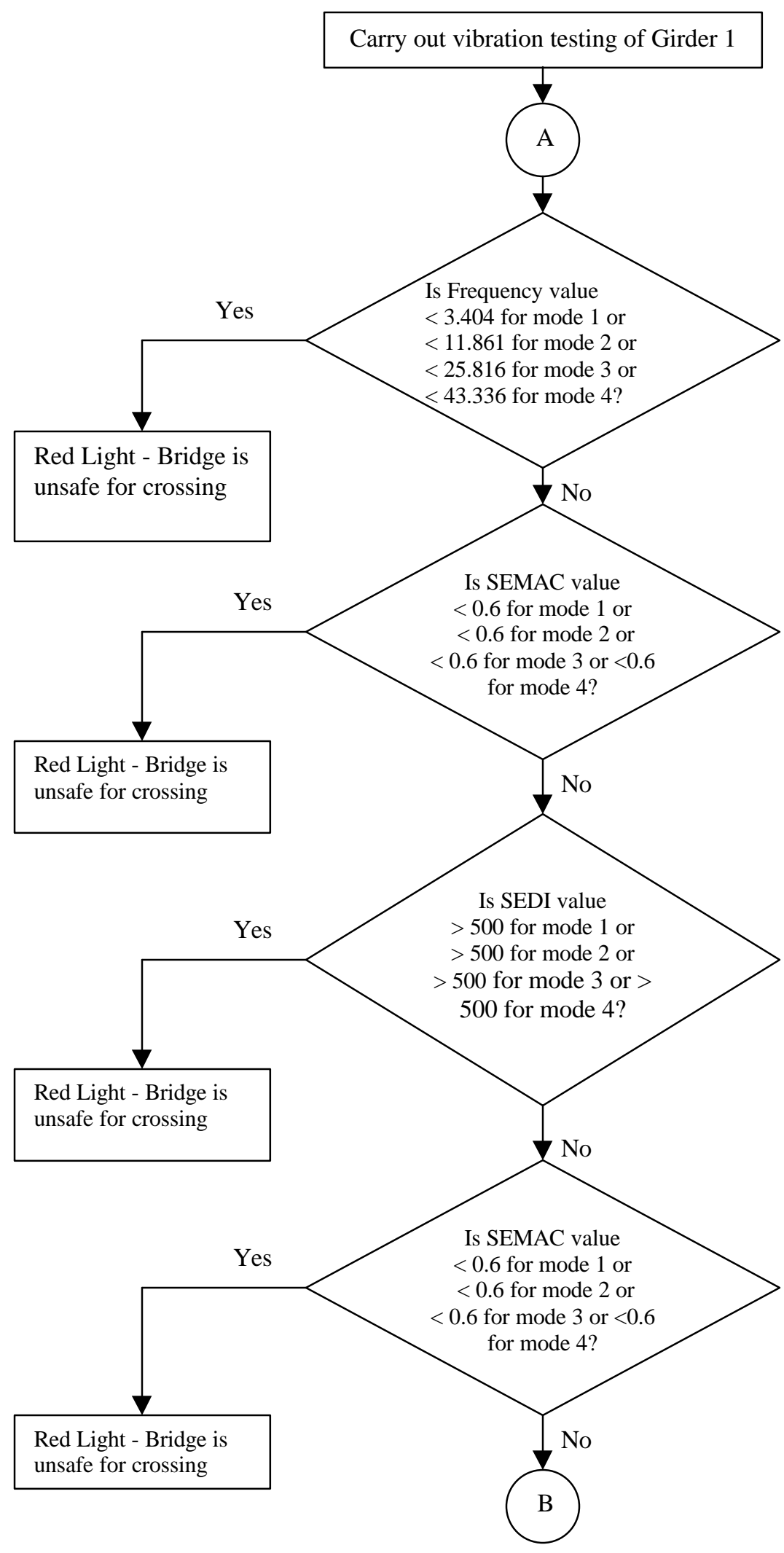

Figure 4.4 Flowchart of the Vibration Inspection Procedure 


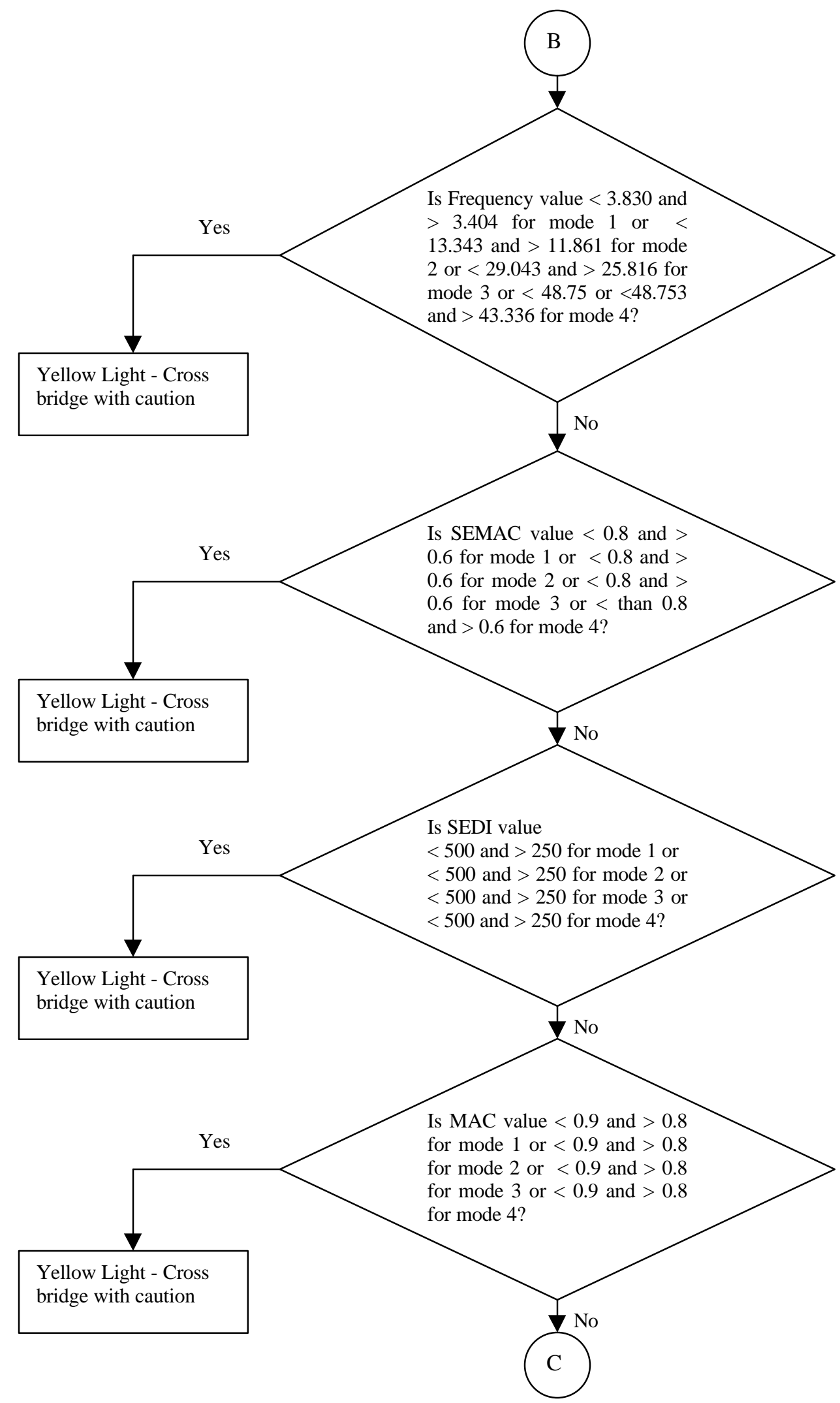

Figure 4.4 (continued) 


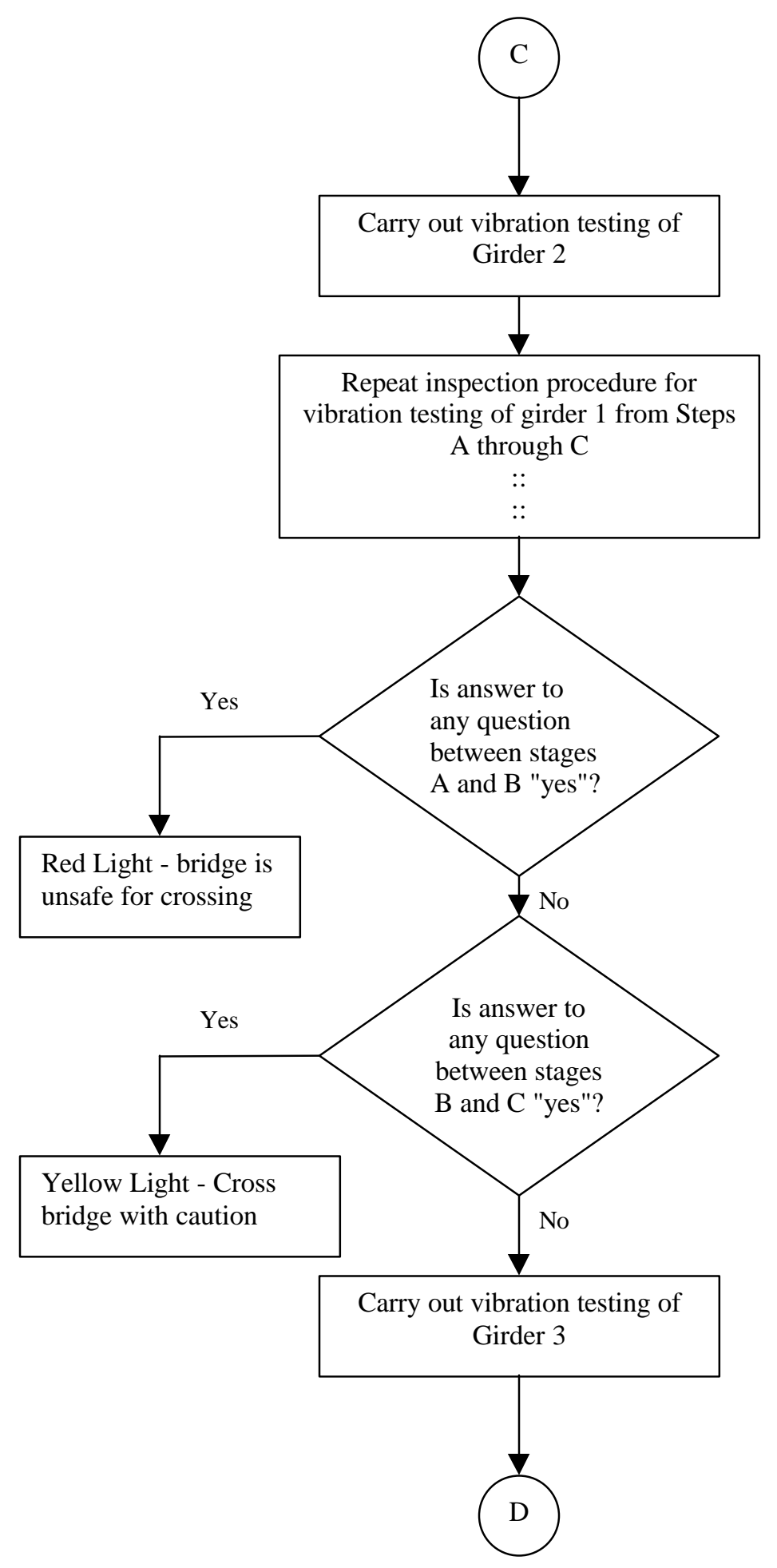

Figure 4.4 (continued) 


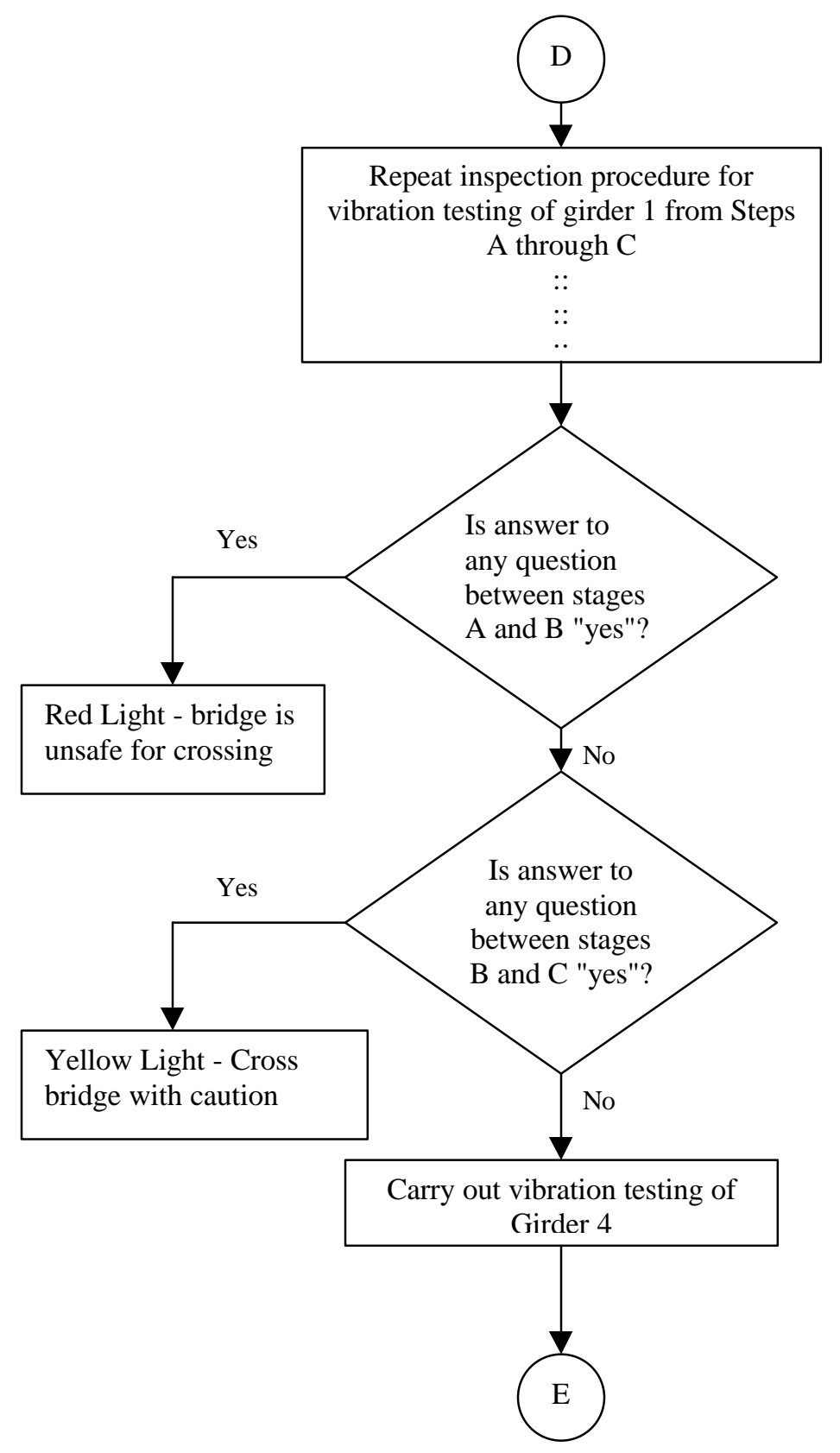

Figure 4.4 (continued) 


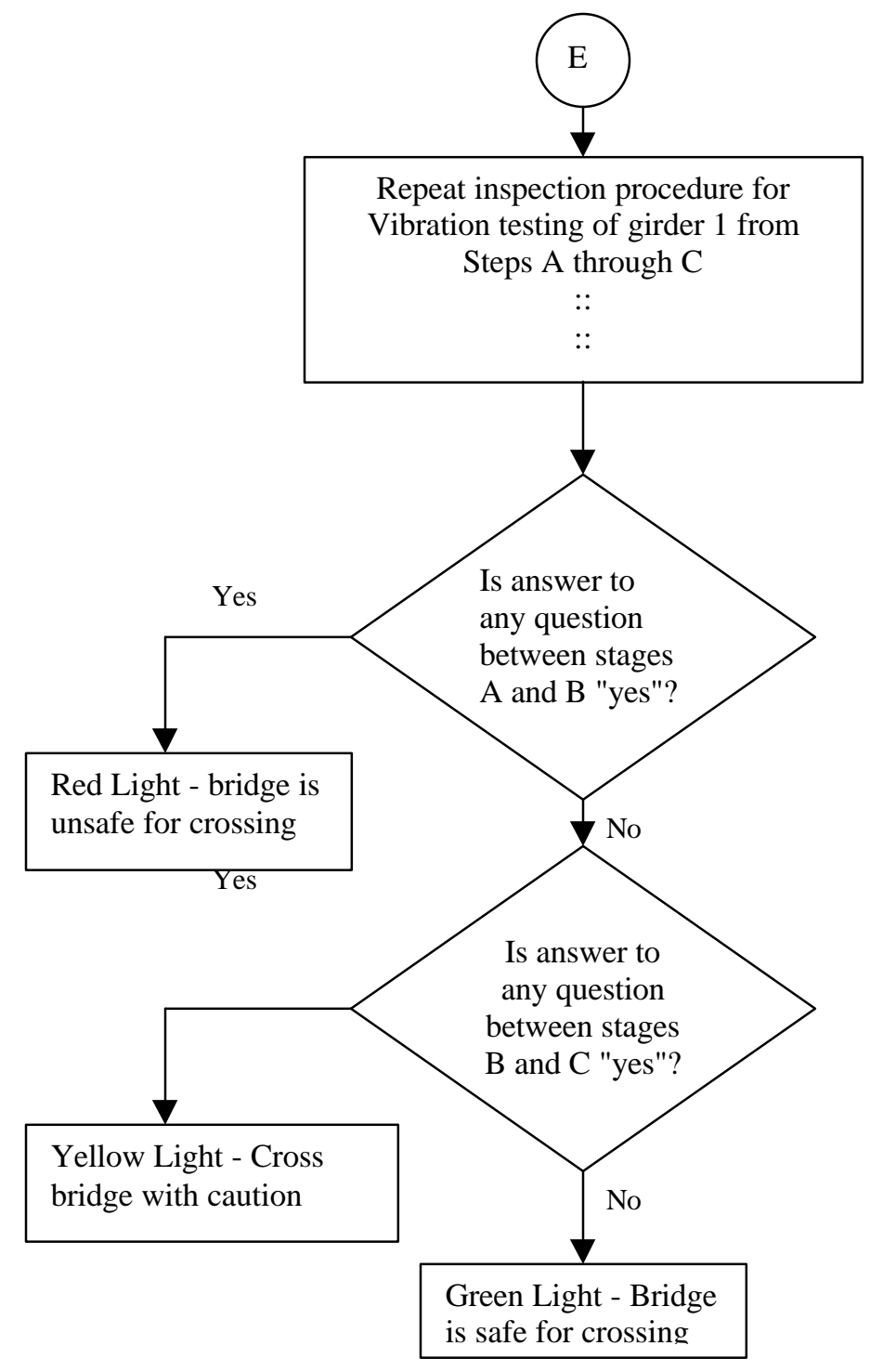

Figure 4.4 (continued) 
Table 4.2 Vibration Inspection Decision-making Rules

\begin{tabular}{|c|c|c|c|c|}
\hline Frequency Value & SEMAC value & SEDI value & MAC value & Result \\
\hline $\begin{array}{l}\text { Mode } 1<3.404 \\
\text { Mode } 2<11.861 \\
\text { Mode } 3<25.816 \\
\text { Mode } 4<43.336\end{array}$ & $\begin{array}{l}\text { Mode } 1<0.6 \\
\text { Mode } 2<0.6 \\
\text { Mode } 3<0.6 \\
\text { Mode } 4<0.6\end{array}$ & $\begin{array}{l}\text { Mode } 1>500 \\
\text { Mode } 2>500 \\
\text { Mode } 3>500 \\
\text { Mode } 4>500\end{array}$ & $\begin{array}{l}\text { Mode } 1<0.8 \\
\text { Mode } 2<0.8 \\
\text { Mode } 3<0.8 \\
\text { Mode } 4<0.8\end{array}$ & Red light \\
\hline $\begin{array}{l}3.404<\text { Mode } 1<3.83 \text { or } \\
11.86<\text { Mode } 2<13.343 \text { or } \\
25.82<\text { Mode } 3<29.043 \text { or } \\
43.34<\text { Mode } 4<48.75\end{array}$ & $\begin{array}{l}0.6<\text { Mode } 1<0.8 \text { or } \\
0.6<\text { Mode } 2<0.8 \text { or } \\
0.6<\text { Mode } 3<0.8 \text { or } \\
0.6<\text { Mode } 4<0.8\end{array}$ & $\begin{array}{l}250<\text { Mode } 1<500 \text { or } \\
250<\text { Mode } 2<500 \text { or } \\
250<\text { Mode } 3<500 \text { or } \\
250<\text { Mode } 4<500\end{array}$ & $\begin{array}{l}0.8<\text { Mode } 1<0.9 \text { or } \\
0.8<\text { Mode } 2<0.9 \text { or } \\
0.8<\text { Mode } 3<0.9 \text { or } \\
0.8<\text { Mode } 4<0.9\end{array}$ & Yellow light \\
\hline \multicolumn{4}{|c|}{$\begin{array}{l}\text { Frequency, SEMAC, SEDI and MAC values for all } 4 \text { girders and all } 4 \text { modes not in Red light and Yellow } \\
\text { light zones }\end{array}$} & Green light \\
\hline
\end{tabular}

Table 4.2 shows the decision criteria employed by the vibration inspection section in arriving at a decision as shown in Figure 4.4.

These data are then entered into the vibration inspection section of the DSS. Figure 4.5 shows the ASCII text format from which the data from the signal-processing program will be read into the DSS. In Figure 4.5, the first four lines are the frequency values of the four modes of the test sample. The next four lines are the SEMAC values. The four lines after that are the SEDI values, and followed by 4 lines of MAC values.

This module has a rules base with limit states for the various vibration parameters. Limit state values are threshold values that indicate the safety zone in which the bridge lies. These values are subjected to refinement as more tests are conducted and Finite Element (FE) models of test cases are simulated. 


\section{Figure 4.5 ASCII Text File Format from which Vibration Data is read into the DSS}

A sample code of the vibration inspection section is illustrated below

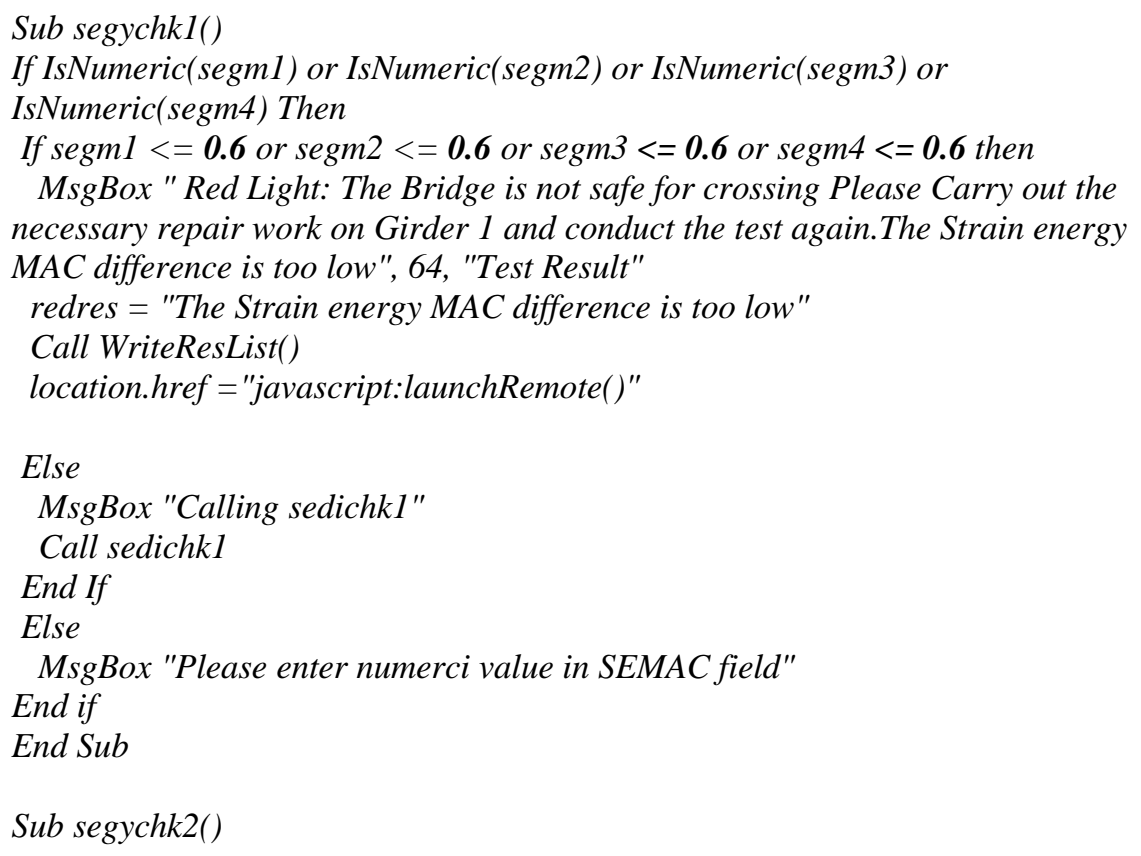




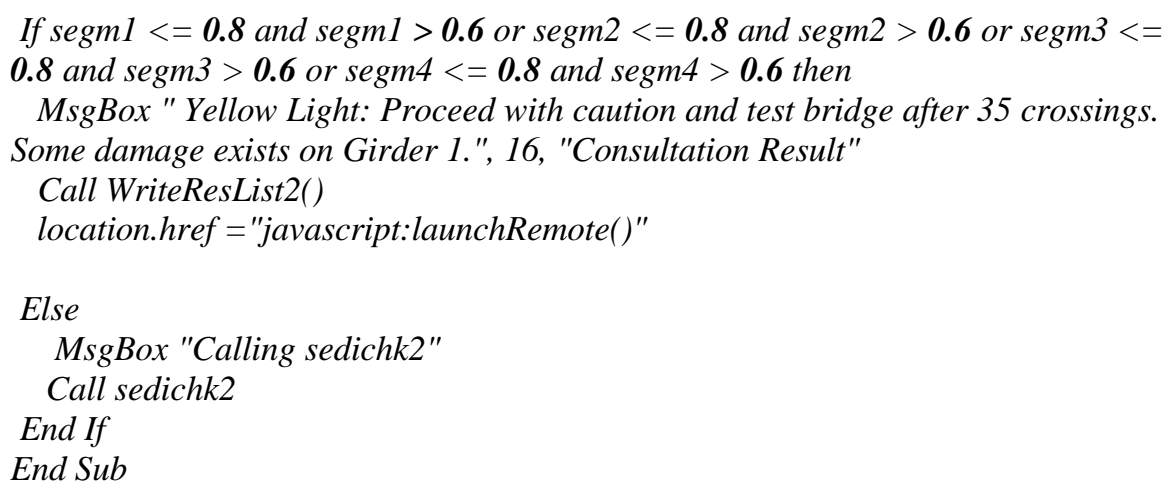

The above section of code is a portion of the vibration inspection program code. The first subroutine in the code - sub segychkl-, first verifies that a numeric value has been entered in the SEMAC value field. It then checks the value entered by the user against the limit state values (in bold). If the SEMAC values for any of the 4 modes are too low, it causes the program to display a red light and classifies the bridge as unsafe for crossing. If the SEMAC values for any of the four modes is less than the limit state values, the program will proceed to call another subroutine that checks the strain energy damage index values.

The second subroutine - sub segychk2- in the code exemplifies the checking the user input value against the predefined "yellow light" zone of safety. This portion of the program code is executed only after the previous checks for red light for the different modal parameters have failed. If the SEMAC value for any the four modes lies within the range defined for a "yellow light" in the code, the program displays a "yellow light" and a recommendation message. Otherwise, the program calls the next subroutine to check the strain energy damage index value against the limit states. These limit state values, as shown in bold, have been set currently based on the knowledge of structural experts about the structural behavior. 


\subsubsection{Accounting for Uncertainty in Data}

To reach a valid conclusion within an expert system, basic uncertainty handling is often crucial, especially in circumstances where the knowledge used is complex or unclear (Bielawski et al. 1988). In the current application, uncertainty is handled through "confidence factors" or "certainty factors". Certainty factors are numerical weights that can be attached to certain facts or user responses, to suggest an overall degree of certainty within the system in reaching a particular conclusion.

A facility for the user to express confidence factor is provided for various queries, during consulting the visual inspection section of the expert system module. The user is presented with an option of entering a confidence factor on a scale of 0 to 10 for each of the questions, which has a "yes" answer. A user response of "10", to a question for which the answer is "yes", indicates $100 \%$ confidence in the response. A response of 0 , on the other hand, indicates no confidence in the response or that the answer for the question is "unknown". A default confidence level factor of 10 implies $100 \%$ confidence in answering "no". If the user does not present a confidence factor, a default confidence factor has been provided. The use of this factor is made with the awareness of the user, and is explained in the instructions before the consultation of the system.

The confidence level values for each of the stages are then averaged out. The averaged value is stored in the memory and used to determine the final conclusion. As an example, in the first stage of visual inspection section of the expert system:

If there is significantly large crack or through crack at the center hinge $=$ Yes

And confidence factor $=8 / 10$

If there is a significant cracking in the connector area $=$ true 
And confidence factor $=9 / 10$

If there is a through crack in the bottom connector pin or it is missing $=$ true

And confidence factor $=7 / 10$

In this example, the bridge is considered unsafe for crossing with $90 \%$ confidence level. This inference is arrived as follow: The three questions in this stage for which the answer was no take a default certainty value of 10 each. The overall system confidence is estimated as

$$
\frac{10+8+10+9+10+7}{60}=.9
$$

Thus for this sample, the overall system confidence is 0.9 or $90 \%$ confidence.

In the same manners, for the next three stages the confidence factors are calculated. As mentioned previously, the expert system proceeds to stage 2 only if all questions in stage 1 are answered "no".

Present algorithm adopts a simple averaging technique to arrive at an overall degree of certainty within the system. In future with some alteration, the system confidence calculation portion of the program can be modified to accommodate more elaborate theories for calculating compounded uncertainties.

\subsection{Checks and Maintenance Module Development}

This Module has been developed primarily to aid the user with on-line assistance. An image map of the AVLB is available in this module. This is a scanned image of a picture of AVLB model 60 taken from the PMCS manual. The bridge components are hot-keyed, so that a clicking on the component of interest, one can access the instructions for that 
component. Structural elements for which the information has been provided, include:

Tie Rod Assemblies

Deck Extrusions

Center Hinge

Splice Doubler Angle

Launching Diaphragm

Hydraulic Cylinder Lines

Top Center Connector

Top/Bottom Connector Pin

Main Aluminum Angles

Connector Area along the Bottom Chord

Cross Bracing (located under treadways)

Hose Assemblies and Quick Disconnects

Scissoring Cylinder

Cross Pin Socket

Interconnecting Braces

Splice Plate along Bottom of Chord

Web Girder Plate

Deck curbing

The inspection plan for each of the components is maintained as a separate HTML file. The main page of the module has been scripted in HTML 4.0 and JavaScript programming languages.

Currently, the instructions are incomplete, and should be improvised by more information from the US Army. 


\subsection{Database Module Development}

This module enables the storage and retrieval of useful bridge vibration and visual inspection data. The whole operation is managed by MS-PWS (Microsoft Personal Web Server). The data are maintained by Microsoft Access and can be queried for various details from within the web browser interface.

\subsubsection{Composition of the Database Module}

Each AVLB is uniquely identifiable by an identification number. Details of each AVLB, such as year of manufacture, military class, number of crossings, etc., are maintained in the database. Similarly, the inspector's record contains inspector's identification number, name and designation. This record is maintained for gathering specific details about a particular bridge tested on a particular date. The vibration inspection record for each of the four girders, contains data from each vibration test carried out on the AVLB:

1. Inspection Id

2. AVLB Id

3. Inspection date

4. Inspector Id

5. Girder number

6. Percentage frequency shift

7. Strain Energy Modal Assurance Criteria (SEMAC)

8. Strain Energy Damage Index (SEDI)

9. Modal Assurance Criteria (MAC)

10. Damage Location

11. Remarks concerning vibration or visual inspection 
In addition to the above, provision has also been made in the database to maintain such records as crack growth rate and major crack length, wherever possible.

\subsubsection{The Anatomy of the Database Module}

The database module is composed of three separately identifiable entities. The front end is the user interface, the back end is where the data are stored. Also available is the Application Programming Interface (API), which allows the user to abstract any element from a database. During development, the script files that execute the queries of the user and call the Open DataBase Connectivity (ODBC) driver, are stored on MS PWS in Windows 95.

The Web browser is the front end through which queries of various types are run and where user required records displayed. Microsoft Access, relational database software stores the data input, in an organized and meaningful format in various tables. The Microsoft ODBC driver facilitates the Web-based program to talk to the MS Access database. The Web browser program is coded in the ODBC language, which is a combination of ODBC API function calls and SQL (Structured Query Language). The ODBC manager interprets the SQL, retrieves the required data from the MS Access database, and then sends it back to the browser program. The browser program then displays the information in a preformatted manner in the web browser.

To perform retrieval and display of records from the database, two program scripts are run. These pages are coded in HTML and have a .htx and idc extension, which stand for HTML Template and Internet Database Connectivity (IDC) respectively. A flow chart representing how the Internet Database Connectivity technology works an IDC Chain is shown in Figure 4.6. 


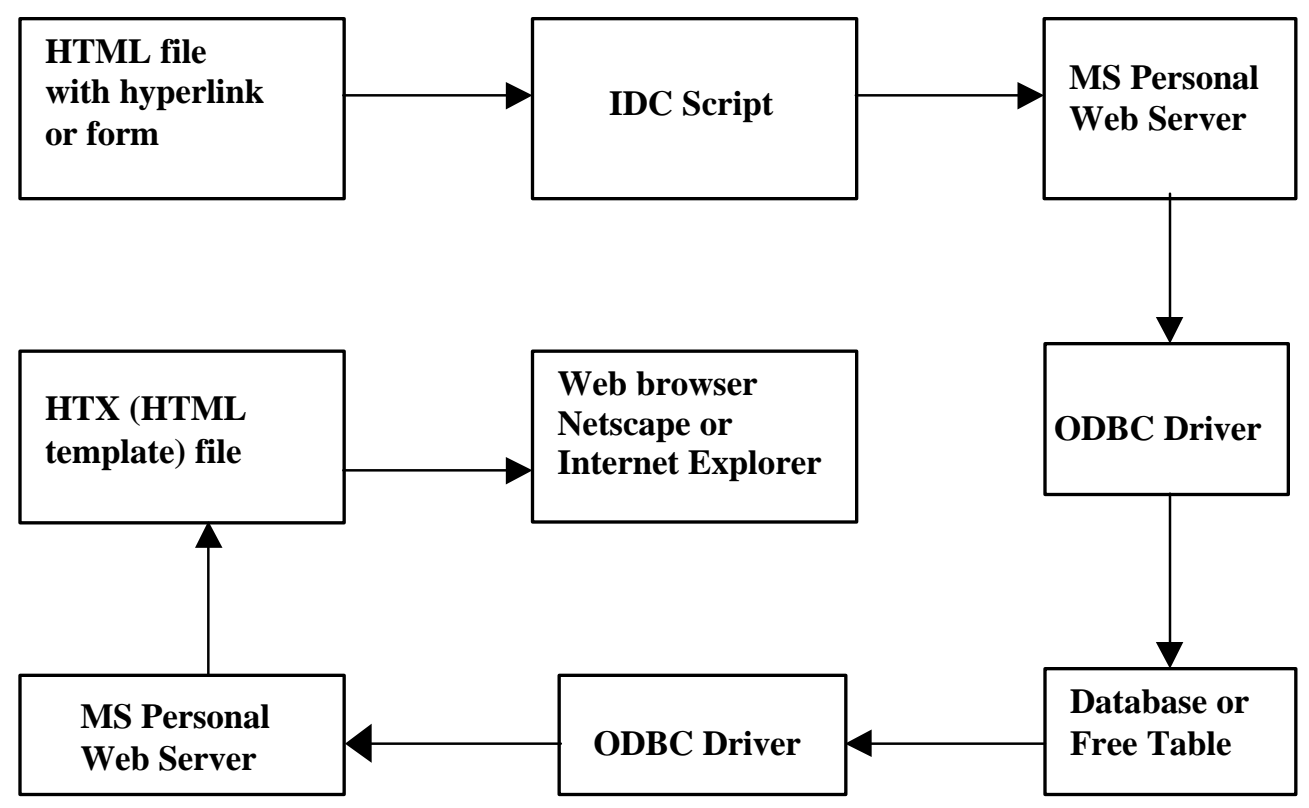

Figure 4.6 Internet Database Connectivity Chain

After the user entered the search string, by which the database has to be queried in the text box, the search information is processed as a SQL statement by the IDC program script. This script invokes the ODBC driver on the computer, which determines the database file that has to be opened, and retrieves the necessary data field values corresponding to the query value. This value is sent back to the web server, which displays the values in a formatted manner as an HTML template document on the web browser.

The data are stored in six tables of the Microsoft Access database. The data can be queried based on various criteria. Those that are implemented are:

1. AVLB Identification number

2. Inspection date

3. Inspector Id

4. Location

5. Military Class 


\author{
6. Military Class and Number of Crossings done \\ 7. Number of crossings done \\ 8. Year of Manufacture
}

\title{
4.6 Summary
}

In this chapter the development of the various modules of the AVLB DSS have been discussed. The AVLB has four modules: Introduction Module, Expert System Inspection Module, Database Module, and Checks and Maintenance Module. These modules can be independently consulted. The expert system module consists of visual inspection and vibration inspection evaluation sections. The database module provides AVLB information retrieval and storage capabilities from remote locations for timely availability of important facts. The maintenance module provides online access of the preventive maintenance checklist for select AVLB components. 


\section{CHAPTER 5 \\ SYSTEM IMPLEMENTATION}

\subsection{Introduction}

This chapter discusses the implementation of the AVLB Decision Support System and presents in detail the utility of the system. The implementation of the system is demonstrated by explaining the various modules and sub-modules of the DSS. The problem solving strategy employed is also presented herein.

\subsection{Implementation of the AVLB DSS in the US Army}

The AVLB DSS is developed primarily to aid damage assessment on the AVLB. From a broader perspective, it can also be used as an AVLB management system to keep track of overall AVLB inventory worldwide. The application can be hosted on any Web server managed by the US Army. The database module can be used as a central information system for the AVLB. Information regarding a particular bridge, such as number of crossings carried out on a particular bridge, its current physical location, year of manufacture, specific remarks including defects, can be maintained in the database and updated from time to time. This would permit a better management of the AVLB and aid in decision making related to the deployment of a particular AVLB, for a specific mission. The dynamic inspection data gathered in the database can be analyzed to build prediction models to refine the expert system for assessing the condition of the bridge.

With the rapid growth of the Internet, web access in remote parts of the world is becoming an increasing possibility. Only designated personnel should be provided with 
authorization for accessing the system. The database module can permit 'read only' and 'write' access to different levels of authorized personnel. Thus only authorized personnel would be able to add information to the database.

\subsection{Consulting the AVLB Decision Support System (AVLB-DSS)}

The AVLB DSS has to be accessed only through MS Internet Explorer (MSIE) Ver. 4.0 or greater. The HyperText Transfer Protocol (HTTP) web address of the DSS is designated and called by the user on the Internet to access the system. The user will be asked for a password on the main page. Upon entering the system, the user is presented with a web page split into two frames. The frame on the left provides a menu of the main modules from which the user can select his/her course of action. The selected option would appear on the right side frame. The left side frame with an option menu provides for easy navigation from one task to another.

\subsubsection{Consulting the AVLB Introduction Module}

The introduction module consists of a brief history of the AVLB and the comparison data about AVLB60 and AVLB70. A brief overview of the expert system philosophy is also given here. This module is more of a informative document, and as such, does not have any functional features. 


\subsubsection{Consulting the Expert System Inspection Module}

The user, on accessing the Inspection module from the main menu, is presented with an option of accessing any of the following three programs:

- Simplified Visual Inspection Section

- Detailed Visual Inspection Section

- Vibration Inspection Section

The formulation of these procedures was described in detail in Chapter 4.

\subsubsection{Consulting the Visual Inspection Section}

The quick visual inspection procedure involves visual evaluation of critical AVLB components whose failure would jeopardize the structural integrity of the AVLB. This inspection is to be conducted only when a detailed visual inspection, has been deemed unnecessary under the circumstances or has been carried out in the recent past - the recentness is to be decided by army personnel.

Figure 5.1 shows the consultation screen of the quick visual inspection. Eight questions that fundamentally deem the bridge unsafe for crossing are posed to the user. Hence if the answer to any of the questions is yes, a "bridge unsafe for crossing" message is displayed. In this figure, seven of the eight questions are shown. The user can scroll down the vertical scroll bar to view the eighth question. 


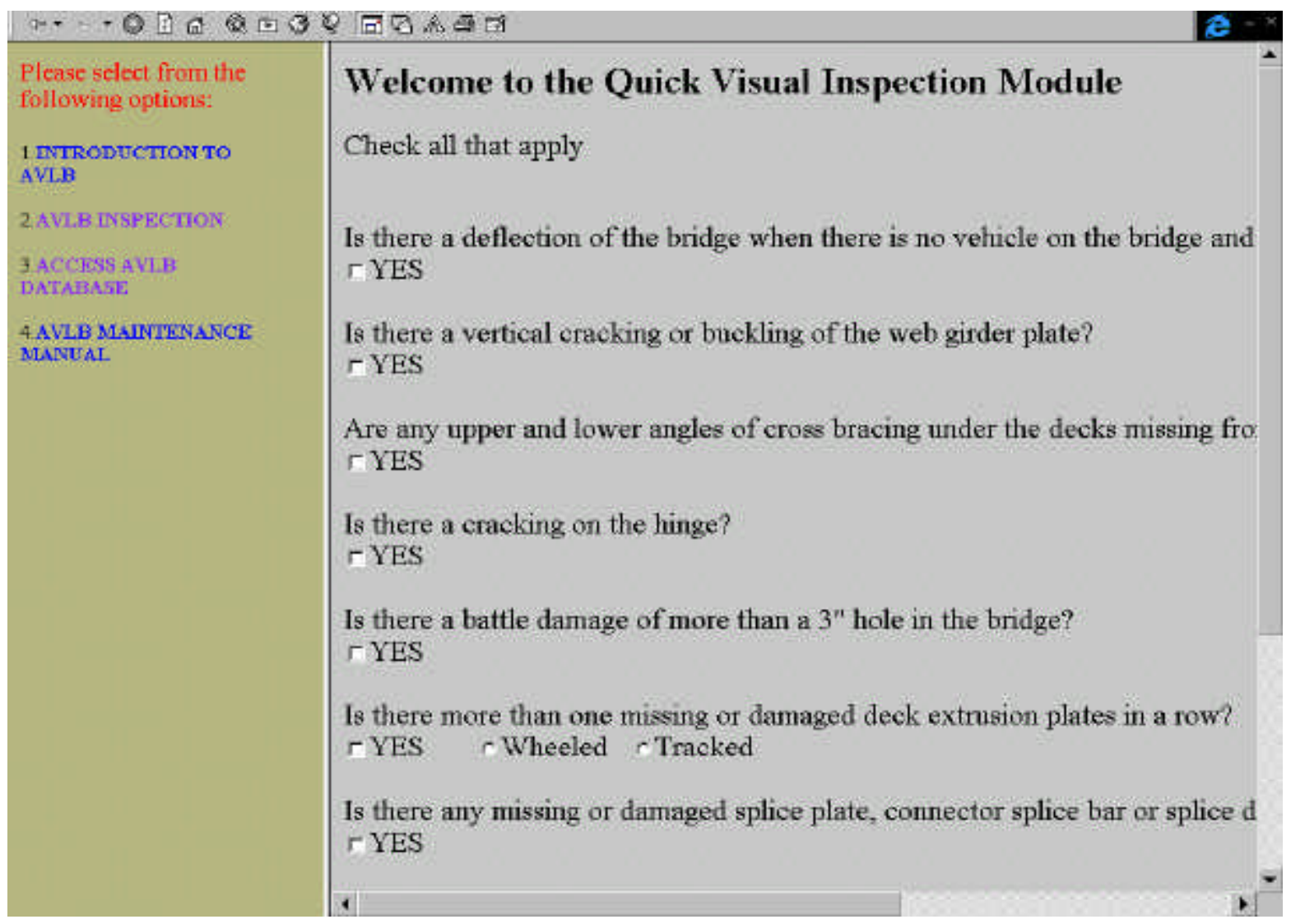

\section{Figure 5.1 Quick Visual Inspection Consultation}

Detailed visual inspection module is consulted when a thorough visual inspection procedure is to be employed to assess the bridge condition. This module has been developed to determine the structural integrity progressively from the most critical component to the least critical one. On accessing this section, the user is presented with a brief instruction and the philosophy governing the detailed inspection procedure.

The philosophy on which the detailed inspection has been developed is as follows: A hierarchy has been set based on the criticality of the components. The visual inspection system has a top-down procedure wherein the components from most critical to least critical 
are checked for structural fitness. This procedure is divided into four stages. Figure 5.2 shows the first interface of the detailed visual inspection section.

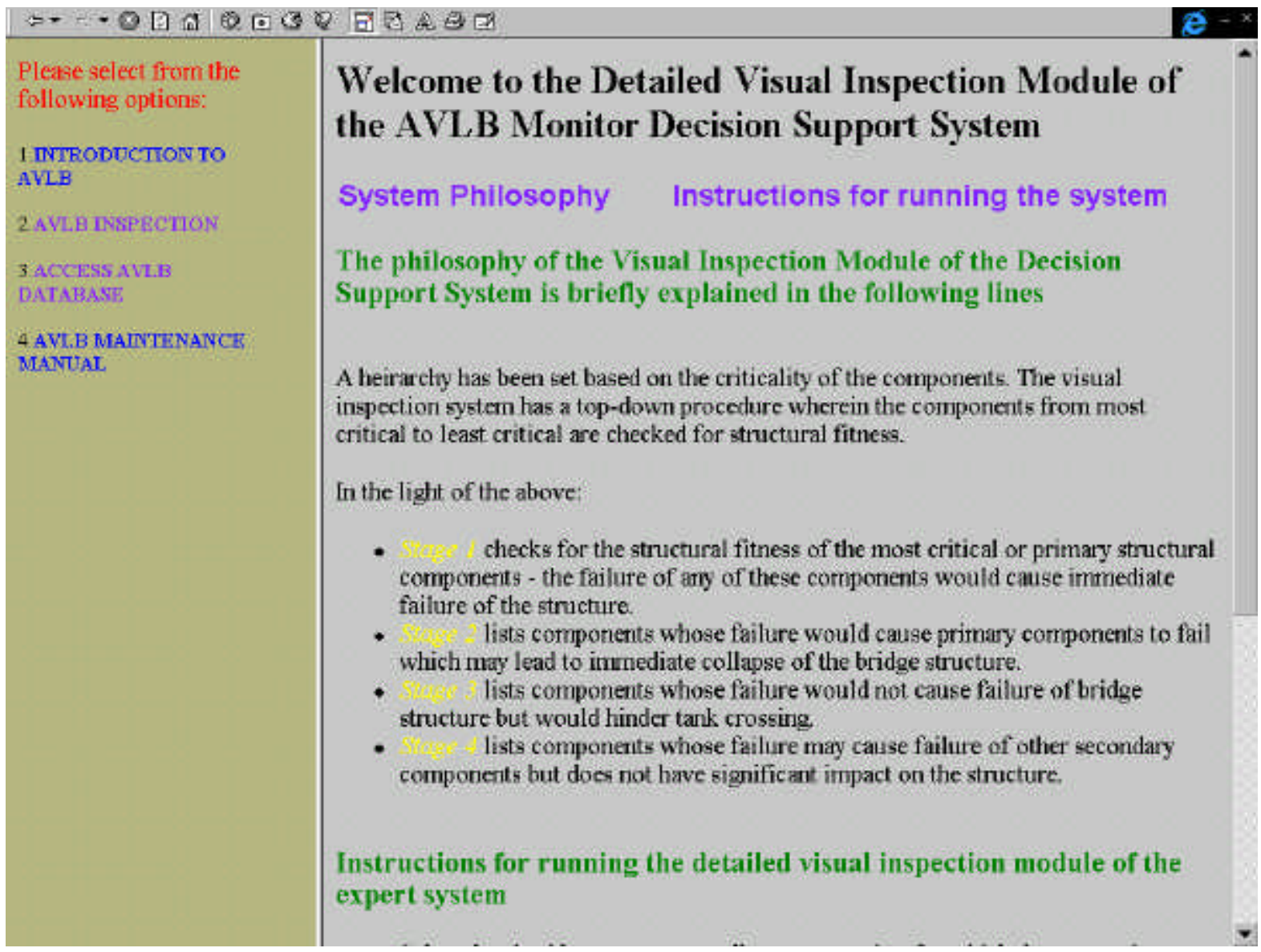

Figure 5.2 First Interface of the Detailed Visual Inspection Section

It is recommended that first time users of the system read this page before proceeding to the detailed visual inspection. Three points are elaborated in the instructions for consulting the detailed visual inspection section and these can be viewed by scrolling down the screen. Point 1 instructs the user to check all applicable boxes. Point 2 is related to the confidence level of the user regarding the answer to the corresponding question. The third point instructs the user to strictly adhere to the above for effective working of the system. 


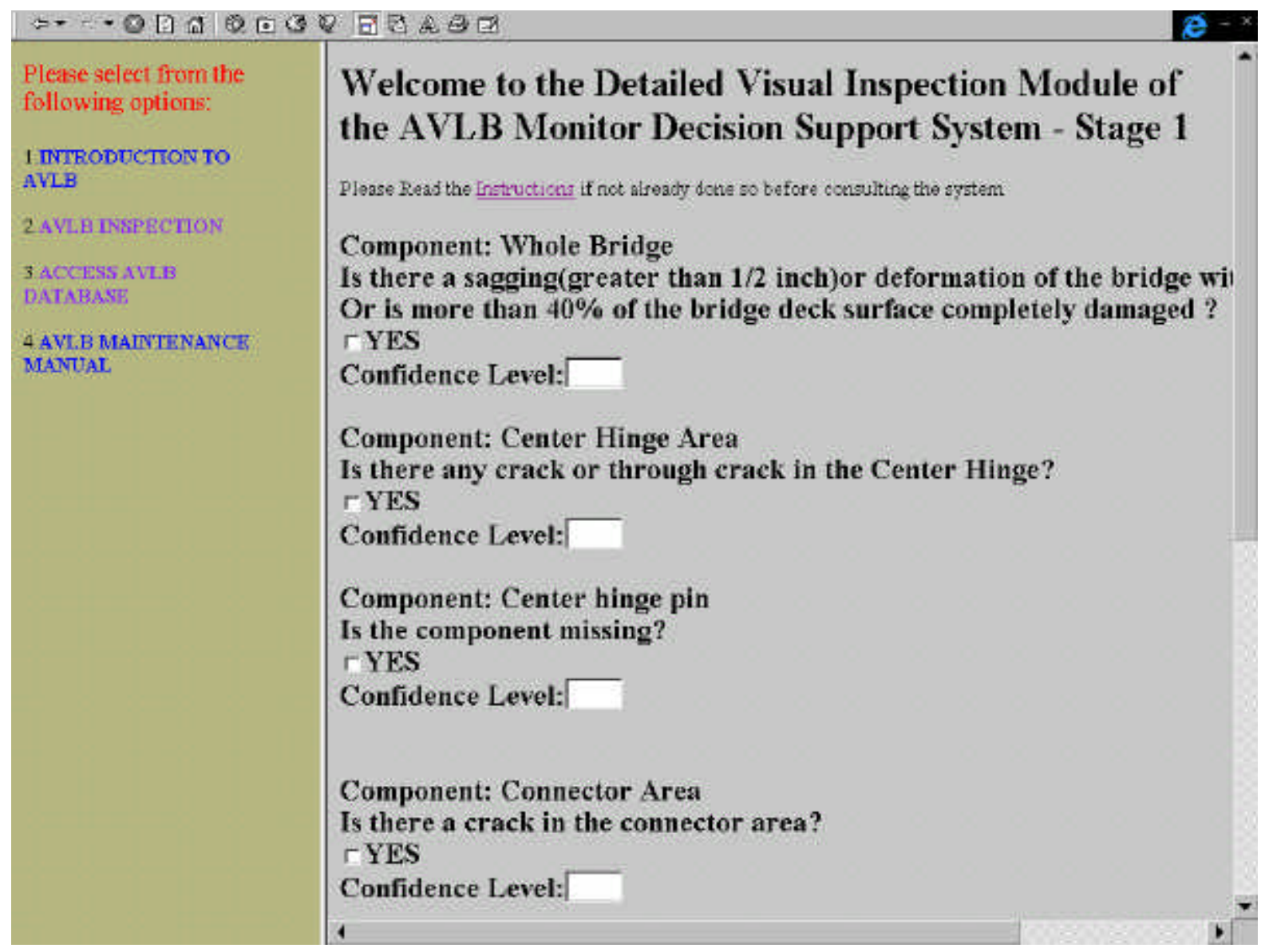

Figure 5.3 First Stage of Visual Inspection Section Consultation

Figure 5.3 shows a screen shot of the first stage of the detailed visual inspection section while under consultation. If any of the boxes at this stage are checked, the system displays one or more message boxes related to the problem and then displays a screen showing the results of the consultation, the bridge status and recommended actions (Figure $5.4)$. 


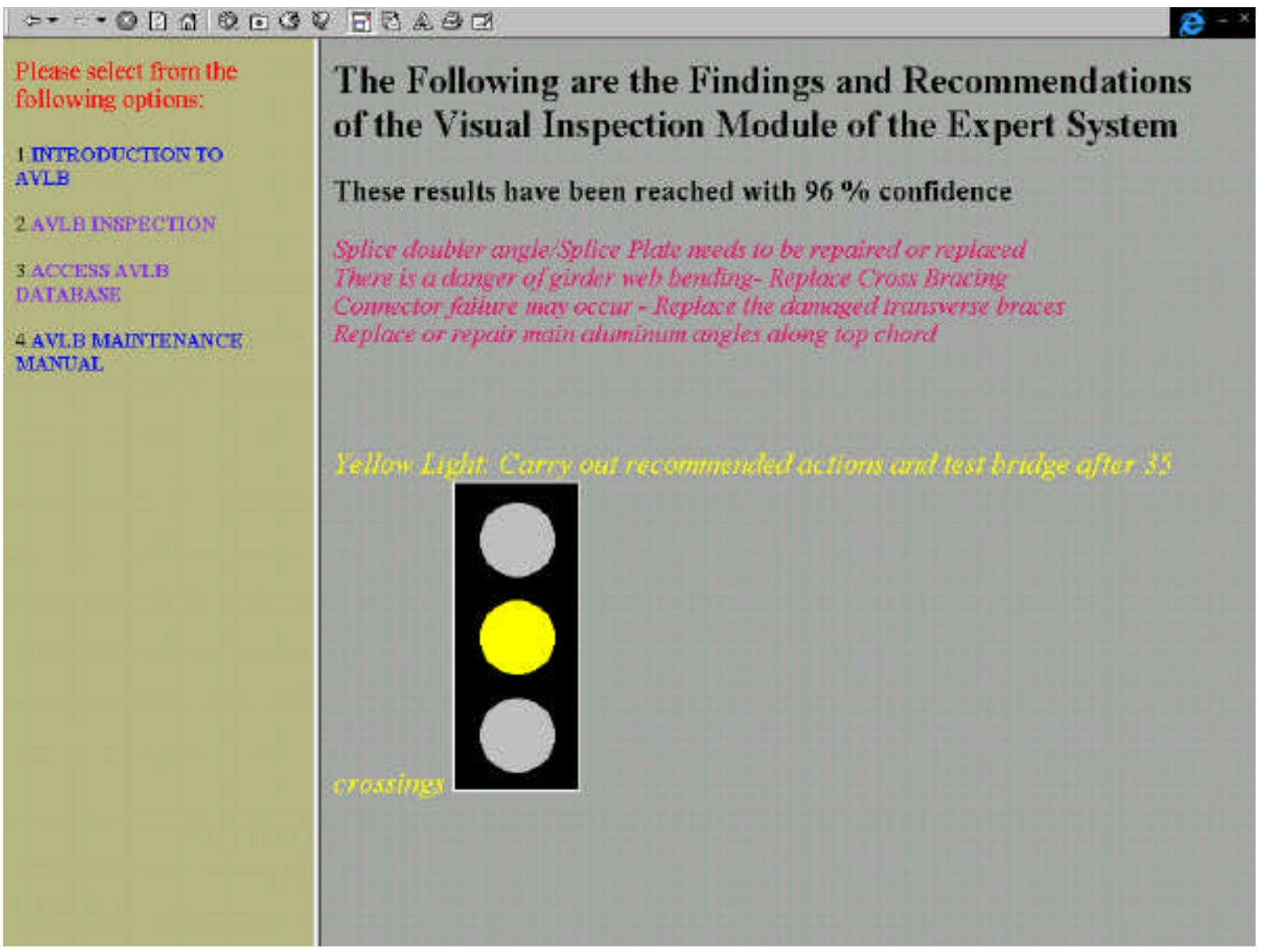

Figure 5.4 Visual Inspection Results

\subsubsection{Consulting the Vibration Inspection Section}

The vibration test result data is read from an ASCII text file directly into the respective textboxes of the interface. Figure 5.5 shows an inspection on a passed AVLB where vibration data has been read from the prepared text file. 


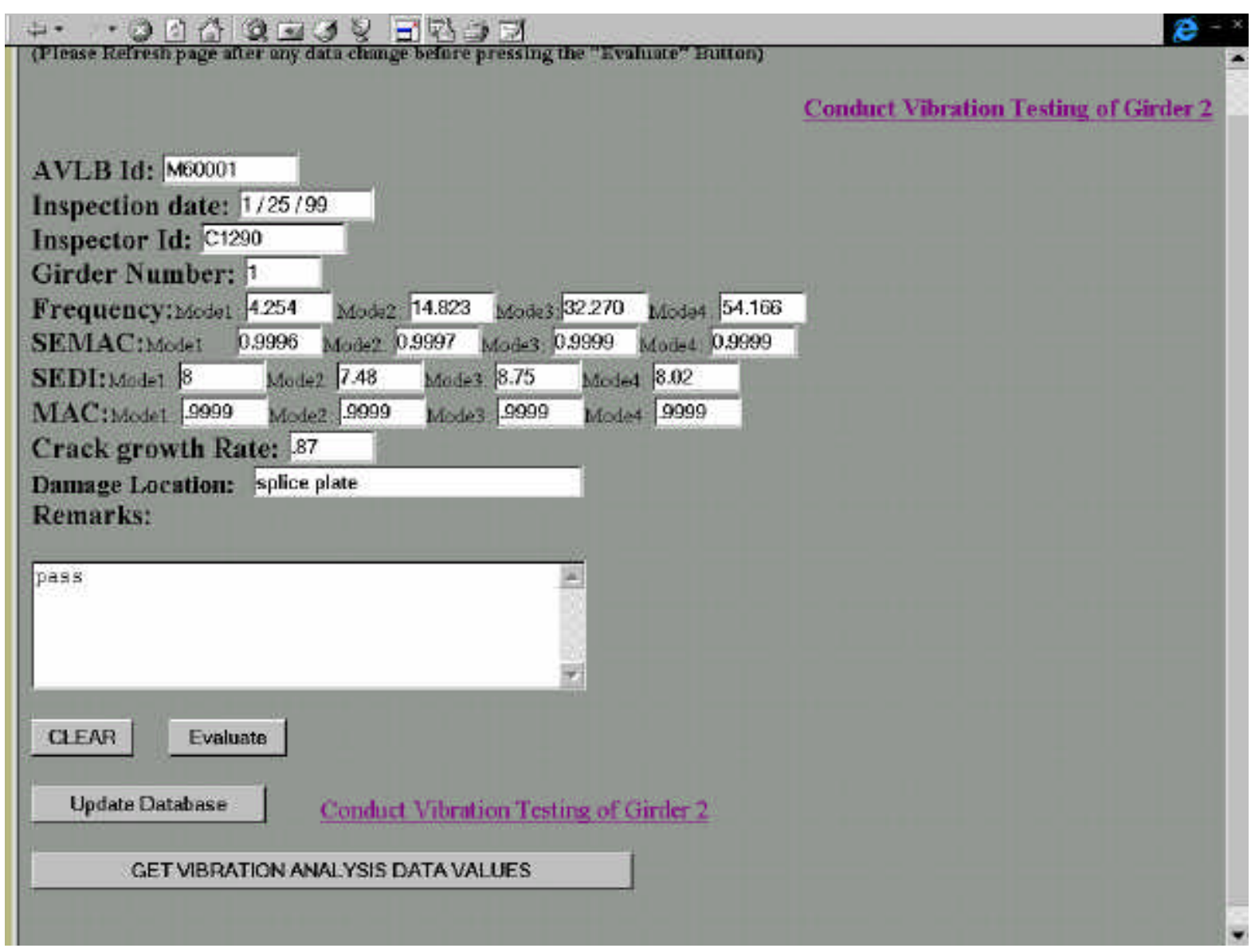

Figure 5.5 Vibration Inspection Section Consultation

When the user presses the evaluate button, the program first checks to see if the data entered in the various text fields are within the expected range and no unexpected characters have been entered. The data are then processed by testing against the various rule bases. If the dynamic characteristics indicate that the structure is in the "red" or "yellow" zone, the program establishes unsafe results and concludes the evaluation. If the data values are in the "green" or safe zone the consultation proceeds to the next screen which is the vibration inspection for girder 2. The inference mechanism thus progressively checks all four girders, and if there is damage indication at any stage a corresponding result is displayed and the evaluation terminated. 


\subsubsection{Execution of the Checks and Maintenance Module}

This module consists of descriptions of the inspection and repair procedures as outlined in the PMCS Manual. This section is a tool to assist and remind the user, the maintenance procedures for any of the components. The instruction window pops up by just clicking on the component in the image map of the bridge. Figure 5.6 shows the instruction window for check and maintenance of a cross brace.

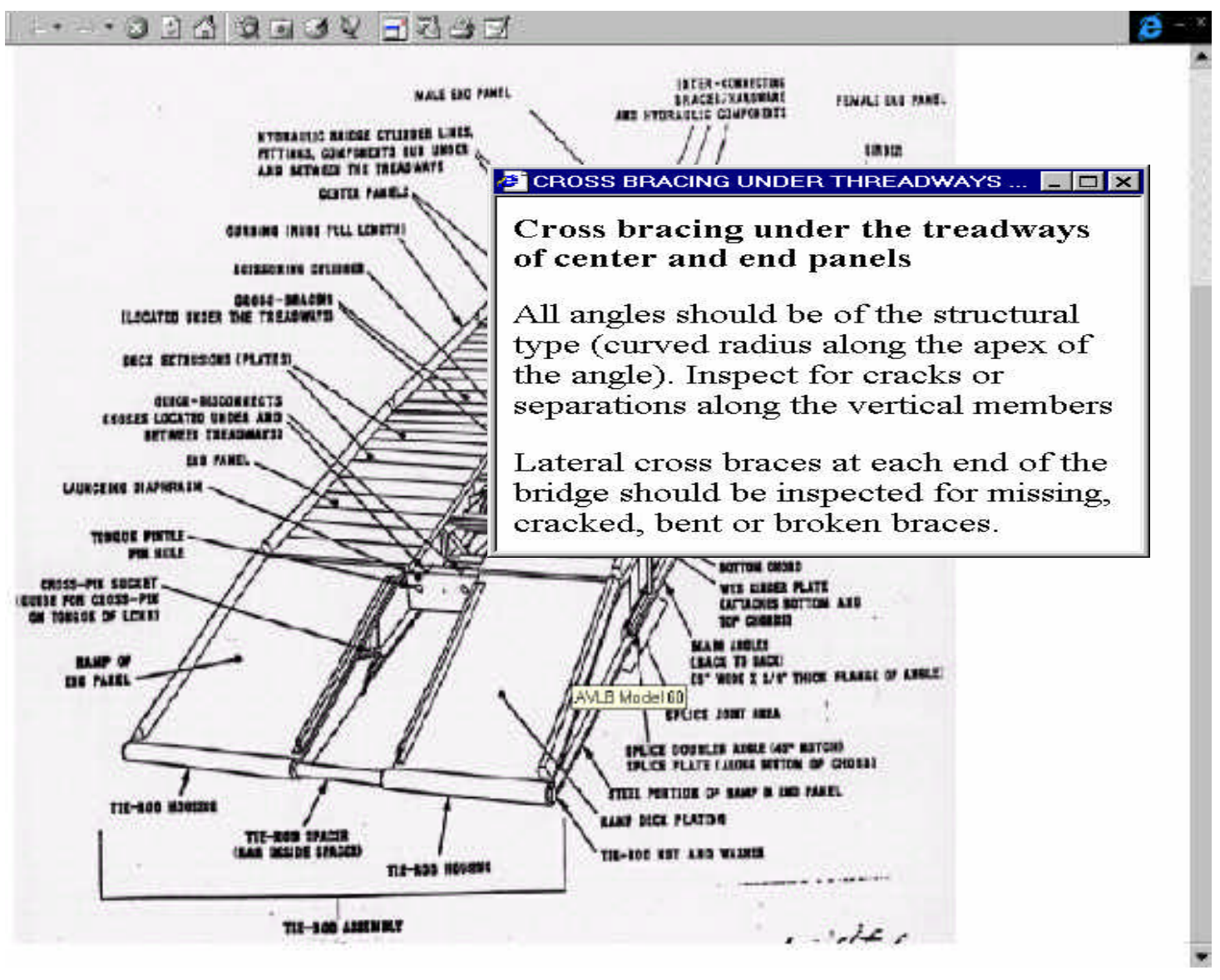




\subsubsection{Execution of the Database Module}

The database module is accessed when inspection data or specific bridge inspection details needs to be appended or retrieved from the AVLB database. The data can be retrieved according to various criteria as per the user requirements and is displayed in a convenient format. On entering the database module, the user is presented with three choices:

1. Updating the database with bridge/inspector data.

2. Searching or querying the database by various criteria.

3. Updating the database with bridge inspection data.

On selecting choice "1" from above, the user is pipelined to another screen to determine if bridge data or inspector data have to be appended. On making a selection the user is again pipelined to a screen with form fields (Figure 5.7) to enter the pertinent data.

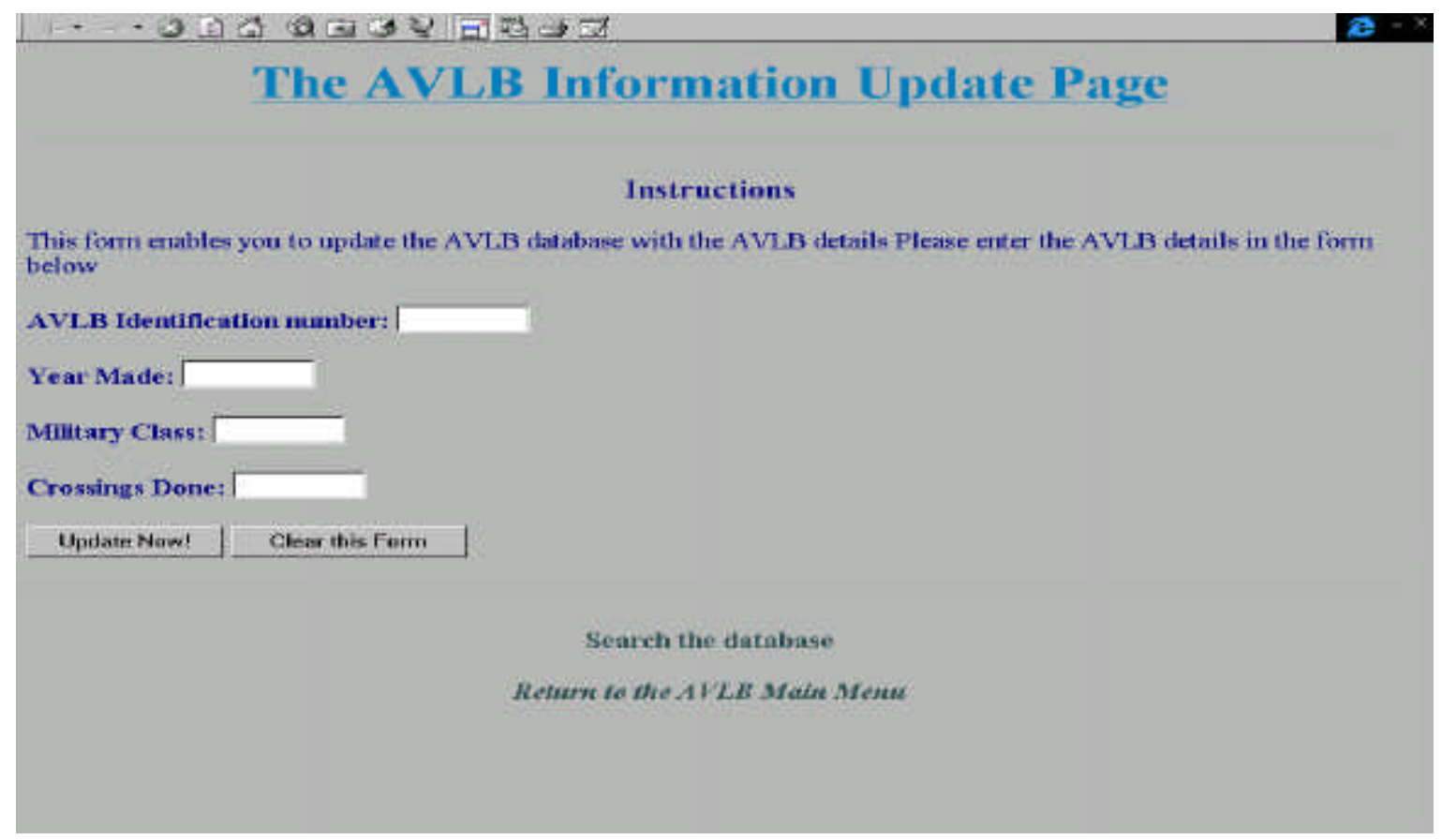

Figure 5.7 AVLB Database Information Update Screen

On selecting choice "2", the user is taken to another screen that displays the various 
criteria by which the AVLB database can be queried (Figure 5.8). Eight options are provided of which the user can select one at a time.

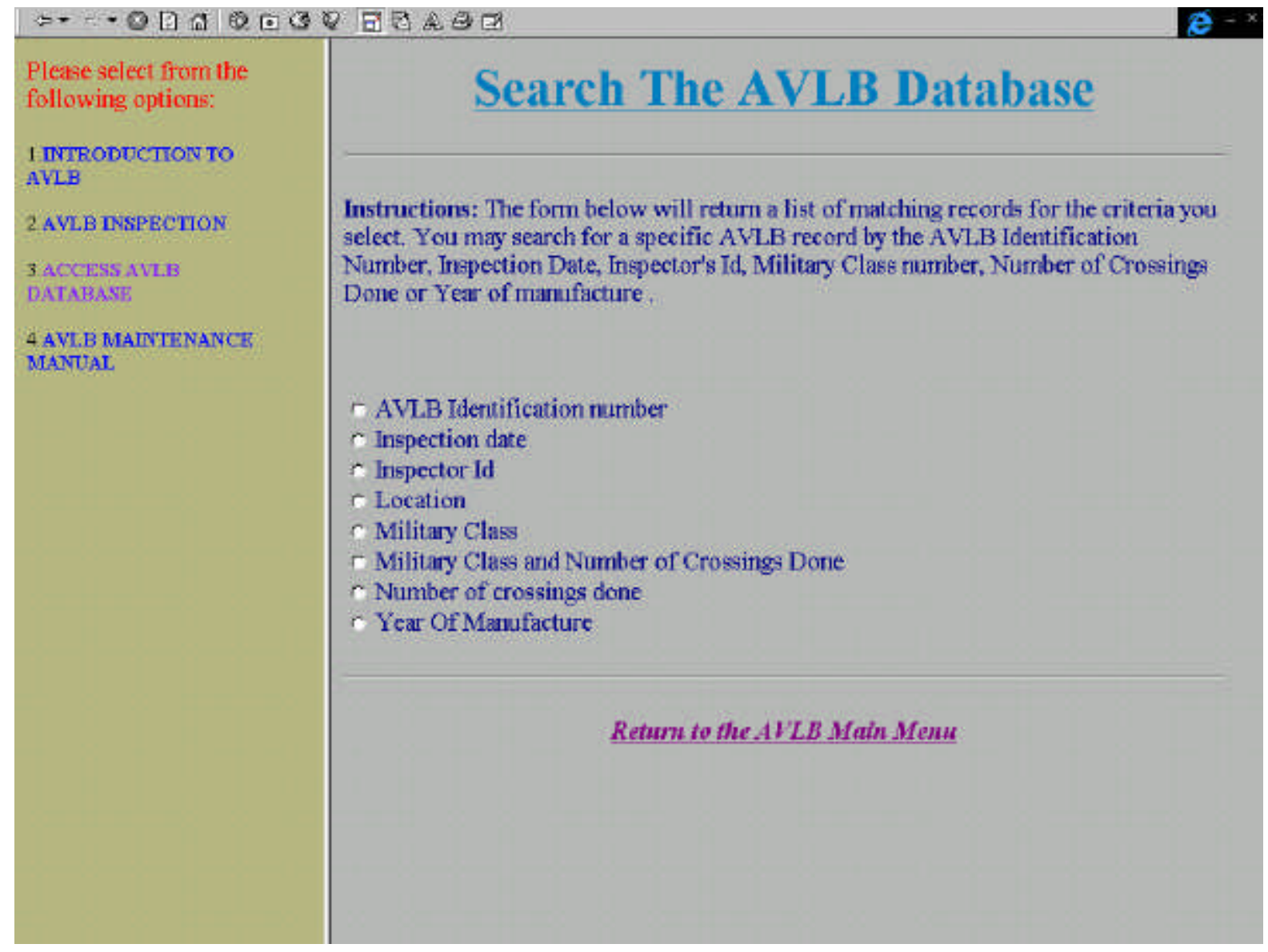

Figure 5.8 AVLB Database Search Screen

As an example, if AVLB identification number is selected as the search criteria, the "AVLB database search by AVLB identification number" screen will be displayed with a text box asking for the AVLB identification number. Figure 5.9 shows the AVLB Database search page where input for AVLB identification number is requested. 


\title{
The AVLB Database Search Pages
}

\author{
Instructions
}

This form enables you to search the AVLB database using the AVLB Identification number as the search criteria Please enter the AVLB Identification number or if you are not sure about the whole ID, just type in the first letter, or first few letters, and records will be retumed which begin with the letter or letters which you type in.

AVLB Identification number: M600

Search Now! Clear this Furm

\section{New Search}

Retum to the AVLB Main Ment

Figure 5.9 Database Querying by AVLB Identification Number.

The AVLB identification number is a six character alphanumeric code beginning with M60 for military class "M60" AVLBs and beginning with M70 for military class "M70" AVLBs. When the user enters the full or partial AVLB identification number, all the records in the database corresponding to AVLB identification number field matching the entry are retrieved. If there are no entries matching the input identification number, the application will display "No matching entries were found in the database". A screen shot of the output when the user inputs M600 in the query text box is shown in Figure 5.10. The results retrieved for the records that match the user input used in this example is displayed. Eight bridge records have been located and retrieved of which three have been shown in the figure. The vertical scroll bar can be used to view all eight records. By further clicking on the 
individual AVLB identification numbers, the actual inspection records for the bridge can be retrieved from the database. The army can change the bridge identification numbers to match their current bridge assignment format.

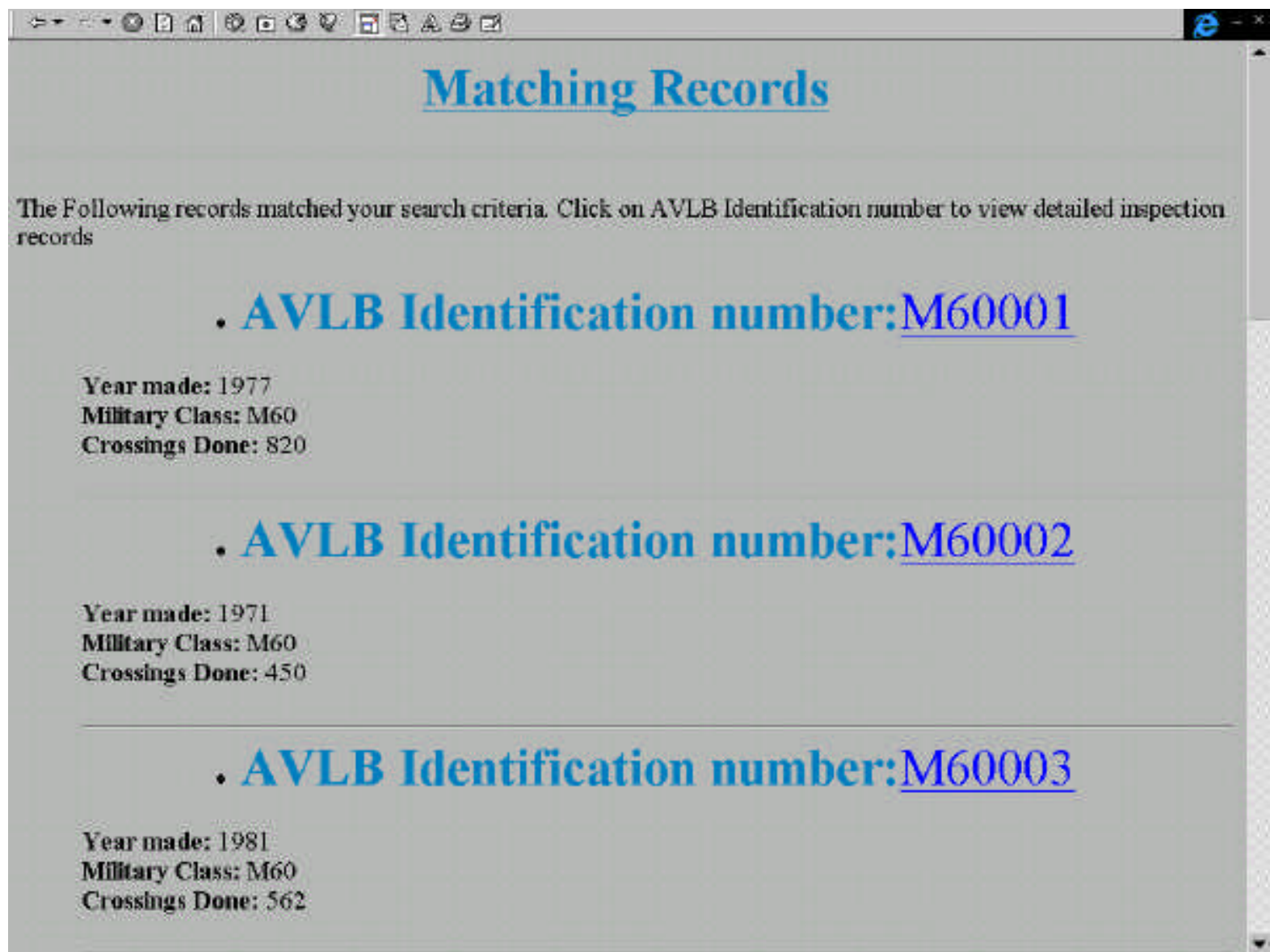

Figure 5.10 Information Retrieved for a User Input Query of M600 in Figure 5.9 


\section{CHAPTER 6}

\section{DISCUSSION}

\subsection{Introduction}

Issues pertaining to the successful implementation of the prototype AVLB-DSS developed are being addressed in this chapter. The discussion relates to areas that are essential to system development. Some areas, such as testing and evaluation of the application could only be carried out to a limited degree due to the evolving nature of the problem.

\subsection{Testing and Evaluation Issues}

Testing and evaluation are important in the successful development of a decision support system. Testing is related to system validation and verification. Verification requires

that the system be built according to its specifications. Validation is the process of determining that the system actually fulfills the purpose for which it was intended. Evaluation reflects the acceptance of the system by the users and its performance in the field. In other words (Wentworth et al., 1995):

Verify to show the system is built right.

Validate to show the right system was built.

Evaluate to show the usefulness of the system.

Testing is carried out to confirm that the DSS is designed to meet its intended objectives. This involves ascertaining that the various modules function in a manner desired 
and the results are satisfactorily close to what is actually expected.

Test scenarios were devised and a study was conducted to test the application for such aspects as reliability, stability and program errors. These scenarios were aimed at detecting logical flaws in the program, bugs in program, and problems that may arise due to specific system settings. A total of ten study cases have been tested and presented in Appendix D.

Evaluation is done to ensure that the system offers an improvement over existing practices including supplementation, the ease of use, maintenance and other such aspects.

\subsubsection{System Verification}

The system requirement for the AVLB-DSS is to develop a condition assessment system capable of determining the structural integrity of the bridge. To address this need, the expert system module has been developed as a part of the larger decision support system. To enhance its function, this module has been devised to combine the already existing visual inspection procedure with the more scientific and reliable damage detection algorithm using structural vibration characteristics. The visual inspection procedure has been stratified in a top-down procedure aimed at carrying out a faster and more pragmatic method of inspection. The system design incorporating these two aspects meet the requirements to a substantial degree, although certain inadequacies remain due to lack of available historic data.

Another important aspect in system verification is to check, if the code accurately reflects the design requirements. In the current work, certain visual and vibration inspection parameters were identified that would be used to assess the structural integrity of the AVLB. It is pertinent here to point out a few issues that might be important but difficult to consider at this point in time, on the basis of available knowledge and tools to measure damage 
effects. In case of visual inspection, there might be other factors such as interaction of damages in two or more secondary structural elements, crack growth rate and fatigue parameters that may indicate structural deterioration, were not considered in the assessment system. In case of vibration inspection, while considering the modal parameters, the bending modes have been identified and studied, but other modes such as torsional modes may be induced in the structure. These modes could also provide vital information about structural deterioration and damage, but were not considered due to the complexity of their identification and behavior interpretation.

The program was coded such that only the acceptable range values can be entered in the text boxes and processed. This prevents incorrect or ambiguous data from being tested against the expert system rule base. It also ensures that only the proper values are stored in the various fields of the database.

Verification of the database module involves ascertaining whether the data storage provisions are adequate. Due to the evolving nature of this work, making a conclusive statement on the adequacy of the data parameters in the database is difficult. However, the database has provision for future modification.

\subsubsection{System Validation}

System validation answers the question "is the right system being built?", "is the knowledge base correct?", or "is the program doing the job that it was intended to do?" Thus, validation is the determination whether the expert system performs the required functions, matching the intended purposes. Typically in expert systems, the scope of the specifications is rarely precise, and it is practically impossible to test a system under all the rare events possible (Wentworth, 1995). Therefore, it is impossible to have an absolute 
guarantee that a program satisfies its specification, only a degree of confidence that a program is valid can be obtained.

The final deliverable system has to be built upon the program features demonstrated in the current system. As more historical data become available and tests are carried out on the AVLB, the program and knowledge base can be expanded, refined to achieve a better integration of the system.

\subsubsection{System Evaluation}

System evaluation should be an ongoing process that needs to be carried out during development to ensure maximum usage of the system when deployed. Although there are no universally accepted standards for evaluation, some of the relevant issues in evaluation are (Wentworth, 1995):

- Check for correctness of results and logic: The fundamental question in defining correctness of an expert system is to ask whether the program works for its intended purpose. Current expert system for evaluating a structure relies on the understanding of the behavior of the structure, its damage processes and finally the ability to define the criticality of a specific damage scenario. While no system can be claimed workable until its field application, in the current system a conservative approach has been used in defining the limit states, ensuring that the structure is not allowed to reach its absolute critical stage. Hence, for the goal of providing safety to the structure, current system is adequate. However, future refinements to the system logic and limit states can be made with availability of more data and these should be further evaluated. 
- Offer improvement over existing practices: Current visual inspection practice requires that the PMCS manual be followed closely. However, a close exam of the manual has revealed that the inspection procedure is based on checking for missing components, broken parts, etc, and not on how it affects the structure in general. The criteria are arbitrary and do not have a distinct hierarchy. By systematically studying the manual, the visual inspection procedure has been reestablished with a top-down hierarchy for decision making, and categorical classification of the procedures into a systematic approach. The addition of the vibration measurement technique, further provides a scientifically based damage assessment. Utilization of the AVLB-DSS would help refine inspection procedure, enhance bookkeeping, cut down potential long-term costs, and promote understanding of AVLB mechanism and design.

- Ease of learning: During system evaluation, simplified instructions for consulting various modules of the AVLB-DSS were provided at all the necessary stages to make the application easy to learn. By trying not to use provocative technical language, the program has been made comprehensible and easy to learn.

- User Friendliness: Some of the essential features that make the program user friendly are, point and click simplicity, objective manner of response elicitation, easy access to various program modules with provision for returning to previous consultation stages, explicit instructions and display of results in a manner understandable to the end-user. These aspects were reviewed during evaluation and improved upon wherever necessary.

- Modifiability: One of the essential aspects to be considered during evaluation was the ease of modifiability of the program so that refinements to the code by future developers would be easy. The program code was made as easy to learn and comprehend as possible 
and remarks about the functioning of different sections of the program code were also provided with a view to simplifying the modification process.

\subsection{Discussion on Existing DSS and Structural Evaluation}

This work which has integrated such diverse fields as decision support systems, expert systems, structural engineering and Internet programming involved thorough literature reviews of the state-of-the-art in these areas. Most of the expert systems and decision support systems in the area of structural assessment have knowledge bases that are developed from literature, expert knowledge and historical data. (Melham et al., 1990; Tazir et al., 1992; Zuk, 1992; Wilson et al., 1994; Avramadis et al., 1995;). Certain systems also had an integrated database module to store inspection or other records and make it available for retrieval when required (Salvaneschi et al., 1995; Males, 1992). Present study also follows suit and developed its knowledge base through expert consultation and literature review. However, under the circumstance that no historical records can be found, current work is limited in its scope and accuracy.

The survey also revealed that a few of the systems developed have uncertainty handling capabilities through confidence factors (Kuprenas, 1996; Mikami, 1994) or by using, the theory of fuzzy sets (Ross et al., 1990; Ogawa, 1985; Yao, 1985). In the present application confidence factors have been used to handle uncertain responses from the user in the visual inspection section. Currently the program uses a simple averaging method to compute the final confidence factor of the result. This can be modified to a weighted average method once the relative importance of the different bridge components has been decided.

In the areas of decision support systems, an increasing number of systems are being 
developed as web-based systems in order to have consistent decision making tools and criteria available throughout the enterprise, from different locations (Department of Defense, 1998; Osmond, 1995). The AVLB-DSS also takes advantage of the Internet, making it possible to collect and update AVLB records from remote locations.

\subsection{Discussion on AVLB System Reliability Concept}

An attempt has been made to assess the possibility of developing a reliability model in order to assess the reliability of the AVLB. Reliability is defined as "the probability that a system or product will perform in a satisfactory manner for a given period when used under specified operating conditions" (Modarres, 1993). In developing such a model, damage states of the bridge would have to be assessed frequently based on available information of measured and recorded data. In addition, information on the damage path and failure behavior of AVLBs as it deteriorates would have to be gathered. In order to develop this model, certain deterministic data, such as the failure rate of the bridge girder, are required. The following is a proposed system reliability concept for AVLB.

In the case of the AVLB wherein a girder by girder vibration inspection is carried out, it is assumed that the four girders form a series configuration of a reliability model. This is based on the worst case scenario, which is under the assumption of the premise that if a single girder fails, the whole bridge would fail. In a system having a series configuration of the reliability block diagram, the functional success is guaranteed only if all its items successfully function during the intended mission time of the system.

Thus if the reliability of girder 1 is represented as $R_{1}$, that of girder 2 is represented as $R_{2}$ and so on, the system reliability $R_{s}$, would be given by 


$$
\mathrm{Rs}=\mathrm{R} 1 . \mathrm{R} 2 . \mathrm{R} 3 . \mathrm{R} 4=\prod_{i=1}^{4} R_{i}
$$

Let the initial reliability of each girder be unity. Thus initially

$$
\mathrm{R}_{\mathrm{s}}=\mathrm{R}_{1} \cdot \mathrm{R}_{2} \cdot \mathrm{R}_{3} \cdot \mathrm{R}_{4}=1 \cdot 1 \cdot 1 \cdot 1=1
$$

Assuming a constant hazard function (mortality rate), $\lambda_{\mathrm{i}}$, for each unit, the system constant failure rate would be:

$$
\lambda_{s}=\sum_{i=1}^{n} \lambda_{i}
$$

By combining Equations (1) and (2), and the constant failure rate reliability model for each unit,

$$
R_{i}(t)=\exp \left(-\int \lambda_{i} t\right)
$$

We get the system reliability as:

$$
R_{s}(t)=e^{-\int_{0}^{t} \lambda_{i} t d t}
$$

The relationship between the reliability of the system with time (in this case number of crossings) is exponential decay. Thus as the number of tank crossings increases, the reliability of the AVLB decreases exponentially (Figure 6.1). 


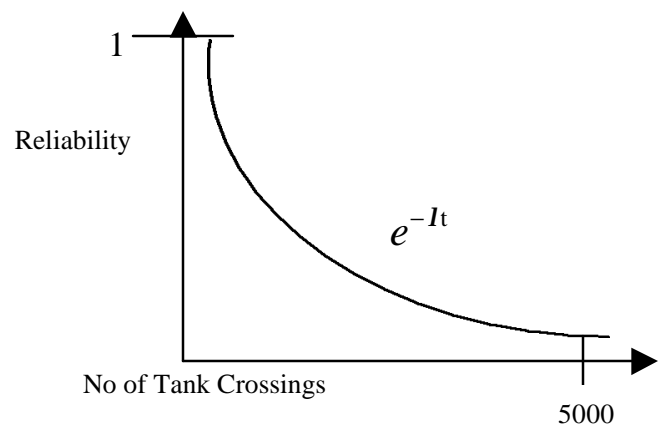

Fig 6.1 Exponential Decay of AVLB Reliability with Increase in Tank Crossings

Assuming average lifetime of AVLB for tank crossings as 5000, Equation (4) can be written as

$$
\mathrm{R}_{\mathrm{s}}(t)=e^{-(1 / 5000) \mathrm{t}}
$$

For the AVLB the failure rate is assumed to be $1 / 5000=0.0002$

Substituting values of total number of tank crossings carried out on an AVLB at any time in Equation (5), the corresponding reliability value can be estimated.

\subsection{Discussion on the Study of Benefit-Cost Analysis of the Project}

An attempt has been made to study the possibility of carrying out a benefit-cost analysis of the present work. Benefit-cost analysis provides a means of determining the extent of usefulness of the current project in terms of dollar value to the sponsoring agency.

In a benefit-cost study of investments, it must be defined precisely what constitutes the user's benefits and sponsor's costs. In this case the user and the sponsor are the same agency. To find out the user's net benefits, the project outcomes must be identified in terms of those that are favorable (benefit) and unfavorable (referred to as disbenefits) to the user. 
Thus

Net user's benefit $=$ Favorable benefits - disbenefits

(Park et al, 1990)

The net cost to the sponsor can be computed by identifying the expenditures required in undertaking and implementing the project:

Net sponsor's cost $=$ Capital cost + operating and maintenance cost.....(7)

In the current study, the benefit would accrue from using the AVLB structure over a longer period of time. On account of a more scientific method available to assess the structural integrity, a more tolerable limit state may be established to avoid premature "deadlining" of AVLB. Some of the benefits that accrue from the successful implementation of the project are increased safety of army personnel using the bridge, increased safety of tanks and other vehicles crossing the bridge and possibly increased active life of the bridge. As these benefits are not tangible ones it is difficult to estimate their value in monetary terms.

For the sake of simplicity, one method although an approximate one, that could be used for estimating the benefit of implementing the AVLB-DSS is as follows:

Assuming the cost of single AVLB is $\mathrm{X}$, and it was designed for 5000 crossings so cost per crossing $=\mathrm{X} / 5000$. Let the average number of crossings after which a bridge was disposed before implementing the system was 3500 crossings. Let the average number of crossings carried out on $\mathrm{N}=800$ bridges were 4000 over a period of time, after implementing the system. Then the benefit associated with implementing the system would be. 


$$
4000\left(\frac{X}{5000}\right)-3500\left(\frac{X}{5000}\right)=0.8 X-0.7 X=0.1 X
$$

Thus benefit B associated with implementing the system for 800 bridges is

$$
\mathrm{B}=800 * 0.1 \mathrm{X}=80 \mathrm{X}
$$

The cost associated with the implementation of the system, C, includes the capital cost $\mathrm{CC}$, incurred in developing the system and the operating and maintenance cost $\mathrm{OM}$ incurred during the same period of time. Thus,

$$
\mathrm{C}=\mathrm{CC}+\mathrm{OM}
$$

The operating and maintenance costs include the cost of maintaining the laser vibration gantry system and the cost of man-hours spent in setting up the inspection system and consulting the condition assessment system.

The project would be considered beneficial if the value of $\mathrm{B}$ is greater than $\mathrm{C}$, in other words if: $80 \mathrm{X}>\mathrm{CC}+\mathrm{OM}$.

In assessing project benefits, an important economic factor to be considered is that of, time value of money. The benefits obtained would increase in value over time due to interest earned on it. If "I" \% is the annual rate of return (interest), then the value of benefit $\mathrm{B}=80 \mathrm{X}$ after $\mathrm{N}$ years would be $80 \mathrm{X}^{*}(1+\mathrm{I} / 100)^{\mathrm{N}}$. The benefits accruing from the project would thus increase each year due to the effect of compounding of interest.

\subsection{Web-based Application Trade-off}

The growth of the World Wide Web over the last few years has seen the emergence of more applications developed as Web-based applications over the Internet or the Corporate 
Intranet. The Internet is based on the client-server model. In the client/server model of computing, data and processing power are distributed on the network between the "clients" and "servers" to the machine most able to perform the function (Laudon, 1998). This model makes it possible for any two machines having a network connection to communicate with each other for storage/retrieval of data, exchange of information and running program scripts. These features of the client/server model, which is manifested in the Internet results in reduced communication costs, enhanced communication and coordination, and accelerated distribution of knowledge. The tradeoffs of web-based applications have been discussed with regard to their advantages and limitations.

\subsubsection{Advantages of Web-Based Applications}

The AVLB-DSS is a web-based application that uses MS Internet Explorer® as the software. The specific advantages associated with using the MS Internet Explorer ${ }^{\circledR}$ webbrowser as the system development environment and deploying the application over the Internet are as follows:

- The web-browser is a free software and is available from the manufacturer as a part of the Windows $\mathrm{O} / \mathrm{S}$ environment.

- It is easy to use and does not require any special skill on the part of the user to be trained in utilizing it, as opposed to custom-built software applications that might require time and effort to get familiarized with.

- The language for programming applications on the web-browser uses a code that can be comprehended easily by a new developer. This feature lends itself suitably for modifying 
and expanding the coding of the DSS application in the future as and when the knowledge base and program have to be refined.

- The application can be used by multiple users simultaneously without having to install software separately on the computer before being able to run it.

- The web-browser software permits easy embedment of a variety of user interface media such as sound, video, graphics, animation, etc which makes it a suitable environment from a futuristic standpoint.

\subsubsection{Limitations of Web-based Applications}

Along with the benefits that accrue from implementing web-based applications, there are also certain drawbacks and limitations associated with them.

- Network Reliability: The area of network technology is complex and networking is highly sensitive to different versions of operating systems and platforms, with some applications requiring specific versions. In deploying the Internet-based AVLB-DSS application, uniformity of operating system and web-browser versions at all locations has to be ensured. The software components required to run the application effectively and trouble-free also need to be available on the client computers.

- Network Security: Security is of paramount importance in Internet applications wherein sensitive and/or classified information is disseminated over networks. Networks provide unauthorized individuals many points of access and opportunities to intercept, modify or steal data over the network. Such manipulation or pilfering of data, as it passes through many computer systems before reaching its destination, could prove dangerous. When the final version of the present system has to be deployed, system administration 
provisions should be strictly enforced to identify people authorized to access and modify different databases and the personnel responsible for maintaining them. 


\section{CHAPTER 7}

\section{CONCLUSIONS AND RECOMMENDATIONS}

\subsection{Conclusions}

A thorough literature review indicated that structural condition assessment was a suitable domain for developing expert systems. Most of the systems known were developed as stand-alone systems primarily to aid structural inspectors in monitoring, diagnosing and assessing the structural integrity of civilian bridges. In most instances, the systems were developed based on deterministic bridge data, knowledge gathered from experts and through heuristic knowledge.

In this study, an expert system was developed as a part of the Decision Support System (DSS) for AVLB. This system would assess the bridge condition based on knowledge gathered from technical manuals, experts, and vibration data, which are synthesized to identify damage or adverse scenarios. AVLB with its different interconnecting hydraulic and structural members is a more complex structure than most civilian bridges, and hence data interpretation and correlation with severity of damage has been found to be quite a daunting task.

The database module of the DSS was developed to facilitate future gathering and analysis of bridge vibration data. The Internet access potential of the system ensures that the inspection data gathered at different test sites could be entered into a central database and accessed by any authorized personnel whenever required.

As a summary, the following key points can be concluded from this study:

- A systematic and scientific DSS for evaluation of the AVLB has been developed.

- An integrated database system is provided for long-term data collection, which could be 
used later to build prediction models for limit state refinements.

- In the absence of historical data, it is difficult to develop an accurate model for predicting bridge life.

- Other important visual and vibration inspection parameters may exist. These visual inspection parameters could be identified from the experiences of engineers involved in the AVLB field operations.

- The system was tested and evaluated for stability of operation, reliability and consistency of results and was found to be working to a satisfactory degree.

\subsection{Recommendations}

The current work represents a system developed within the framework of existing level of AVLB knowledge and bridge data. The development of an expert system is an evolving process wherein initial designs and implementations rarely last. As dynamic tests are carried out on the bridge and more data become available, knowledge about bridge behavior may be refined. These new data should be transformed into structured rules and the code of the reasoning program should be modified. Current program has been designed as a mainly diagnosis system. The program can be extended to become predication type to predict the remaining life of the bridge in terms of number of crossings possible on the bridge at any time. This however requires dedicated acquisition and study of damage index data and other bridge data over a period of time.

Some of the recommendations for future work on developing the DSS include:

- Maintenance of a good record keeping is essential for the success of the AVLB-DSS. As more bridge inspection data become available, theoretical levels of different damage 
indices corresponding to different damage scenarios need to be established. The correlated values can be incorporated into the vibration section program of the expert system module to make the program results more accurate.

- As better understanding of the damage mechanism of the AVLB is developed, integration between visual inspection and vibration inspection sections of the expert system can be done with suitable modifications.

- The data fields in database should be expanded to record information about other parameters that might be deemed pertinent for better AVLB structural evaluation, as and when such parameters are identified.

- Different media such as graphical images of high stress zones, sound, video, charts, animations, etc for expressing ideas, monitoring and display of results in an effective manner, can be embedded with relative ease within the web browser applications, which are important for a more accurate assessment. 


\section{BIBLIOGRAPHY}

American Association of State Highway and Transportation Officials, "Guidelines for bridge management systems", Washington, DC, AASHTO, 1993.

Arlington Software Corporation, "History of Decision Making" Retrieved from the World Wide Web: http://www.arlingsoft.com/history.htm, 1997.

Aktan, A. E., "Modal Testing for Structural Identification and condition assessment of constructed facilities." Proceedings of the 12th Intl. Modal Analysis Conference, 1994, pp. 462-468.

Alampalli, S., Fu, G. and Aziz I.A., "Modal Analysis as a bridge engineering tool"

Proceedings of the 10th Int. Modal Analysis Conference, Vol. 2, 1992, pp. 1359-1366.

Avramidis, I. E. , Manolis, G.D., and Andreadakis, M.G., "PADEX- A preliminary antiseismic design expert system" Computing in Civil and Building Engineering, Pahl and Werner (eds.), Rotterdam, 1995, pp.215-220.

Barnett, D., Jackson, C. and Wentworth, J.A., " Developing Expert Systems," Publication No. FHWA-TS-88 -022, Federal Highway Administration, Washington, D.C., 1988

Barr, A., and Feigenbaum, E.A., (eds.). The Handbook of Artificial Intelligence, volume 1, William Kaufmann Inc., Los Altos, CA, 1981.

Bentley, K., "Freeway to the Future", Civil Engineering, ASCE, Vol. 68(6), 1998, pp. 58-61.

Bielawski, L., Lewland, R., Expert Systems Development: Building PC-Based applications, QED Information sciences, Inc. Wellesly, Ma, 1988.

Borphy, K., Koets, T., Teach Yourself VbScript in 21 days, Sams Publishing, 1996.

Buchanan, B.G., and Shortliffe, E.H., Rule-Based Expert Systems: The MYCIN Experiments of the Stanford Heuristic Programming Project, Addison Wesley Publishing Company, Reading, MA, 1984.

Carrico, M.A., Girard, J.E., Jones, J.P., Building Knowledge Systems: Developing and Managing Rule Based Applications, McGraw Hill Book Company, NY, NY, 1989.

Chen S.E., Venkatappa, S., Petro, S.H., GangaRao, H.V.S., "Bridge Vibration Sensor System," Phase I, Final Report, TACOM, Warren, MI, 1997.

Chen S.S. and Ballard, C.M., "Retrofit Design Verification via In-Service Monitoring Over the Internet: A Case Study", in Information Processing in Civil and Structural Engineering Design, B. Kumar, Editor, Civil-Comp Press, 1996, pp.183-187. 
Cho, N.K., "Final Report Preproduction for Qualification Test of the Armored Vehicle Launched Bridge MLC 70 Upgrade Program. " Report number CSTA - 7567, 1994.

Department of Defense, "CPMS Expert System Beta Test Site" Retrieved from the World Wide Web: http://www.cpms.osd.mil:8080/Wren/menu.htm, 1998.

Drain, L.E., The Laser Doppler Technique, John Wiley \& Sons, NY, NY, 1980.

Duda, R.O. and Rene, R., "AI and Decision Making: The PROSPECTOR experience." In Artificial Intelligence Applications for Business, W. Reitman. Norwood, NJ, Ablex Publishing Corp., 1984.

Durrans, R.F., Osgood, C., Threlfall, D.C. and Whitton, P.N., "The Engineering Assessment Workbench", in Structural Integrity Assessment, P. Stanley, Editor, Elsevier Science Publishers Ltd., 1992, pp. 193-202.

Foghlu, M.O., Perl 5 Quick Reference, Que Corporation, Indianapolis, IN, 1996.

Fuhr, P. L., Huston, D. R., Ambrose, T. P., Mowat, E. F., "INTERNET monitoring of an instrumented civil structure", in Smart Structures and Materials 1995: Smart Structures for Bridges, Structures and Highways, L. K. Matthews, Editor, Proceedings of SPIE - Smart Structures and Materials, Vol. 2446, 1995, pp. 301-306.

Goodier, A. and Matthew's, S., "Knowledge Base systems Applied to Real-Time Structural Monitoring", in Information Processing in Civil and Structural Engineering Design, Editor B.Kumar, Civil-Comp Press, 1996, pp. 263-270.

Harmon, P., King, D., Expert Systems: Artificial Intelligence in Business, John Wiley \& Sons Inc, NY, 1985.

Hayes Roth, F., Waterman, D.A., Lenat, D.B.,(eds.), Building Expert Systems, AddisonWesley Publishing Company, Inc., Reading, MA., 1983.

Henry, G., Inge, J., and Cruz, J.D. "Addendum to the final report for First Article Test Goverment (FAT-G) of the Military Load Class 70 Armored Vehicle Launched Bridge." Report number ATC- 7865, US Army, 1996.

Kaplan, D.J., Krishnan, R., Padman, R. and Peters, J., Accounting Information System DSS. Retrieved from the World Wide Web: http://howland.heinz.cmu.edu/ djk/ais.html, 1998.

Kraft, A., "XCON: An Expert Configuration system at Digital Equipment Corporation". In The AI Business: The Commercial Uses of artificial Intelligence, edited by P. H. Winston and K. A. Prendergast. The MIT Press, Cambridge, MA, 1984. 
Kunz, J.C., Kehler T.P., and Williams, M.D., "Applications Development Using a Hybrid AI Development System." AI Magazine, Vol. 5 (3), 1984.

Kuprenas, J.A. and Manios, J., "A Knowledge-based system for the Evaluation of Earthquake Damaged Structures", Building an International Community of Structural Engineers, Vol.2, Proceedings of Structures Congress XIV, pp.742-749, Chicago, IL, 1996.

Laudon, K.C., and Laudon, J.P., Management Information Systems: New Approaches to Organization and Technology, Prentice Hall Inc, Upper Saddle River, NJ, 1998.

Liebowitz, J., The Dynamics of Decision Support Systems and Expert Systems, Dryden Press, Hinsdale, IL, 1990.

Logic Programming Associates, "LPA Flex", Retrieved from the World Wide Web http://www.lpa.co.uk/flx.html, 1997.

McDermott, J., "R1: The Formative years." AI Magazine, Vol. 2 (2), 1981.

Males, R.M., Cyle, J.A., Grayman, W.M., Clark, R.M., Borchers, H.J., Hertz, B.G., "Knowledge Acquisition for an Expert System for Handling Inquiries on Water Quality" in Knowledge Acquisition in Civil Engineering, Arciszewski, T. and Rossman, L.A. (eds.), ASCE, 1992.

Melham, H.G., and Wentworth, J.A., "FASTBRID: An Expert System for Bridge Fatigue", Public Roads, Vol. 53 (4), 1990, pp. 109-117.

Mikami, I., Tanaka, S., Kurachi, A., "Expert System with Learning ability for Retrofitting Steel Bridges", Journal of Computing in Civil Engineering, Vol.8 (1), 1994, pp.88-102.

Miyamoto, A., Sakamoto, M., Konishi, H., Yasuda, K., "A knowledge based system for risk management in construction works of steel bridge", in Computing in Civil and Building Engineering, Pahl and Werner (eds.), Rotterdam, 1995, pp.1557-1564.

Modarres, M., What every engineer should know about reliability and risk analysis, M. Dekker, NY, 1993.

Multilogic Inc., "Multilogic Rapid Application Development". Retrieved from the World Wide Web: http://multilogic.com/software/default.cfm, 1997.

NASA, CLIPS Ver. 6.0 Reference Manual, Software Technology Branch, Lyndon B. Johnson Space Center, Houston, 1993.

Ogawa, H., Fu, K.S., and Yao, J.T.P., "An Inexact Inference for Damage Assessment of Existing Structures", International Journal of Man-Machine Studies, Vol. 22(3), 1985, pp.295-306. 
Osmond, D.L., Line, D.E., Gale, J.A., Gannon, R.W., Knott, C.B., Bartenhagen, K.A., Turner, M.H., Coffey, S.W., Spooner, J., Wells, J., Walker, J.C., Hargrove, L.L., Foster, M.A., Robillard, P.D. and Lehning, D.W., WATERSHEDSS: Water, Soil and HydroEnvironmental Decision Support System. Retrieved from the World Wide Web: http://h2osparc.wq.ncsu.edu, 1995.

Park, C.S., and Sharp-Bette, G.P., Advanced Engineering Economics, John Wiley \& Sons, Inc., NY, 1990

Pople, H.E., Myers, J.D., and Miller, R.A., "DIALOG: A model of diagnostic logic for internal medicine". In Proceedings of the Fourth International Joint Conference on Artificial Intelligence, 1975, pp.848-855.

Power, D.J., DSS Research Resources. Retrieved from the World Wide Web: http://dss.cba.uni.edu/glossary/dssglossary.html, 1997.

Proffer, W.J., "Cyberdream come true", Traffic Technology International, UK \& International Press, Feb/Mar 1998, pp. 24.

Ross, T. J., Sorensen, H. C., Savage, S. J. and Carson, J. M., "DAPS: Expert System for Structural Damage Assessment", Journal of Computing in Civil Engineering, Vol.4, 1990, pp.327-348.

Salane, H.J., Baldwin, J.W., "Identification of Modal Properties of Bridges", Journal of Structural Engineering, ASCE, Vol. 116(7), 1990, pp.2008-2021.

Salvaneschi, P., Cadei, M. and Lazzari, M., "Artificial intelligence, monitoring and evaluation of structures: Examples and lessons learned", in Computing in Civil and Building Engineering, Pahl and Werner (eds.), 1995, pp.949-953.

Sawyer, B., VP-Expert-Rule Based Expert System Development Tool, WordTech Systems Inc., 1995.

SDRC, "Final Report on Acquisition of Frequency Response Data on an Armored Vehicle Launched Bridge." SDRC Project Number 19558 submitted to CFC, WVU, internal report, 1997.

Shirole, A.M., "Bridge management to the year 2000 and beyond." Transportation Research Circular, Vol. 423, 1994, pp.150-153.

Shirole, A.M., Winkler, W.J. and Hill, J.J. "Bridge management systems -- state of the art" Transportation Research Record, Vol. 1290, 1991, pp.149-156.

Shirole, A.M., Winkler, W.J. and Fitzpatrick, M.W. "Bridge management decision support", Transportation Research Circular, Vol. 423, 1994, pp.27-34. 
Stapleton, A., "Interpreted vs. Compiled: Selecting a programming Language" Retrieved from the World Wide Web: http://slis-two.lis.fsu.edu/ program/, 1998.

Tazir, Z., Pagnoni, T. and Gavarini, C., "Knowledge Acquisition for post-earthquake usability decisions" in Knowledge Acquisition in Civil Engineering, Arciszewski, T. and Rossman, L.A. (eds.), ASCE, 1992, pp. 147-168.

Teknowledge Corporation, "M4 Expert Software" Retrieved from the World Wide Web: http://www.teknowledge.com/M4, 1997.

Thierauf, R.J., User Oriented Decision Support Systems: Accent on Problem Finding, Prentice Hall, Inc., Englewood Cliffs, NJ, 1988.

US Army, "TM 5-5420-203-14, Technical Manual: Operator's, Unit, Direct Support, and General Support Maintenance for Bridge, Armored Vehicle Launched: Scissoring Type: Class 60 and Class 70 Aluminum; 60 Foot Span; For M48A5 and M60 Launcher, MLC60 and MLC 70", Headquarters, Department of The Army, Washington, D.C., 1990.

US Army, "Armored Vehicle Launched Bridge System". Internal Report, Headquarters, Department of the Army, 1995.

Venkatappa, S. G., "Damage detection using vibration measurements", thesis presented to West Virginia University, Morgantown, WV, in partial fulfillment of the requirements for the degree of Master of Science, 1997.

Wilson, J.L. and Wagaman, S.J., "Bridge Evaluation Using A Hybrid Information System", in Proceedings of Structures Congress XII, ASCE, Vol. 2, 1994, pp.1131-1136.

Wentworth, J.A., Knaus, R., Aougab, H., Verification, Validation and Evaluation of Expert Systems, FHWA Handbook, Volume 1, 1st Edition, Ver 1.2, Retrieved from the World Wide Web http://www.tfhrc.gov/advanc/vve/toc.htm, 1995

Yao, J. T. P., Safety and reliability of existing structures, Pitman Publishing Inc., MA, 1985.

Zuk, W., "Expert System for Determining the Disposition of Older Bridges" Transportation Research Record, Vol.1290, 1992, pp. 145-148. 


\section{APPENDIX - A \\ VP-Expert Program Code for the Initial Prototype System}

The initial portion of this effort consisted of developing a prototype expert system to demonstrate the capabilities and the suitability of expert system. This expert system application was developed using VP-Expert (Sawyer, 1995), an expert system shell. VPExpert is a software package running under the DOS operating system environment and interacts with Lotus 123 spreadsheet program files.

The prototype program is a system consisting of:

8 knowledge base program files $(* . \mathrm{kbs})$

1 worksheet file $(* . w k 1)$

4 ASCII text files

The ASCII text files are used to store variable values and pass them from one file to another. The worksheet file contains limit state values of the modal parameters and can be retrieved by the program to test against the user input values.

The code of the program files is presented below.

\section{Bgrmain.Kbs}

[This file asks the user for the identification number of the model whose testing has to be carried out and extracts the corresponding limit state values of the modal parameters from the worksheet file.]

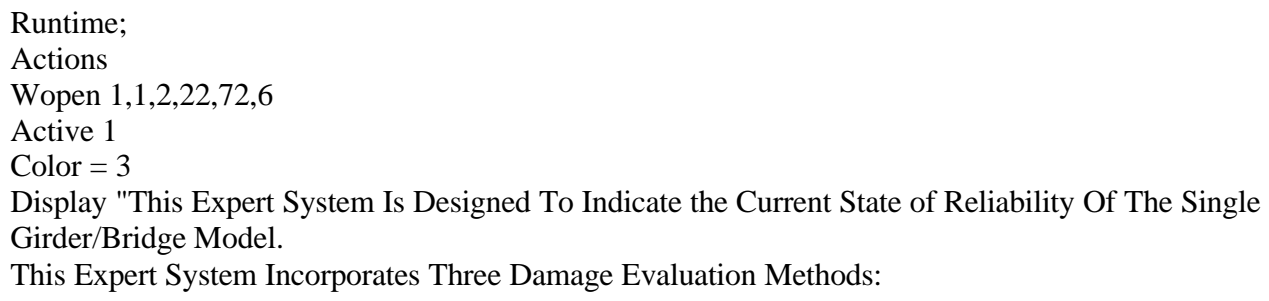


1. Vibration Testing

2. Visual Inspection

3. Fracture Analysis

Based On The Parameters Derived From The Inspections And Prescribed Limit States The System Algorithm Will Provide Predictions Of The Damage State Of The Bridge.

Press Any Key To Begin Consultation. "

\section{Wclose 1}

Wopen 2,2,4,18,68,5

Active 2

Color $=10$

Find Info

Cls;

Rule A

If Modelno $=$ Modela

Then Info $=\mathrm{Ok}$

Wks Freq,B2..B6,Brexp1

For $\mathrm{X}=1$ To 5

$\operatorname{In}[\mathrm{X}]=($ Freq $[\mathrm{X}])$

End

Wks Dratio,B7..B11,Brexp1

For $\mathrm{Y}=1$ To 5

$\operatorname{Idr}[\mathrm{Y}]=($ Dratio $[\mathrm{Y}])$

End

Wks Sediff,B12..B16,Brexp1

For $\mathrm{Z}=1$ To 5

Ised $[Z]=($ Sediff $[Z])$

End

Wks Modalac,B17..B21,Brexp1

For $\mathrm{P}=1$ To 5

$\operatorname{Imac}[\mathrm{P}]=($ Modalac $[\mathrm{P}])$

End

Savefacts Home

Chain Brgr1;

Rule B

If Modelno $=$ Modelb

Then Info $=\mathrm{Ok}$

Wks Freq,C2..C6,Brexp1

For $\mathrm{X}=1$ To 5

$\operatorname{In}[\mathrm{X}]=($ Freq $[\mathrm{X}])$

End

Wks Dratio,C7..C11,Brexp1

For $\mathrm{Y}=1$ To 5

$\operatorname{Idr}[\mathrm{Y}]=($ Dratio $[\mathrm{Y}])$

End

Wks Sediff,C12..C16,Brexp1

For $Z=1$ To 5

Ised $[Z]=($ Sediff $[Z])$

End

Wks Modalac,C17..C21,Brexp1

For $\mathrm{P}=1$ To 5

$\operatorname{Imac}[\mathrm{P}]=(\operatorname{Modalac}[\mathrm{P}])$

End

Savefacts Home

Chain Brgr1;

Rule C

If Modelno $=$ Modelc

Then Info $=\mathrm{Ok}$

Wks Freq,D2..D6,Brexp1

For $\mathrm{X}=1$ To 5 


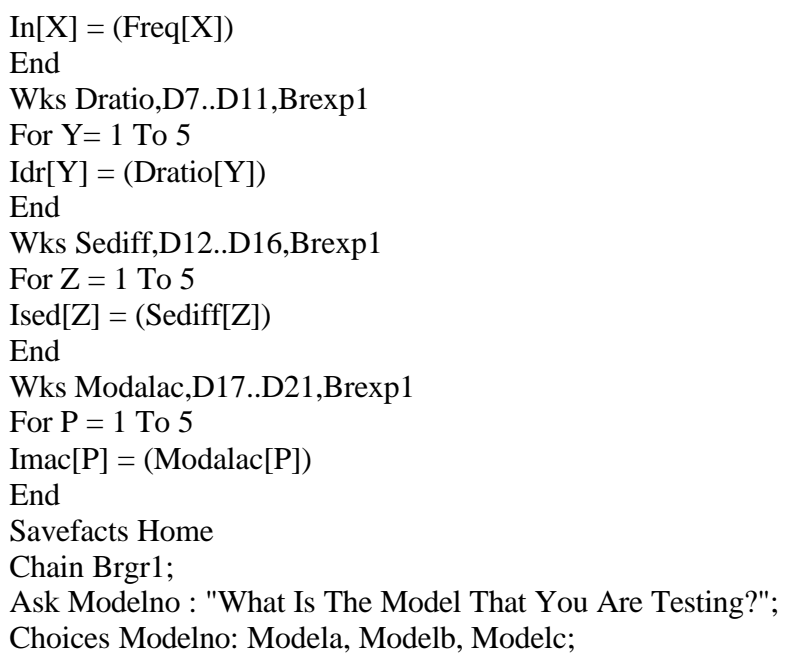

\section{Brgr1.Kbs}

[This file asks the user to input the frequency values and damping ratio values of the single-girder bridge model being tested and checks them against the rules in the knowledge base.]

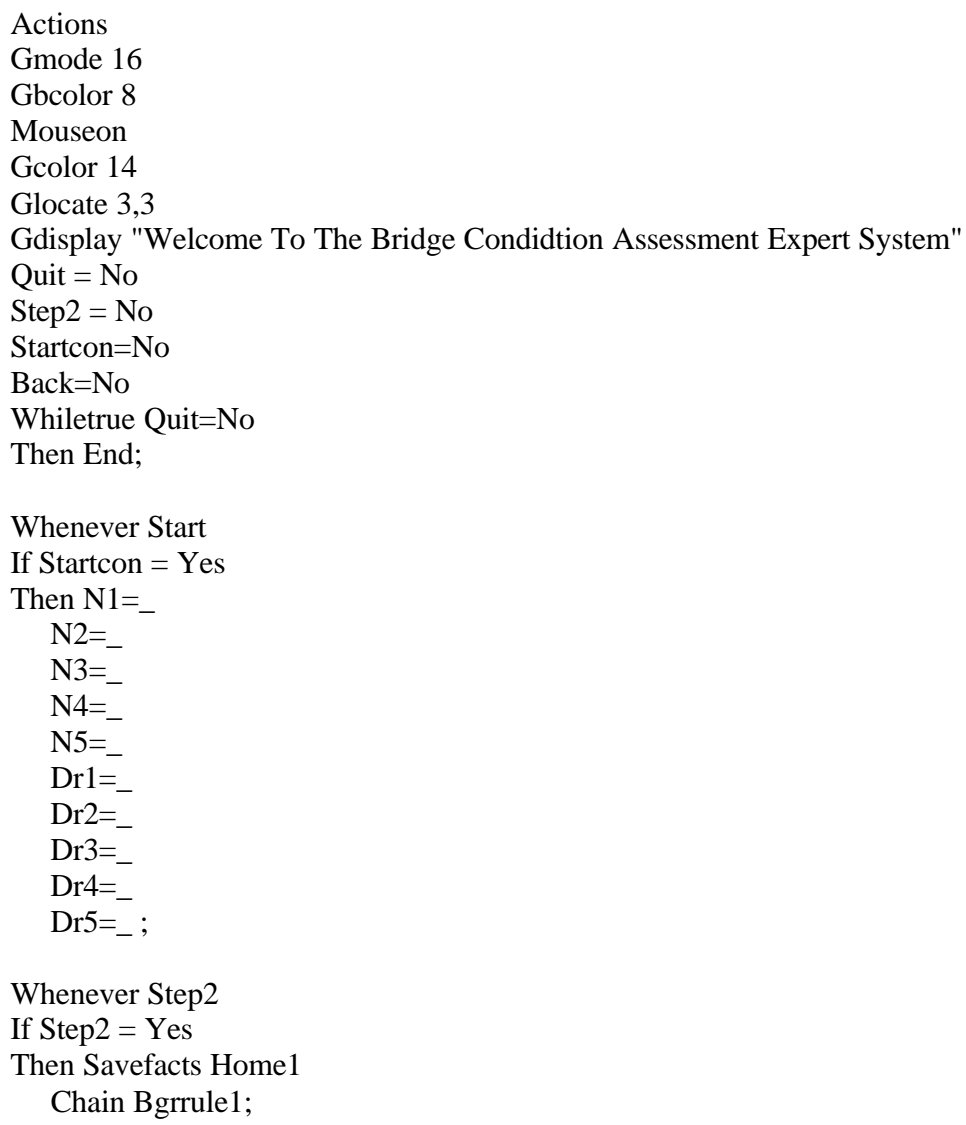

Whenever Step2

If Step2 = Yes

Then Savefacts Home1 Chain Bgrrule1; 
Formfield N1:30,8,4,12;

Ask N1:"Enter Freq.Of First Mode ";

Formfield N2:30,10,4,12;

Ask N2:"Enter Freq.Of Second Mode";

Formfield N3:30,12,4,12;

Ask N3:"Enter Freq.Of Third Mode ";

Formfield N4:30,14,4,12;

Ask N4:"Enter Freq.Of Fourth Mode";

Formfield N5:30,16,4,12;

Ask N5:"Enter Freq.Of Fifth Mode ";

Formfield Dr1:69,8,4,12;

Ask Dr1:"Enter Damp.Ratio Of First Mode ";

Formfield Dr2:69,10,4,12;

Ask Dr2:"Enter Damp.Ratio Of Second Mode";

Formfield Dr3:69,12,4,12;

Ask Dr3:"Enter Damp.Ratio Of Third Mode ";

Formfield Dr4:69,14,4,12;

Ask Dr4:"Enter Damp.Ratio Of Second Mode";

Formfield Dr5:69,16,4,12;

Ask Dr5:"Enter Damp.Ratio Of Third Mode ";

Lbutton Startcon:20,5,9,11,Start_Consultation;

Lbutton Step2:10,21,9,11,To_The_Next_Page;

Lbutton Quit:70,21,9,11,Done;

\section{Bgrrule1.Kbs}

[This file checks the user input frequency and damping ratio values of the single girder bridge model being tested and checks the input values against the rules in the knowledge base.]
Actions
Loadfacts Home
Loadfacts Home1
Find Tempn 1
Find Tempn2
Find Tempn3
Find Tempn 4
Find Tempn5
Find Tempdr1
Find Tempdr2
Find Tempdr3
Find Tempdr4
Find Tempdr5
Savefacts Home1
Chain Brgr2;
Rule 1
If N1 < $=\left(0.98^{*} \operatorname{In}[1]\right)$
Then Tempn1 = Red;
Rule 2
If $\mathrm{N} 1>(0.98 * \operatorname{In}[1])$
And N1 < $=(0.99 * \operatorname{In}[1])$
Then Tempn $1=$ Yellow
Else Tempn 1 = Green; 
Rule 3

If N2 < $=(0.98 * \operatorname{In}[2])$

Then Tempn 2 = Red;

Rule 4

If $\mathrm{N} 2>(0.98 * \operatorname{In}[2])$

And N2 < $(0.99 * \operatorname{In}[2])$

Then Tempn 2 = Yellow;

Rule 5

If $\mathrm{N} 2>(0.99 * \operatorname{In}[2])$

Then Tempn2 = Green;

Rule 6

If $\mathrm{N} 3<=(0.98 * \operatorname{In}[3])$

Then Tempn3 = Red;

Rule 7

If $\mathrm{N} 3>(0.98 * \operatorname{In}[3])$

And N3 < = $(0.99 * \operatorname{In}[3])$

Then Tempn3 = Yellow;

Rule 8

If N3 > $(0.99 * \operatorname{In}[3])$

Then Tempn3 = Green;

Rule 9

If $\mathrm{N} 4<=(0.98 * \operatorname{In}[4])$

Then Tempn4 = Red;

Rule 10

If $\mathrm{N} 4>(0.98 * \operatorname{In}[4])$

And N4 < $(0.99 * \operatorname{In}[4])$

Then Tempn4 = Yellow;

Rule 11

If N4 > $(0.99 * \operatorname{In}[4])$

Then Tempn4 = Green;

Rule 12

If N5 < $=(0.98 * \operatorname{In}[5])$

Then Tempn5 = Red;

Rule 13

If N5 > $(0.98 * \operatorname{In}[5])$

And N5 < $(0.99 * \operatorname{In}[5])$

Then Tempn5 = Yellow;

Rule 14

If N5 > $(0.99 * \operatorname{In}[5])$

Then Tempn5 = Green;

Rule 15

If $\operatorname{Dr} 1<(0.98 * \operatorname{Idr}[1])$

Then Tempdr1 = Red;

Rule 16

If $\operatorname{Dr} 1>=(0.98 * \operatorname{Idr}[1])$

And Dr1 < $(0.99 * \operatorname{Idr}[1])$

Then Tempdr1 = Yellow; 
Rule 17

If $\operatorname{Dr} 1>=(0.99 * \operatorname{Idr}[1])$

Then Tempdr1 = Green;

Rule 18

If $\mathrm{Dr} 2<\left(0.98^{*} \operatorname{Idr}[2]\right)$

Then Tempdr2 = Red;

Rule 19

If Dr2 > $=(0.98 * \operatorname{Idr}[2])$

And Dr2 < $(0.99 * \operatorname{Idr}[2])$

Then Tempdr2 = Yellow;

Rule 20

If Dr2 > $=(0.99 * \operatorname{Idr}[2])$

Then Tempdr2 = Green;

Rule 21

If Dr3 < $(0.98 * \operatorname{Idr}[3])$

Then Tempdr3 = Red;

Rule 22

If $\operatorname{Dr} 3>=(0.98 * \operatorname{Idr}[3])$

And Dr3 < $(0.99 * \operatorname{Idr}[3])$

Then Tempdr3 = Yellow;

Rule 23

If $\operatorname{Dr} 3>=(0.99 * \operatorname{Idr}[3])$

Then Tempdr3 = Green;

Rule 24

If $\operatorname{Dr} 4<(0.98 * \operatorname{Idr}[4])$

Then Tempdr4 = Red;

Rule 25

If $\operatorname{Dr} 4>=(0.98 * \operatorname{Idr}[4])$

And Dr4 < $(0.99 * \operatorname{Idr}[4])$

Then Tempdr4 = Yellow;

Rule 26

If $\operatorname{Dr} 4>=(0.99 * \operatorname{Idr}[4])$

Then Tempdr4 = Green;

Rule 27

If Dr5 < $(0.98 * \operatorname{Idr}[5])$

Then Tempdr5 = Red;

Rule 28

If $\operatorname{Dr} 5>=(0.98 * \operatorname{Idr}[5])$

And Dr5 < $(0.99 * \operatorname{Idr}[5])$

Then Tempdr5 = Yellow;

Rule 29

If Dr5 > $=(0.99 * \operatorname{Idr}[5])$

Then Tempdr5 = Green; 


\section{Brgr2.Kbs}

[This file asks the user to input the Strain Energy Damage Index (SEDI) values and Modal Assurance Criteria (MAC) values of the single girder bridge model being tested.]

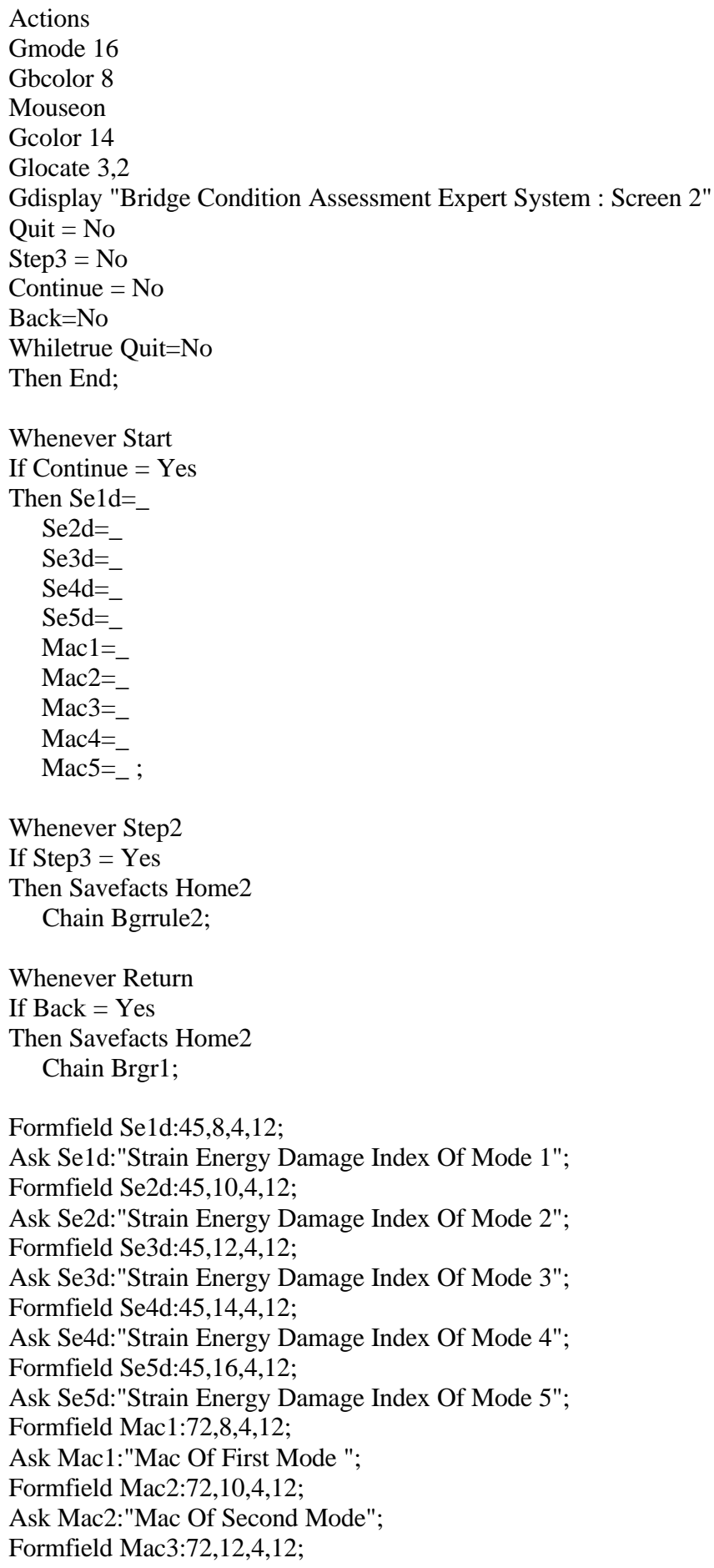


Ask Mac3:"Mac Of Third Mode ";

Formfield Mac4:72,14,4,12;

Ask Mac4:"Mac Of Fourth Mode";

Formfield Mac5:72,16,4,12;

Ask Mac5:"Mac Of Fifth Mode ";

Lbutton Continue:20,5,9,11,Continue_Session;

Lbutton Step3:7,21,9,11,To_The_Next_Screen;

Lbutton Quit:70,21,9,11,Done;

Lbutton Back:36,21,9,11,Back_To_Screen_1;

\section{Bgrrule2.Kbs}

[This file checks the user input values of Strain Energy Damage Index (SEDI) and Modal Assurance Criteria values of the single girder bridge model being tested against the rules in the knowledge base.]

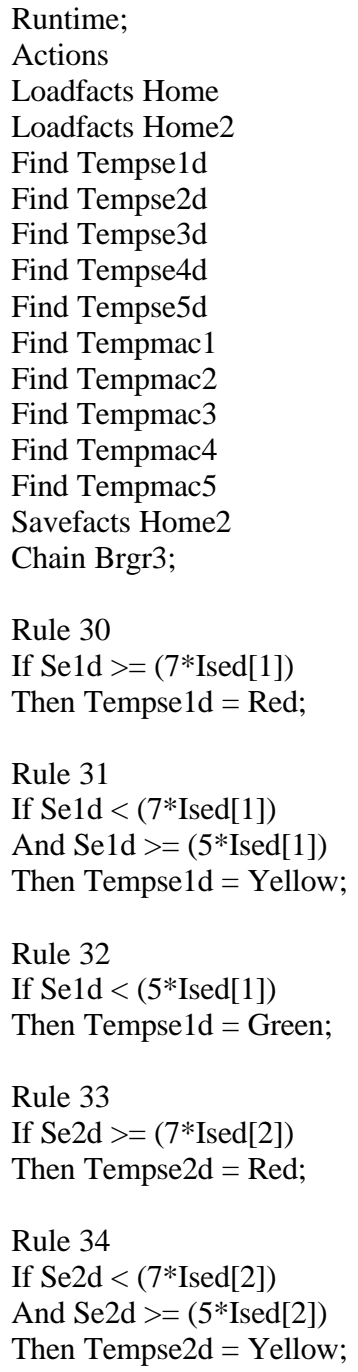


Rule 35

If $\mathrm{Se} 2 \mathrm{~d}<\left(5^{*}\right.$ Ised[2] $)$

Then Tempse2d = Green;

Rule 36

If $\mathrm{Se} 3 \mathrm{~d}>=(7 *$ Ised[3] $)$

Then Tempse3d = Red;

Rule 37

If $\mathrm{Se} 3 \mathrm{~d}<(7 *$ Ised[3])

And Se3d $>=(5 * \operatorname{Ised}[3])$

Then Tempse3d = Yellow;

Rule 38

If Se3d < $\left(5^{*}\right.$ Ised[3])

Then Tempse3d = Green;

Rule 39

If $\mathrm{Se} 4 \mathrm{~d}>=(7 *$ Ised[4])

Then Tempse4d = Red;

Rule 40

If Se4d < (7*Ised[4])

And Se4d $>=(5 *$ Ised[4])

Then Tempse $4 \mathrm{~d}=$ Yellow;

Rule 41

If Se4d < (5*Ised[4])

Then Tempse $4 \mathrm{~d}=$ Green;

Rule 42

If Se5d >= (7*Ised[5])

Then Tempse5d = Red;

Rule 43

If Se5d < (7*Ised[5])

And Se $5 d>=(5 *$ Ised[5])

Then Tempse5d = Yellow;

Rule 44

If Se $5 d<\left(5^{*}\right.$ Ised[5])

Then Tempse $5 \mathrm{~d}=$ Green;

Rule 45

If $\mathrm{Mac} 1<=\left(0.8^{*} \operatorname{Imac}[1]\right)$

Then Tempmac1 = Red;

Rule 46

If Mac1 > $(0.8 * \operatorname{Imac}[1])$

And Mac1 <= (0.9*Imac[1])

Then Tempmac1 = Yellow;

Rule 47

If $\mathrm{Mac} 1>(0.9 * \operatorname{Imac}[1])$

Then Tempmac1 = Green;

Rule 48

If Mac2 < $=(0.8 * \operatorname{Imac}[2])$

Then Tempmac 2 = Red;

Rule 49 


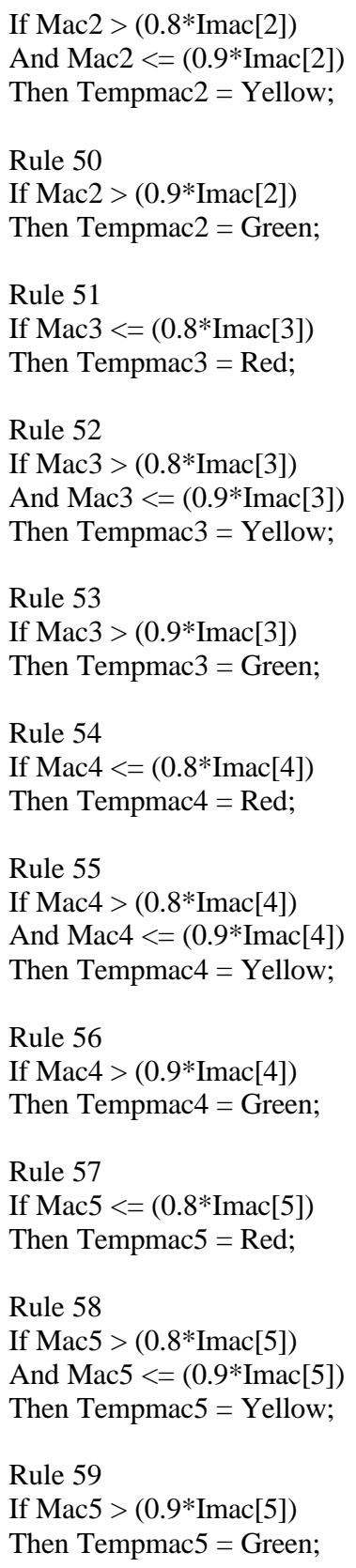

\section{Brgr3.Kbs}

[This file consists of visual inspection of the bridge model and asks answers to questions regarding visual inspection of important structural components.]

Actions

Gmode 16

Gbcolor 8

Mouseon

Gcolor 14 


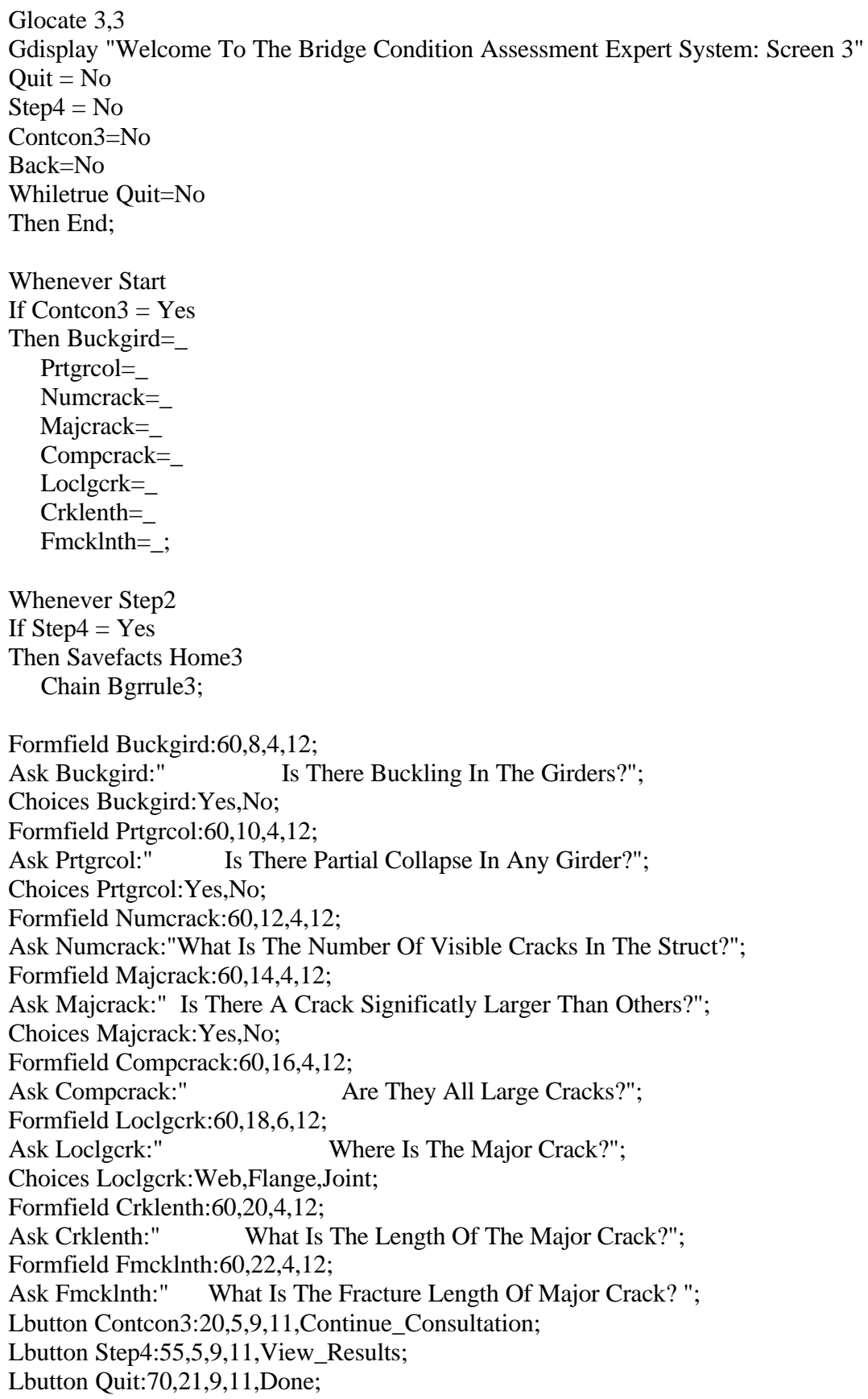

\section{Bgrrule3.Kbs}

[This file checks the input values of the visual inspection parameters against the rules in the knowledge base.]
Actions
Loadfacts Home
Loadfacts Home3 
Find Tempbuck

Find Tempgrcol

Find Tempcrack

Find Visweb

Find Visweb

Find Visjoint

Find Fmweb

Find Fmjoint

Find Fmflange

Savefacts Home3

Chain Brgr4;

Rule 60

If Buckgird $=$ Yes

Then Tempbuck = Red;

Rule 61

If Buckgird $=$ No

Then Tempbuck = Green;

Rule 62

If Prtgrcol $=$ Yes

Then Tempgrcol = Red;

Rule 63

If Prtgrcol $=$ No

Then Tempgrcol = Green;

Rule 64

If Numcrack $>=5$

Then Tempcrack =Red;

Rule 65

If Tempgrcol $=$ Green

And Numcrack < 5

And Majcrack $=$ No

And Compcrack $=$ No

Then Tempcrack =Green;

Rule 66

If Tempgrcol $=$ Green

And Numcrack < 5

And Majcrack $=$ No

And Compcrack $=$ Yes

Then Tempcrack =Red;

Rule 67

If Numcrack $<5$

And Majcrack $=$ Yes

Then Tempcrack $=$ Yellow

Find Vis

Find Fm;

Rule 68

If Tempcrack $=$ Yellow

And Loclgcrk $=$ Web

And Crklenth $>=(0.25 * 8)$

Then Vis $=$ Found

Visweb = Red;

Rule 69

If Tempcrack $=$ Yellow 
And Loclgcrk $=$ Web

And Crklenth $<(0.25 * 8)$

And Crklenth $>=(0.2 * 8)$

Then Vis $=$ Found

Visweb = Yellow;

Rule 70

If Tempcrack $=$ Yellow

And Loclgcrk $=$ Web

And Crklenth $<(0.2 * 8)$

Then Vis $=$ Found

Visweb = Green;

Rule 71

If Tempcrack $=$ Yellow

And Loclgcrk $=$ Flange

And Crklenth $>=(0.75 * 10)$

Then Vis $=$ Found

Visflange = Red;

Rule 72

If Tempcrack $=$ Yellow

And Loclgcrk $=$ Flange

And Crklenth $<\left(0.75^{*} 10\right)$

And Crklenth $>=(0.5 * 10)$

Then Vis $=$ Found

Visflange $=$ Yellow;

Rule 73

If Tempcrack $=$ Yellow

And Loclgcrk $=$ Flange

And Crklenth < $\left(0.5^{*} 10\right)$

Then Vis $=$ Found

Visflange $=$ Green;

Rule 74

If Tempcrack $=$ Yellow

And Loclgcrk $=$ Joint

And Crklenth $>=(0.25 * 6)$

Then Vis $=$ Found

Visjoint $=$ Red;

Rule 75

If Tempcrack $=$ Yellow

And Loclgcrk $=$ Joint

And Crklenth $<\left(0.25^{*} 6\right)$

And Crklenth $>=(0.2 * 6)$

Then Vis $=$ Found

Visjoint = Yellow;

Rule 76

If Tempcrack $=$ Yellow

And Loclgcrk $=$ Joint

And Crklenth $<(0.2 * 6)$

Then Vis $=$ Found

Visjoint $=$ Green;

Rule 77

If Visjoint $=$ Red Or Visjoint $=$ Green Or Visjoint $=$ Yellow

And Loclgcrk $=$ Joint

And Fmcklnth > $=(0.7 * 10)$

Then Fm $=$ Ok 
Fmjoint $=$ Red

Rule 78

If Visjoint $=$ Red Or Visjoint $=$ Green Or Visjoint $=$ Yellow

And Loclgcrk $=$ Joint

And Fmcklnth $<(0.7 * 10)$

And Fmcklnth $>=(0.5 * 10)$

Then $\mathrm{Fm}=\mathrm{Ok}$

Fmjoint $=$ Yellow;

Rule 79

If Visjoint $=$ Red Or Visjoint $=$ Green Or Visjoint $=$ Yellow

And Loclgcrk $=$ Joint

And Fmcklnth $<\left(0.5^{*} 10\right)$

Then $\mathrm{Fm}=\mathrm{Ok}$

Fmjoint = Green;

Rule 80

If Visweb $=$ Red Or Visweb $=$ Green Or Visweb $=$ Yellow

And Loclgcrk $=$ Web

And Fmcklnth $>(0.8 * 10)$

Then $\mathrm{Fm}=\mathrm{Ok}$

Fmweb = Red;

Rule 81

If Visweb $=$ Red Or Visweb $=$ Green Or Visweb $=$ Yellow

And Loclgcrk $=$ Web

And Fmcklnth $<\left(0.8^{*} 10\right)$

And Fmcklnth $>=\left(0.5^{*} 10\right)$

Then $\mathrm{Fm}=\mathrm{Ok}$

Fmweb = Yellow;

Rule 82

If Visweb $=$ Red Or Visweb $=$ Green Or Visweb $=$ Yellow

And Loclgcrk $=$ Web

And Fmcklnth $<\left(0.5^{*} 10\right)$

Then $\mathrm{Fm}=\mathrm{Ok}$

Fmweb = Green;

Rule 83

If Visflange $=$ Green Or Visflange $=$ Yellow Or Visflange $=$ Red

And Loclgcrk $=$ Flange

And Fmcklnth $>=(0.8 * 10)$

Then $\mathrm{Fm}=\mathrm{Ok}$

Fmflange $=$ Red;

Rule 84

If Visflange $=$ Green Or Visflange $=$ Yellow Or Visflange $=$ Red

And Loclgcrk $=$ Flange

And Fmcklnth $<\left(0.8^{*} 10\right)$

And Fmcklnth $>=(0.7 * 10)$

Then $\mathrm{Fm}=\mathrm{Ok}$

Fmflange $=$ Yellow;

Rule 85

If Visflange $=$ Green Or Visflange $=$ Yellow Or Visflange $=$ Red

And Loclgcrk $=$ Flange

And Fmcklnth $<(0.7 * 10)$

Then $\mathrm{Fm}=\mathrm{Ok}$

Fmflange $=$ Green; 


\section{Brgr4.Kbs}

[This file displays the result of the expert system consultation in terms of red, yellow and green lights for the various parameters checked by the system.]

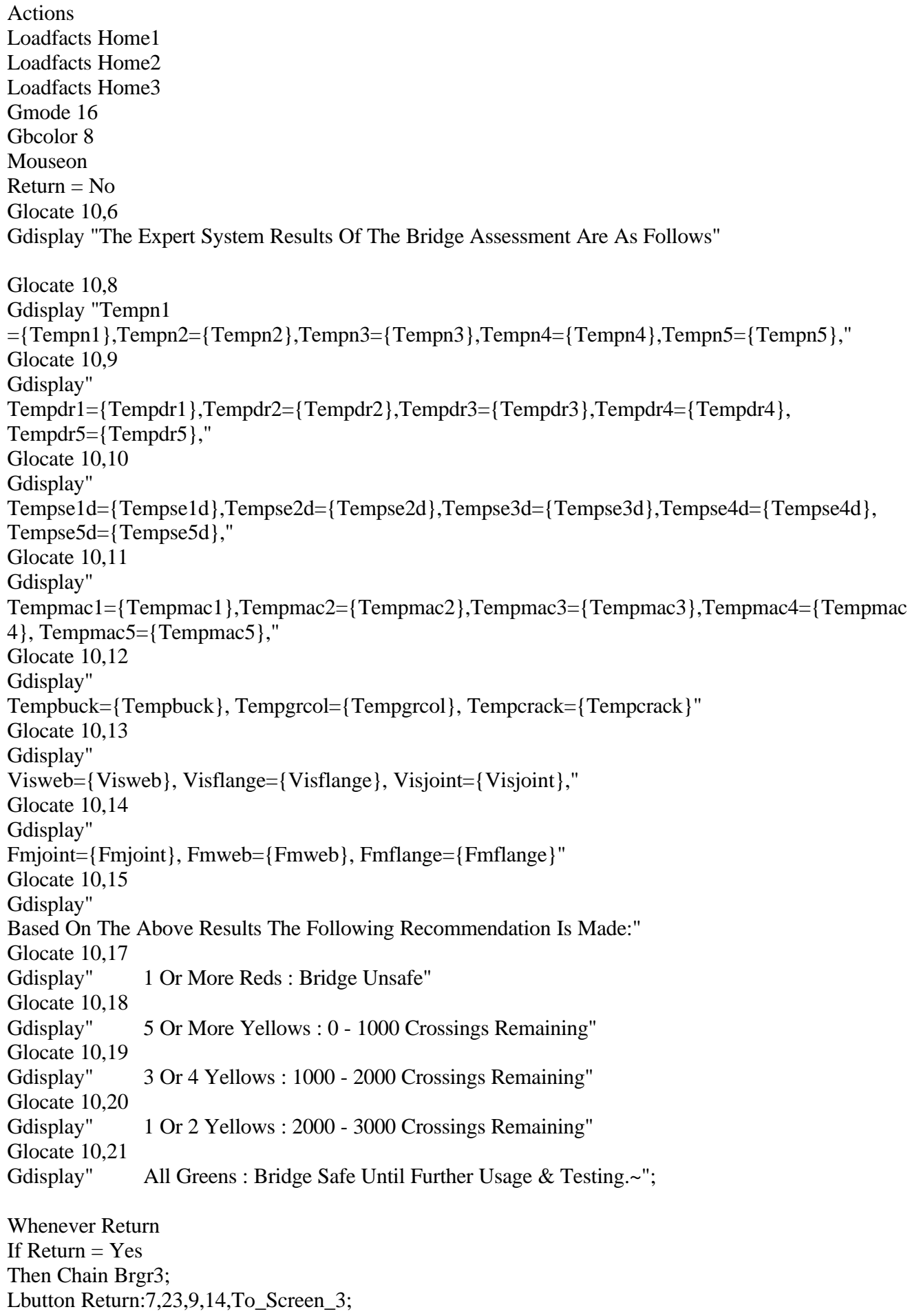




\section{APPENDIX B \\ Knowledge Acquisition through Interview of AVLB Personnel}

The following is a transcript of the survey questions developed as a part of knowledge

elicitation required in developing a robust expert system and the responses provided by the concerned army authority.

Date: September $2^{\text {nd }}, 1997$

Audience: Bridge Engineers, testing engineers and researchers.

Participants: WVU-CFC Researchers, Army- TACOM, Aberdeen Proving Ground, Ft. Belvoir

\section{General Questions:}

Q: Who does the inspections?

A: At depot - quality control personnel, in field - Soldiers, operators, crew, maintenance personnel, on semi-annual inspection. At the test site, engineers

Q: Who deadlines an AVLB?

A: Soldier performing PMCS. If deficiency is termed not mission capable (nmc) and approved by the master sergeant or maintenance supervisor.

Q: Who manufactured the bridges?

A: There are about 6 to 8 different manufacturers. The most current is Southwest Mobile Systems. Some others are Inner-Alloy and G.W.Galloway.

Q: What is the total number of existing AVLB?

A: 720 Launchers and 900 Bridges

Q: How many AVLB are currently in service?

A: Approximately $80 \%$ are termed "Operational".

Q: And how many AVLB model 60 upgrades?

A: 50 plus sections for 4 more bridges.

Q: Which Army Units use AVLB?

A: Combat Engineer Battalion with Bridge Company and Heavy assault units. 
Q: Where are the locations of these AVLBs?

A: Worldwide namely Germany, Korea, and USA.

Q: What is the inspection teams' background?

A: Varies but no technical training to inspect Bridge.

Q: Are they all soldiers?

A: Yes in the field

Q: Are there any supervisors?

A: Yes

Q: Are they engineers?

\section{A: Army Engineers No Degreed Engineers}

Q: What about the retrofit team? Are they engineers?

A: No not all usually there is an appointed engineer that oversees the program

Q: Are they certified welder, mechanics?

A: Maybe certified by army not AWS

Q: Do they usually receive any kind of training to inspection the bridge?

\section{A: Not really just OJT}

Q: In reality, how long or how often are these bridges been thoroughly inspected? (NBIS requires every two years of federal bridges.)

A: Semi-annual, annual inspections at the depot. Probably never in the field. During development they are thoroughly inspected but once shipped to the field there is no controlling agency.

Q: How long does it take to complete a thorough inspection following the PMCS manual?

A: Probably not more than a $1 / 2$ hour. There is no formal inspection procedure.

Q: Each time a bridge is launched, do you check it regularly (i.e. full inspection, cursory inspection, no inspection)?

A: No, unless if it is at the beginning of a mission, and only for parts. Also inspected if something goes wrong. $i$. e. funny noises

Q: Does the army have detailed records (i.e. shipping records, AVLB quality control of manufacturing)?

A: Yes, there are shipping records. No quality control records - just forms saying everything is o.k. DA2408-3.

Q: Does it get inspected before shipping?

A: Yes if being shipped from the depot after a rebuild or upgrade, No if just shipped by a unit to another unit, unless the receiving unit is overseas. 
Q: Is there a record of parts being replaced on the AVLB along with the date maintained on site or at the place of repair?

A: No, depot should know about the parts that are thrown away.

Q: Where are the repair shops?

A: Anniston Army Depot does a lot of the refurbishment.

Q: Do they repair on site?

A: Depends on the nature of the repair, a "contact team' from support level can make some on site repairs.

Q: Do they carry parts on site?

A: Usually no parts, only hardware items and welding capability. LRU's

Q: How are the AVLBs transported (i.e. stacked up)?

A: Normal mode of operation is to transport bridge on launcher (folded). At unit bridges are laid folded or length-wise on ground using wood dunnage to keep them from touching ground. They are only stacked at depots.

Q: Has any AVLB ever failed?

A: Yes during both dynamic, fatigue and static testing (Namely collapsed or damaged beyond repair, under the intended loading condition.)

Q: Have you actually seen a bridge failed during regular operation?

A: No

Q: Are you aware of an AVLB failure?

A: Yes. 1 failed at 3000 cycles during testing

Q: If you do, can you describe how it failed? (Slow, fast, sudden, heard a big bang, etc.)

A: Not sure

Q: What is the basis for deadline a bridge?

A: If primary structural member is defective or if two or more rivets in a row or line are missing or broken.

Q: Do you follow the PMCS manual for your inspection?

A: The units are required to conduct PMCS on a periodic basis. Soldiers do from memory, but they should follow PMCS. Reliability test will use PMCS.

Q: Do you have a checklist for inspection?

A: Yes, the depot has a quality control inspection checklist that they use. Not as a standard procedure.

Q: Do the bridges always have the top pins installed during tank crossing?

A: No 
Q: Or are they removed?

A: Yes

Q: In your opinion, how detail an inspection procedure should be, to be practical?

A: Keep the procedure as simple and non-technical as possible. Remember, the soldiers must inspect their bridges according to the PMCS.

Q: Where?

A: Key areas to inspect center hinges, lower beams (chords) connectors and splice joint area.

Q: When you perform inspection, how precise do you inspect the structure, i.e. do you look carefully for hairline cracks? What do you look for (i.e. 5" crack, 1" crack, or hairline crack)?

A: During R\&D at Depot using Dye penetrant testing yes hairline cracks are reported once in the field the answer is no.

Q: Do you inspect the gusset plates, angle plates, splice plates or stiffeners, every time?

A: Only according to PMCS. Also depends on how many crossings a day.

Q: When you replace the components, do you take a brand new piece, or just salvage parts from some other AVLBs?

A: In most cases new parts. It depends on parts availability. do not know, but may be both

\section{Detailed Questions:}

Q: What components are most frequently replaced?

A: Panels, decking tie-rods and curbing among the structural parts. The most frequent replaced parts are the hydraulic fittings.

Q: How are large parts being replaced onsite?

A: Panels or sections can be ordered by units for replacement, same for inter connections braces and members. Most all repairs are done at DS/GS levels.

Q: Has the failure of a particular component lead to the immediate failure of the bridge?

A: Yes, the center hinge, bottom chord, buckling of top chord, breaking of a connector (center to end panel)

Q: What are the most common damages that you have observed during the following conditions (broadly speaking)?

-During launch/retrieve operations

A: During launch/retrieve operation a bridge came off of launcher's tongue assembly cracked splice doubler angles also hinge wear, no consequence, hydraulic fitting 
Q: During shipping (how do they transport AVLB)

A: Separately from launcher aboard truck, rail, ships and planes Bottom chordsscratch and Tie- down ring bend

Q: During tank crossing?

A: Wear of deck panels, curbing

Q: When under attack (What kind of battle damage)

A: unknown

Q: Environmental degradation?

\section{A: Salt corrosion from ODS (Operation Desert Storm)}

Q: Gradual breakdowns (i.e. rivets coming out one by one).

A: Rivet heads have fallen off under corrosion, exfoliation of metal due to corrosion.

Q: Have you ever seen any interconnecting braces (i.e. cross bracing) bent, or distorted, during normal operation?

A: Cross bracing damaged, probably due to torsion during testing.

Q: Have you ever observed any interconnecting braces (i.e. cross bracing) cracked, during normal operation?

A: In field - no. During testing - yes

Q: Have you observed dropped rivets, or nuts and bolts? How often do you think it will happen?

A: No nuts and bolts, however observed the old hot-rivet heads fall off due to corrosion behind the manufactured head only.

Q: Have you seen any large amount of rivets, or nuts and bolts dropped (say more than 10 rivets), during normal operation?

A: No, only a few hot rivet heads and these were on bridges returned from Saudi Arabia after operation Desert Storm.

Q: Have you ever observed bending of the four girders?

A: Do you mean permanent set, if so only during static testing of the production model AVLB-70 upgraded bridge

Q: Have you observed any obvious cracking of the girders, either hairline crack or large opening cracks?

A: If web girders, only during testing of AVLB-70 upgraded bridge, if bottom chords, No

Q: Have you ever observed any kind of damage to the center hinge?

A: Yes, during testing 
Q: Has a center hinge failure ever been observed?

\section{A: Yes, during testing}

Q: Have you observed any separation between web plate and the flange angles, due to loosing of rivets, bending of plates or cracking?

\section{A: Only during testing}

Q: Have you observed gusset plates, splice plates or splice angles bending, or distortion?

\section{A: Not under normal conditions}

Q: Have you observed gusset plates, splice plates or splice angles cracked? (Including hairline crack or large opening cracks)

A: Yes, under special training conditions at the Engineer School (continuous launching and retrieving of bridges, no vehicle crossings)

Q: Have you ever observed any bending or twist of tie-rod spacers?

\section{A: Yes, they do get pretty beat up during launch}

Q: Which components do you think are the most critical to the integrity of the bridge?

A: Center hinges (area of highest moment of force creating the highest pressures with the material. Connectors area of weakness due to corrosion. Splice joint - area of potential weakness and concern it is where the steel and aluminum parts of the bridge meet in the ramp panels. Bottom chord and related hardware

Q: Here is a way that we list the "criticality" of the bridge components, do you agree? If not, why?

A - If component failure will cause immediate collapse of structure (i.e. web girder plate crack through or has very large crack ( $1 / 2$ depth), center hinge crack through, center hinge pin missing or cracked through).

\section{Yes a catastrophic failure}

B - If component failure will cause other components to fail, which may cause immediate collapse of structure (i.e. significant amount of hinge rivets missing).

Or severly cracked or broken secondary treadway support members or bracing, yes a contributor

C - If component failure will cause immediate dysfunction of structure (i.e. bridge deck damaged will not weaken structure, but will not allow tank crossing).

D - If component failure will cause other components to fail. But will not lead to immediate collapse of structure (i.e. splice doubler angles failed will induce damage at the splice plates and the girder plate

E - If component failure will cause extensive replacements

F - If component failure will not have significant impact on structure and can be replaced much later.

Based on the above method, we prioritize the structural components as follow. Do you think this list is accurate? 
A: Order of criticality (based on testing experience with AVLB)

1. Center Hinges plus pins

2. Splice joint area (splice doubler angles and splice plate)

3. Bottom connectors and pins

4. Main bottom chord back to back angles

5. Web extensions of the main angles in splice joint area

6. Main angles in top chord

7. Web girder plate

8. Inter connecting bracing between treadways

9. Under treadway cross bracing

10. Fasteners for assemblage of components.

1. Bottom chord and all related hardware

2. Shear panels

3. Center Connectors (Bracing between two treadways)

4. Geometry

\begin{tabular}{|c|c|c|}
\hline $\begin{array}{l}\text { Item } \\
\text { number } \\
\text { (Numbers } \\
\text { according } \\
\text { to the } \\
\text { PMCS } \\
\text { inspection } \\
\text { procedure) }\end{array}$ & Component name & $\begin{array}{l}\text { Priority } \\
(1-\text { most } \\
\text { critical } \\
20 \text { - least } \\
\text { critical) }\end{array}$ \\
\hline $8 \mathrm{a}$ & Center Hinge + pins & \\
\hline $8 \mathrm{~b}$ & Center hinge pin and retainer clip & \\
\hline 10 & $\begin{array}{l}\text { Connector area along the bottom chord (connectors for AVLB } 60 \text { and } \\
\text { splice bars and spacers for AVLB-70) }\end{array}$ & \\
\hline 26 & Web girder plate & \\
\hline 12 & Splice doubler angles in bottom chord & \\
\hline 13 & Splice plate along bottom of each girder & \\
\hline 14 & Main aluminum angle extensions & \\
\hline $7 \mathrm{~b}$ & Bottom connector pins (end to center panels) & \\
\hline $9 \mathrm{a}$ & Main aluminum angles along bottom chords & \\
\hline $4 \mathrm{~b}$ & $\begin{array}{l}\text { Pin rivets, hot-rivets at hinge, connector areas, spliced areas, at bottom } \\
\text { chord and at cross bracing }\end{array}$ & \\
\hline $9 \mathrm{~b}$ & Main aluminum angles along top chords & \\
\hline 11 & Press fit pins along the top chord & \\
\hline $7 \mathrm{a}$ & Top connector pins (end to center panels) & \\
\hline 15 & Cross bracing under the treadways of center/end panels/ of sections & \\
\hline 25 & Transverse braces between center and end panels, or between sections & \\
\hline
\end{tabular}




\begin{tabular}{|l|l|l|}
\hline 24 & Lateral cross braces & \\
\hline $2 \mathrm{a}$ & Deck extrusions & \\
\hline 5 & $\begin{array}{l}\text { Attaching hardware, i.e. Nuts/Bolts/Washers used to secure the braces. } \\
\text { that hold the treadways and hydraulic components together }\end{array}$ & \\
\hline 6 & Top center connector pins & \\
\hline $4 \mathrm{a}$ & $\begin{array}{l}\text { Pin rivets, hot-rivets of all parts other than at hinge, connector areas, } \\
\text { spliced areas, at bottom chord and at cross bracing }\end{array}$ & \\
\hline
\end{tabular}

Q: We think the most critical components (top ten) are the following, do you agree? If not why?

1. Center hinge

2. Center hinge pin and retainer clips

3. Connector area along the bottom chord

4. Web girder plate

5. Splice doubler angles in bottom chord

6. Splice plate along bottom of each girder

7. Main aluminum angle extensions

8. Bottom connector pins

9. Main aluminum angles along bottom chord

10. Pin rivets, hot-rivets at hinge, connector areas, splice areas, at bottom chord and at cross bracing

\section{A: See above}

Q: Have you ever observed any cracks on the critical components?

A: Yes

Q: If cracks are detected, do you "deadline" the bridge immediately?

A: Yes

Q: Have you ever observed multiple cracks on any components?

A: Yes, near cross bracing and angles

Q: What do you do?

\section{A: Have a material specialist analyze the cracks to determine cause}

Q: Have you ever observed any fine hairline cracks on any part of the bridge?

A: Yes, especially near the bracing at the end panels.

Q: Can you recall how long they are?

\section{A: Usually under 1"}

Q: How do you observe hairline cracks?

\section{A: Use dye penetrant spray cut out sample and analyze in lab.}


Q: How bad a damage do you usually tolerate? What do you do under a certain damage scenario? (i.e. when do you decide to replace a part?)

A: Once it is found to be defective (cracked or bent). By manual (PMCS).

Q: Regarding the "Aluminum Links" mentioned in the manual, how have you used it for inspection? Can you describe in detail the operation of these "links"?

A: I am not sure I understand this one. If you are referring to the aluminum links we designed during ODS for the USAES they have only been used in the R\&D

environment to hold an AVLB bridge in a scissored fashion for the crossing over of above ground pipelines. Although not accepted for use we recommended that they be used as an inspection tool so that the bridge could be held open underneath while the bridge is inspected. This was never made available to field units.

\section{EXTRA NOTES:}

1. Sometimes, bracing get loose.

2. Soldiers receive MOS training (military occupational specialty)

3. Very detailed work is done at depot, however, not the whole bridge, but only damaged parts go to depot for salvage or throw away purposes.

4. People at unit level, have some technical background.

5. There are a couple of people from the bridge company all over the place.

6. "Direct" is next level up to "unit" -contractors, LRU - lowest repair units. Below "unit" is the "crew" level.

7. Roughly 25 bridge companies

8. Inspection procedure, put at abutments of $1.8 \mathrm{~m}$ higher on one side

9. Aluminum link is not used in the field.

10. SSP - System Support Package - tells you if a part would meet a certain specs.

11. Cross bracing cracks mostly at Fort Lanerwood, Missouri. Train for operators and maintenance.

12. Two types of tests: 1) Reliability test - what is the probability that the structure will fail? A simulated mission test. 2) Feasibility test - I will let 10 rivets to fall to see when it will fail. 


\section{APPENDIX C \\ DSS Application Requirements}

\section{C.1 System Requirements}

The AVLB DSS is a web-based system, and can be executed through Internet browsers. Hence, the following software are required in the computer:

1. PC running Windows 95/ Windows NT 4.0 or higher

2. MS Internet Explorer (MSIE) version 4.0 or higher

3. Microsoft ActiveX Scripting Engine version 3.1 or greater

MS ActiveX Scripting Engine can be downloaded and installed from the Microsoft Scripting web site at

\section{http://www.microsoft.com/msdownload/vbscript/scripting.asp}

The download site can also be traced from Microsoft scripting technology website at:

\section{http://msdn.microsoft.com/scripting/}

The security privileges in the Internet Options of the MSIE Web browser should be set to "low", or customized to enable and initialize running of all forms of ActiveX Controls and scripts, during the time that the application is being consulted. 


\section{C.2 Application Hosting}

In the current system developed, the application program files were hosted and run from a Microsoft Personal Web Server ${ }^{\circledR}$ (MS PWS). This enables a computer running Windows 95 to have server features and makes specific authorized files of the PC accessible over the Internet. The MS PWS $®$ is a free and scaled-down version of Microsoft Internet Information Server® (MS IIS), which is a more robust commercial server for hosting a website. MS PWS ${ }^{\circledR}$ is available for free download from the Microsoft website and is available as a part of MS FrontPage 98®, which is a Web-site development software of Microsoft Corporation. Some of the web page program codes in the current work were developed using FrontPage 98.

\section{C.3 DSS Program Files}

The total program files encoded in developing the AVLB Decision Support System have been provided below.

Total number of HTML (*.htm, *.html) files : 52

Number of HTML files containing program files: 24

Total number of Microsoft Access database (*.mdb) files: 1

Total number of Internet Database Connector (*.idc) files: 15

Total number of HTML template (*.htx) files: 15

Total number of Java (*.class) files: 3

Total number of ASCII text files: 5

Total number of Graphic Picture (*.gif, *.jpg) files : 2

The total size of all the files is about $800 \mathrm{~KB}$. 


\section{APPENDIX D}

\section{Application Verification Tests}

\section{D.1 Description of Verification Process}

The visual and vibration inspection sections of the AVLB DSS application were tested for program verification. Being Internet-based, the application over the Internet is very important. In order to verify its operability and stability over the network, the program was tested on a number of computers with different network settings.

The computers on which the tests were carried out have been designated as Test Objects A, B, C and D. Test Objects A and B were a part of the application server's Intranet (Site 1) located in the "cerc.wvu.edu" which is a Windows NT domain. Test objects C and D were a part of "coe.wvu.edu" which is a Ultrix (Unix) domain (Site 2) and connected to the application server through the Internet. The application was tested for different damage scenarios.

The "Application Test Sheets for the Visual Inspection Section", which has been presented here only lists questions for positive responses. Three application test sheets for the visual inspection section have been shown here.

The vibration inspection section gives results based on the input values of four dynamic parameters: Frequency, SEMAC, SEDI and MAC. The limit states for these parameters have been shown in Table 4.4. 


\section{D.2 Verification Test Sheets}

\section{Visual Inspection Section - Application Test No. 1}

This test was devised to detect program logical flaws and bugs in Stage 1 of the detailed visual inspection section program. This test was supposed to deem the bridge unsafe for crossing after Stage I of the Visual Inspection Section with a certain degree of confidence. The degree of confidence computed by the program based on input values was verified through manual calculation.

\section{Table D1 Application Test 1}

\begin{tabular}{|l|l|l|}
\hline Question & Reply & Confidence Level \\
\hline $\begin{array}{l}\text { Stage I - } \\
\text { Is there a sagging (greater than 1 ft.) or } \\
\text { deformation of the bridge? }\end{array}$ & Yes & $90 \%$ \\
\hline $\begin{array}{l}\text { Stage I - } \\
\text { Is there a significant large crack or through } \\
\text { crack in the Center Hinge? }\end{array}$ & Yes & $80 \%$ \\
\hline $\begin{array}{l}\text { Stage I - } \\
\begin{array}{l}\text { Is there a through crack in the Bottom } \\
\text { Connector Pin or is it broken or missing? }\end{array}\end{array}$ & Yes & $80 \%$ \\
\hline $\begin{array}{l}\text { Final Result } \\
\text { Red Light } \\
\text { Red Light: Carry out recommended actions } \\
\text { on the following items before further testing } \\
\text { and usage of bridge: }\end{array}$ & $\begin{array}{l}\text { Recommendation } \\
\text { Bridge girder should be } \\
\text { repaired before crossing } \\
\text { Center Hinge Needs to be } \\
\text { changed } \\
\text { Bottom Connector Pins } \\
\text { Needs to be replaced } \\
\text { before further usage. }\end{array}$ & $\mathbf{9 2 \%}$ \\
\hline
\end{tabular}




\section{Visual Inspection Section - Application Test No. 2}

This test was devised to detect program logical flaws and bugs in the 4 stages of detailed visual inspection section program. This test was supposed to deem the bridge safe for crossing with caution i.e. "Yellow light" scenario. The expected values corresponding to the input values were manually checked to verify the results and the degree of confidence computed by the program.

Table D2 Application Test 2

\begin{tabular}{|c|c|c|}
\hline Question & Reply & $\begin{array}{l}\text { Confidence } \\
\text { Level }\end{array}$ \\
\hline \multicolumn{3}{|l|}{$\begin{array}{l}\text { Stage I - } \\
\text { No damages }\end{array}$} \\
\hline $\begin{array}{l}\text { Stage II - } \\
\text { Is there a through crack } \\
\text { in splice doubler angle } \\
\text { bottom chord? }\end{array}$ & Yes & $80 \%$ \\
\hline $\begin{array}{l}\text { Stage II - } \\
\text { Is there a through crack } \\
\text { or buckling under the } \\
\text { treadways of end panel? }\end{array}$ & Yes & $70 \%$ \\
\hline $\begin{array}{l}\text { Stage II - } \\
\text { Is there a through } \\
\text { cracking or buckling or } \\
\text { bending? }\end{array}$ & Yes & $70 \%$ \\
\hline $\begin{array}{l}\text { Stage III } \\
\text { Is there a through crack, } \\
\text { buckling or bending in } \\
\text { lateral cross braces? }\end{array}$ & Yes & $90 \%$ \\
\hline $\begin{array}{l}\text { Stage III } \\
\text { Is there a bend or is the } \\
\text { plating seperated from } \\
\text { the girder? }\end{array}$ & Yes & $80 \%$ \\
\hline $\begin{array}{l}\text { Stage IV } \\
\text { Is there a through crack, } \\
\text { bending or large } \\
\text { deformation of main } \\
\text { aluminum angles along } \\
\text { top chord? }\end{array}$ & Yes & $80 \%$ \\
\hline $\begin{array}{l}\text { Stage IV } \\
\text { Is there a through crack } \\
\text { or are the pins missing? }\end{array}$ & Yes & $70 \%$ \\
\hline
\end{tabular}




\begin{tabular}{|l|l|l|}
\hline Final Result & Recommendation & $\mathbf{9 1 \%}$ \\
Yellow light - Carry out & Splice doubler angle/Splice Plate needs to be repaired or & \\
and test bridge after 35 & replaced & There is a danger of girder web bending-Replace Cross \\
crossings & Bracing & \\
& Connector failure may occur - Replace the damaged \\
& transverse braces & \\
& $\begin{array}{l}\text { The distance between two treadways may be shifted due } \\
\text { to Lateral Cross Brace distortion } \\
\text { Deck plate bending and separation from girder may } \\
\text { cause immediate dysfunction of the bridge } \\
\text { Replace or repair main aluminum angles along top chord } \\
\\
\text { Replace or repair top connector pins }\end{array}$ & \\
\hline
\end{tabular}




\section{Visual Inspection Section - Application Test No. 3}

This test was also devised to detect logical flaws and program errors in the 4 stages of the detailed visual inspection section program. This test was supposed to deem the bridge safe for crossing i.e. "Green light" scenario. Logical flaws or "bugs" in the program while processing the input values through the four stages of the detailed visual inspection section that could not be detected in Application tests 1 and 2, could be detected by this test. The results and the degree of confidence computed by the program based on input values were found to be consistent with expected values.

Table D3 Application Test 3

\begin{tabular}{|l|l|l|}
\hline Question & Reply & $\begin{array}{l}\text { Confidence } \\
\text { Level }\end{array}$ \\
\hline $\begin{array}{l}\text { Stage I - } \\
\text { No damages }\end{array}$ & Replies to all questions "No" & \\
\hline $\begin{array}{l}\text { Stage II - } \\
\text { No damages }\end{array}$ & Replies to all questions "No" & \\
\hline $\begin{array}{l}\text { Stage III } \\
\text { No damages }\end{array}$ & Replies to all questions "No" & \\
\hline $\begin{array}{l}\text { Stage IV } \\
\text { No damages }\end{array}$ & Replies to all questions "No" & \\
\hline $\begin{array}{l}\text { Final Result } \\
\text { Green Light: The Bridge is safe for } \\
\text { crossing. }\end{array}$ & $\begin{array}{c}\text { Recommendation } \\
\text { Bridge is safe for crossing }\end{array}$ & $100 \%$ \\
\hline
\end{tabular}




\section{Vibration Inspection Section - Application Test No. 4}

This test was devised to detect program logical flaws and bugs in the vibration inspection section of the program while inferring towards a "green light" solution. This test was supposed to deem the bridge "safe for crossing" based on checking the input values against the "limit states" in the rule base. Borderline values for SEMAC of Mode 1 and MAC OF Mode 2 were used in this test to detect round-off errors. The result was found to be as expected and thus program was verified for a "green light" scenario in vibration testing.

\section{Table D4 Application Test 4}

\begin{tabular}{|l|l|}
\hline Dynamic Parameter & Value \\
\hline Frequency of Mode 1 & 4.254 \\
\hline Frequency of Mode 2 & 14.825 \\
\hline Frequency of Mode 3 & 32.270 \\
\hline Frequency of Mode 4 & 54.166 \\
\hline SEMAC of Mode 1 & 0.8001 \\
\hline SEMAC of Mode 2 & 0.8003 \\
\hline SEMAC of Mode 3 & 0.9999 \\
\hline SEMAC of Mode 4 & 0.9021 \\
\hline SEDI of Mode 1 & 8 \\
\hline SEDI of Mode 2 & 7.48 \\
\hline SEDI of Mode 3 & 8.75 \\
\hline SEDI of Mode 4 & 8.02 \\
\hline MAC of Mode 1 & .9857 \\
\hline MAC of Mode 2 & .9001 \\
\hline MAC of Mode 3 & .9002 \\
\hline MAC of Mode 4 & .9999 \\
\hline Final Result & Green Light \\
\hline Result verified with respect to limit states. & \\
\hline
\end{tabular}




\section{Vibration Inspection Section - Application Test No. 5}

This test was devised to detect program logical flaws and bugs in the vibration inspection section of the program while inferring towards a "yellow light" solution. This test was supposed to deem the bridge "safe for crossing with caution" due to value of Frequency for Mode 2 lying in the "yellow light" zone. A red zone - yellow zone borderline scenario for SEDI of Mode 3 and MAC of Mode 1 were used in the test to detect borderline program bugs and round-off errors.

\section{Table D5 Application Test 5}

\begin{tabular}{|l|l|}
\hline Dynamic Parameter & Value \\
\hline Frequency of Mode 1 & 3.837 \\
\hline Frequency of Mode 2 & 13.3431 (low - yellow) \\
\hline Frequency of Mode 3 & 31.187 \\
\hline Frequency of Mode 4 & 43.337 \\
\hline SEMAC of Mode 1 & 0.9996 \\
\hline SEMAC of Mode 2 & 0.9985 \\
\hline SEMAC of Mode 3 & 0.9994 \\
\hline SEMAC of Mode 4 & 0.9999 \\
\hline SEDI of Mode 1 & 20 \\
\hline SEDI of Mode 2 & 45 \\
\hline SEDI of Mode 3 & 499.99 \\
\hline SEDI of Mode 4 & 8.1 \\
\hline MAC of Mode 1 & .8001 \\
\hline MAC of Mode 2 & .8787 \\
\hline MAC of Mode 3 & .9959 \\
\hline MAC of Mode 4 & .9799 \\
\hline Final Result & Yellow Light \\
\hline Result verified with respect to limit states & \\
\hline
\end{tabular}




\section{Vibration Inspection Section - Application Test No. 6}

This test was devised to detect program logical flaws and bugs in the vibration inspection section of the program while inferring towards a "red light" solution. This test was supposed to deem the bridge "unsafe for crossing based" due to high value SEDI value for Mode 3 exceeding the "red light" threshold. Borderline values for Frequency of Mode 4 and MAC of Mode 1 were also used in this test so as to detect round- off errors. The result was found to be as expected and thus program was verified for a "red light" scenario in vibration testing.

\section{Table D6 Application Test 6}

\begin{tabular}{|l|l|}
\hline Dynamic Parameter & Value \\
\hline Frequency of Mode 1 & 3.974 \\
\hline Frequency of Mode 2 & 13.213 \\
\hline Frequency of Mode 3 & 31.187 \\
\hline Frequency of Mode 4 & 43.3369 \\
\hline SEMAC of Mode 1 & 0.9921 \\
\hline SEMAC of Mode 2 & 0.9985 \\
\hline SEMAC of Mode 3 & 0.9974 \\
\hline SEMAC of Mode 4 & 0.9889 \\
\hline SEDI of Mode 1 & 220 \\
\hline SEDI of Mode 2 & 45 \\
\hline SEDI of Mode 3 & 545 (High - Red) \\
\hline SEDI of Mode 4 & 31 \\
\hline MAC of Mode 1 & .8009 \\
\hline MAC of Mode 2 & .9738 \\
\hline MAC of Mode 3 & .9859 \\
\hline MAC of Mode 4 & .9992 \\
\hline Final Result & Red Light \\
\hline Result verified with respect to limit states & \\
\hline
\end{tabular}




\section{Vibration Inspection Section - Application Test No. 7}

This test was devised to detect program logical flaws and bugs in the vibration inspection section of the program while inferring towards a "yellow light" solution. This test was supposed to deem the bridge "safe for crossing with caution" due to SEMAC value for Mode 1 lying in the "yellow light" zone. A logical flaw in the program code or a bug in the later stages of the program could be detected from this test. Yellow-green borderline values for Frequency of Mode 3 and MAC of Mode 4 were used in this test so as to detect roundoff errors and program bugs. The result was found to be as expected and thus program was verified for a "yellow light" scenario in vibration testing.

Table D7 Application Test 7

\begin{tabular}{|l|l|}
\hline Dynamic Parameter & Value \\
\hline Frequency of Mode 1 & 4.114 \\
\hline Frequency of Mode 2 & 13.773 \\
\hline Frequency of Mode 3 & 29.044 \\
\hline Frequency of Mode 4 & 49.8350 \\
\hline SEMAC of Mode 1 & 0.8000 (Low - yellow) \\
\hline SEMAC of Mode 2 & 0.9985 \\
\hline SEMAC of Mode 3 & 0.9974 \\
\hline SEMAC of Mode 4 & 0.9889 \\
\hline SEDI of Mode 1 & 220 \\
\hline SEDI of Mode 2 & 45 \\
\hline SEDI of Mode 3 & 487 \\
\hline SEDI of Mode 4 & 31 \\
\hline MAC of Mode 1 & .8478 \\
\hline MAC of Mode 2 & .9667 \\
\hline MAC of Mode 3 & .9242 \\
\hline MAC of Mode 4 & .8001 \\
\hline Final Result & Yellow Light \\
\hline Result verified with respect to limit states & \\
\hline
\end{tabular}




\section{Vibration Inspection Section - Application Test No. 8}

This test was devised to detect program logical flaws and bugs in the vibration inspection section of the program while inferring towards a "red light" solution. This test was supposed to deem the bridge "unsafe for crossing" due to MAC value for Mode 4 lying below the "red light" threshold. A logical flaw or program bug could be detected from this test. Yellow-red borderline values for SEMAC of Mode 1 and MAC of Mode 3 were used in this test so as to detect round-off errors that may exist in some sections of the program code. The result was found to be as expected and thus program was verified for a "red light" scenario in vibration testing.

\section{Table D8 Application Test 8}

\begin{tabular}{|l|l|}
\hline Dynamic Parameter & Value \\
\hline Frequency of Mode 1 & 4.212 \\
\hline Frequency of Mode 2 & 12.924 \\
\hline Frequency of Mode 3 & 30.871 \\
\hline Frequency of Mode 4 & 48.9655 \\
\hline SEMAC of Mode 1 & 0.6001 \\
\hline SEMAC of Mode 2 & 0.9985 \\
\hline SEMAC of Mode 3 & 0.9974 \\
\hline SEMAC of Mode 4 & 0.8002 \\
\hline SEDI of Mode 1 & 220 \\
\hline SEDI of Mode 2 & 45 \\
\hline SEDI of Mode 3 & 88 \\
\hline SEDI of Mode 4 & 31 \\
\hline MAC of Mode 1 & .9542 \\
\hline MAC of Mode 2 & .9872 \\
\hline MAC of Mode 3 & .9001 \\
\hline MAC of Mode 4 & .7999 (Low - Red) \\
\hline Final Result & Red Light \\
\hline Result verified with respect to limit states & \\
\hline
\end{tabular}




\section{Vibration Inspection Section - Application Test No. 9}

This test was devised to detect program logical flaws and bugs in the vibration inspection section of the program while inferring towards a "yellow light" solution. This test was supposed to deem the bridge "safe for crossing with caution" due to SEMAC value for Mode 4 lying in the "yellow light" zone. Borderline value for SEDI of Mode 4 was used in this test to detect round-off errors while processing the input values against the rule base. The result was found to be as expected and thus program was verified for a "red light" scenario in vibration testing.

Table D9 Application Test 9

\begin{tabular}{|l|l|}
\hline Dynamic Parameter & Value \\
\hline Frequency of Mode 1 & 4.055 \\
\hline Frequency of Mode 2 & 13.891 \\
\hline Frequency of Mode 3 & 31.743 \\
\hline Frequency of Mode 4 & 51.965 \\
\hline SEMAC of Mode 1 & 0.9921 \\
\hline SEMAC of Mode 2 & 0.8723 \\
\hline SEMAC of Mode 3 & 0.9974 \\
\hline SEMAC of Mode 4 & 0.6001 (Low - Yellow) \\
\hline SEDI of Mode 1 & 109 \\
\hline SEDI of Mode 2 & 22 \\
\hline SEDI of Mode 3 & 84 \\
\hline SEDI of Mode 4 & 499.99 \\
\hline MAC of Mode 1 & .9991 \\
\hline MAC of Mode 2 & .9738 \\
\hline MAC of Mode 3 & .9859 \\
\hline MAC of Mode 4 & .9992 \\
\hline Final Result & Yellow Light \\
\hline Result verified with respect to limit states & \\
\hline
\end{tabular}




\section{Vibration Inspection Section - Application Test No. 10}

This test was devised to detect program logical flaws and bugs in the vibration inspection section of the program while inferring towards a "red light" solution. This test was supposed to deem the bridge "unsafe for crossing based" due to Frequency value for Mode 4 lying below the "red light" threshold. Borderline values for Frequency of Mode 1 and SEDI of Mode 2 were also used in this test so as to detect round- off errors while processing input values. The result was found to be as expected and thus program was verified for a "red light" scenario in vibration testing.

\section{Table D10 Application Test 10}

\begin{tabular}{|l|l|}
\hline Dynamic Parameter & Value \\
\hline Frequency of Mode 1 & 3.405 \\
\hline Frequency of Mode 2 & 12.571 \\
\hline Frequency of Mode 3 & 31.925 \\
\hline Frequency of Mode 4 & 43.3367 (Low - Red) \\
\hline SEMAC of Mode 1 & 0.9642 \\
\hline SEMAC of Mode 2 & 0.8977 \\
\hline SEMAC of Mode 3 & 0.9211 \\
\hline SEMAC of Mode 4 & 0.9994 \\
\hline SEDI of Mode 1 & 67 \\
\hline SEDI of Mode 2 & 499 \\
\hline SEDI of Mode 3 & 43 \\
\hline SEDI of Mode 4 & 36 \\
\hline MAC of Mode 1 & .9921 \\
\hline MAC of Mode 2 & .9513 \\
\hline MAC of Mode 3 & .9826 \\
\hline MAC of Mode 4 & .9427 \\
\hline Final Result & Red Light \\
\hline Result verified with respect to limit states & \\
\hline
\end{tabular}

The application was found to be stable and results were consistent and as expected for the different scenarios tested. 


\section{D.3 Summary of Verification Tests}

The following table presents a summary of the application verification tests carried out in the visual and vibration inspection sections of the AVLB-DSS. The test scenarios and the results were verified through manual check.

Table D11 Summary of Application Verification Tests

\begin{tabular}{|c|c|c|c|c|}
\hline Test & Site & Section & Scenarios/program sections tested & Result \\
\hline 1 & Test Object $\mathrm{C}$ & $\begin{array}{l}\text { Visual } \\
\text { Inspection }\end{array}$ & $\begin{array}{l}\text { Program tested for a red light scenario with damages } \\
\text { in Stage } 1 .\end{array}$ & $\begin{array}{l}\text { Red } \\
\text { Light }\end{array}$ \\
\hline 2 & Test Object D & $\begin{array}{l}\text { Visual } \\
\text { Inspection }\end{array}$ & $\begin{array}{l}\text { Program tested for a yellow light scenario with } \\
\text { damages in Stage 2,3 and } 4 .\end{array}$ & $\begin{array}{l}\text { Yellow } \\
\text { Light }\end{array}$ \\
\hline 3 & Test Object A & $\begin{array}{l}\text { Visual } \\
\text { Inspection }\end{array}$ & $\begin{array}{l}\text { Program tested for a green light scenario with no } \\
\text { damages in any stage. }\end{array}$ & $\begin{array}{l}\text { Green } \\
\text { Light }\end{array}$ \\
\hline 4 & Test Object D & $\begin{array}{l}\text { Vibration } \\
\text { Inspection }\end{array}$ & $\begin{array}{l}\text { Program tested for a scenario wherein all the modal } \\
\text { parameters are in the "green light" zone. }\end{array}$ & $\begin{array}{l}\text { Green } \\
\text { Light }\end{array}$ \\
\hline 5 & Test Object C & $\begin{array}{l}\text { Vibration } \\
\text { Inspection }\end{array}$ & $\begin{array}{l}\text { Program tested for a scenario wherein Frequency of } \\
\text { Mode } 2 \text { lies in the "yellow light" zone. Borderline } \\
\text { scenario for SEDI of Mode } 3 \text { and MAC of Mode } 1 \\
\text { were used to check for bugs in these sections of the } \\
\text { code. }\end{array}$ & $\begin{array}{l}\text { Yellow } \\
\text { Light }\end{array}$ \\
\hline 6 & Test Object B & $\begin{array}{l}\text { Vibration } \\
\text { Inspection }\end{array}$ & $\begin{array}{l}\text { Program tested for a scenario wherein SEDI of Mode } \\
2 \text { lies in the "red light' zone. Borderline values for } \\
\text { Frequency of Mode } 4 \text { and MAC of Mode } 1 \text { were used } \\
\text { to check for bugs in these sections of the code. }\end{array}$ & $\begin{array}{l}\text { Red } \\
\text { Light }\end{array}$ \\
\hline 7 & Test Object B & $\begin{array}{l}\text { Vibration } \\
\text { Inspection }\end{array}$ & $\begin{array}{l}\text { Program tested for a scenario wherein SEMAC of } \\
\text { Mode } 1 \text { lies in the "yellow light" zone. Borderline } \\
\text { values for Frequency of Mode } 3 \text { and MAC of Mode } 4 \\
\text { were used to check for bugs in these sections of the } \\
\text { code. }\end{array}$ & $\begin{array}{l}\text { Yellow } \\
\text { Light }\end{array}$ \\
\hline 8 & Test Object C & $\begin{array}{l}\text { Vibration } \\
\text { Inspection }\end{array}$ & $\begin{array}{l}\text { Program tested for a scenario wherein MAC of Mode } \\
4 \text { lies in the "red light" zone. Borderline values for } \\
\text { SEMAC of Mode } 1 \text { and MAC of Mode } 3 \text { were used to } \\
\text { check for bugs in the code. }\end{array}$ & $\begin{array}{l}\text { Red } \\
\text { Light }\end{array}$ \\
\hline 9 & Test Object A & $\begin{array}{l}\text { Vibration } \\
\text { Inspection }\end{array}$ & $\begin{array}{l}\text { Program tested for a scenario wherein SEMAC of } \\
\text { Mode } 4 \text { lies in the 'yellow light' zone. Borderline } \\
\text { value for SEDI of Mode } 4 \text { was used to check for bugs } \\
\text { in these sections of the code. }\end{array}$ & $\begin{array}{l}\text { Yellow } \\
\text { Light }\end{array}$ \\
\hline 10 & Test Object A & $\begin{array}{l}\text { Vibration } \\
\text { Inspection }\end{array}$ & $\begin{array}{l}\text { Program tested for a scenario wherein Frequency of } \\
\text { Mode } 4 \text { lies in the "red light" zone. Borderline values } \\
\text { for Frequency of Mode } 1 \text { and SEDI of Mode } 2 \text { were } \\
\text { used to check for bugs in these sections of the code. }\end{array}$ & $\begin{array}{l}\text { Red } \\
\text { Light }\end{array}$ \\
\hline
\end{tabular}




\section{VITA}

The author, Vikram Ramamoorthy was born in Madras, India on April 6, 1974. He did his schooling in General Education Academy, Bombay and Pre-University at South Indian Education Society (SIES) College of Arts, Science and Commerce, Bombay. Thereafter he pursued his Bachelor's degree in Production Engineering at K.J. Somaiya Engineering College, University of Bombay.

After his graduation, from July 1995, he worked as a Production Engineer in Bombay at Godrej-GE Appliances; one of India's leading manufacturers of refrigerators and other household appliances. He started his graduate studies in Industrial and Management Systems Engineering at West Virginia University in August 1996. This thesis was written in partial fulfillment towards the degree of Master of Science in Industrial Engineering during Spring 1999. 


\section{APPROVAL OF THE EXAMINING COMMITTEE}

Dr. B. Gopalakrishnan, Ph.D.

Dr. Shen En Chen, Ph.D.

Dr. Hota V.S. GangaRao, Ph.D.

Date

Dr. R.S. Ahluwalia, Ph.D., Chairman 